\title{
DETERMINAÇÃO DA ACIDEZ POTENCIAL E DA NECESSIDADE DE CALAGEM EM SOLOS DO NORDESTE PARAENSE
}

\author{
MARCOS ANDRÉ PIEDADE GAMA \\ Engenheiro Agrônomo
}

Orientador: Prof. Dr. LUíS IGNÁCIO PROCHNOW

\begin{abstract}
Dissertação apresentada à Escola Superior de Agricultura "Luiz de Queiroz", Universidade de São Paulo, para obtenção do título de Mestre em Agronomia, Área de concentração: Solos e Nutrição de Plantas.
\end{abstract}

PIRACICABA

Estado de São Paulo - Brasil

Dezembro - 1998 
GAMA, Marcos André Piedade Gama. Determinação da acidez potencial e da necessidade de calagem em solos do nordeste paraense. Piracicaba, 1998. 72p. Dissertação (Mestrado) - Escola Superior de Agricultura "Luiz de Queiroz", Universidade de São Paulo.

\section{ERRATA}

1) A chamada de rodapé da página 23 pertence a página 22 ;

2) Na página 26 ( $1^{\text {a }}$ linha do $4^{\circ}$ parágrafo), onde se lê "Pela análise física...", leia-se "Pela análise granulométrica....";

3) Na página 37 ( $5^{\mathrm{a}}$ coluna da Tabela 7), onde se lê "Diferença", leia-se "Índice";

4) $\mathrm{Na}$ nota de rodapé das tabelas 12 e 13 (páginas 51 e 52), onde se lê " $1=A 1 \times 1,5$; $2=2 \times A 1+[2-(\mathrm{Ca}+\mathrm{Mg})] "$, leia-se " $1=\mathrm{Alx} 0,15 ; 2=0,2 \times \mathrm{Al}+[2-0,1(\mathrm{Ca}+\mathrm{Mg})] "$.

5) As tabelas 15 e 16, nas páginas 57 e 58, apresentam resultados médios de $\mathrm{pH}$ e teores de $\mathrm{Ca}$ e Mg que foram obtidos após o cultivo de caupi (Vigna unguiculata);

6) Nas tabelas 17 e 18 (página 60) a unidade utilizada é a "g". 
Dados Internacionais de Catalogação na Publicação (CIP) DIVISÃo DE BIBLIOTECA E DOCUMENTAÇÃO - Campus "Luiz de Queiroz"/USP

Gama, Marcos André Piedade

Determinação da acidez potencial e da necessidade de calagem em solos do nordeste paraense / Marcos André Piedade Gama. - - Piracicaba, 1998.

$72 \mathrm{p}$.

Dissertação (mestrado) - Escola Superior de Agricultura Luiz de Queiroz, 1998.

Bibliografia.

1. Acidez do solo 2. Calagem 3. Fertilidade do solo 4. pH do solo 1. Título 
À Dênmora Araujo pelo carinho e compreensão; Aos meus pais (Raimunda e Eládio); Aos meus irmãos e sobrinho Maurício; Ao tio Francisco Piedade (In memorian)

\section{DEDICO.}




\section{AGRADECIMENTOS}

À Deus, pela força e presença divina em todas as fases de nossas vidas;

Ao Prof. Dr. Luís Ignácio Prochnow pela excelente orientação, manifestada sempre em atenção, apoio, compreensão e liberdade;

À Coordenação do Curso de Solos e Nutrição de Plantas pelo apoio e oportunidade;

À Escola Superior de Agricultura "Luiz de Queiroz" e seus professores pela oportunidade de aprendizagem;

Aos pesquisadores Maria do Socorro A. Kato e Eniel David Cruz da EMBRAPA/CPATU, pela orientação e incentivo na fase inicial de minha vida acadêmica;

Aos professores da Faculdade de Ciências Agrárias do Pará - FCAP, em especial a Dra. Irenice Maria S. Vieira, Dr. Marcos Aurélio L. Nunes, Dr. George Rodrigues, Dra. Maria Marli de L. S. Santos.

A grande colaboração do pesquisador Dr. José Raimundo N. F. Gama, da EMBRAPA/CPATU;

Ao auxílio dos professores Dr. Gerd Sparovek, Dr. Godofredo Cesar Vitti, Dr. Ronaldo Ivan Silveira e Dra. Maria Cristina S. Nogueira da ESALQ/USP;

Ao Instituto do Homem e Meio Ambiente da Amazônia (IMAZON) e aos seus pesquisadores, pela oportunidade de trabalho em pesquisa na Amazônia;

Aos companheiros e amigos que me auxiliaram de alguma forma, como o Tadeu Reis, Marcelo Alves, Fábio Prata, Adriana, Pedro, Simone, Daniele, Ênio, Marchiori, e em especial a Nagib Melém, Belisa Ramos, Michelle e Michell Costa, Claudia Lira, Norberto Noronha, Edson Vidal e Gerlane Reis;

À Coordenação de Aperfeiçoamento de Pessoal de Nível Superior (CAPES) pela concessão da bolsa de estudo, através do programa PICDT/CAPES;

Às outras pessoas, que de forma não menos importante, contribuíram direta ou indiretamente para a realização desse trabalho. 


\section{SUMÁRIO}

Página

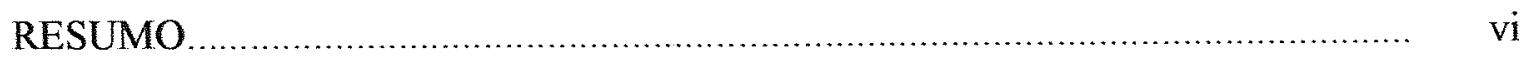

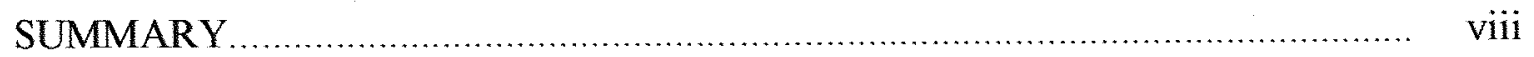

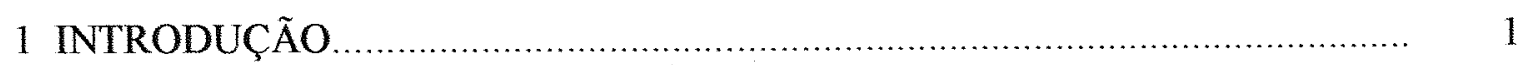

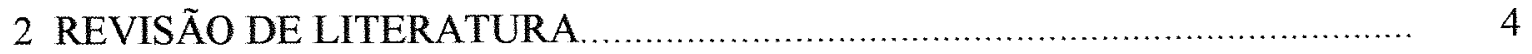

2.1 O Nordeste Paraense..................................................................... 4

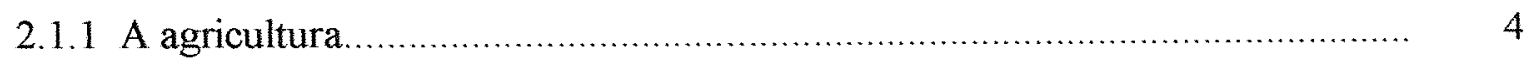

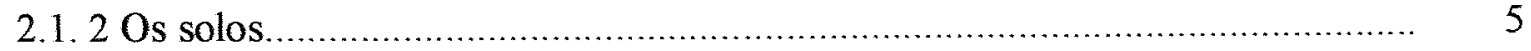

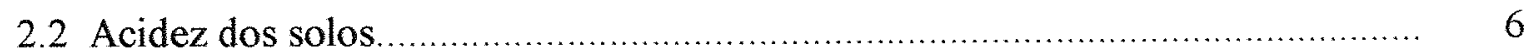

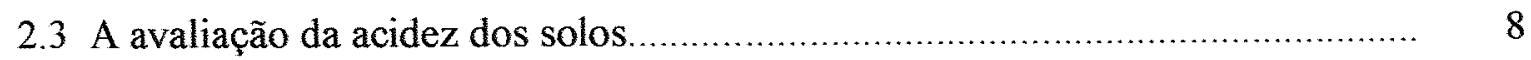

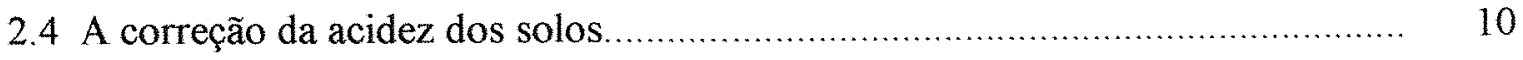

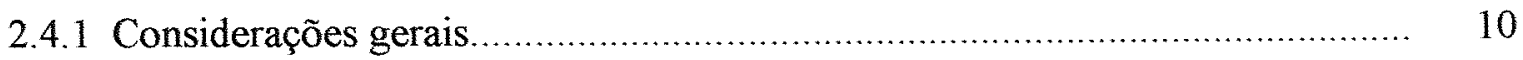

2.4.2 Métodos para determinar a necessidade de calagem............................... 12

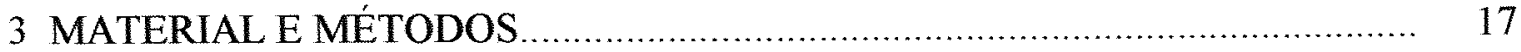

3.1 Relação entre alguns atributos de amostras de terra do nordeste paraense $\ldots . . . . . . \quad 17$

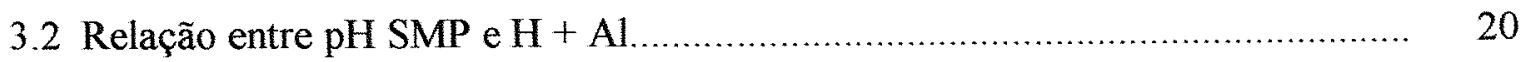

3.3 Relação entre o pH da suspensão de acetato de cálcio e acidez potencial ........... 21

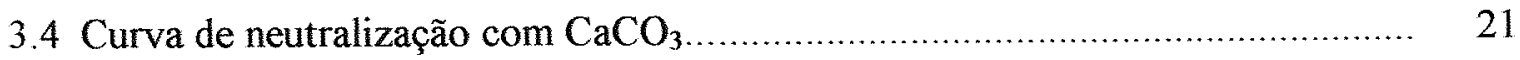

3.5 Avaliação agronômica dos métodos de recomendação de calagem................... 22

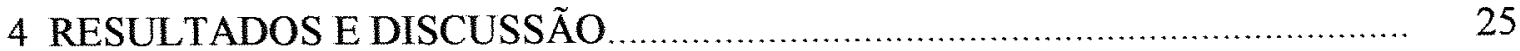

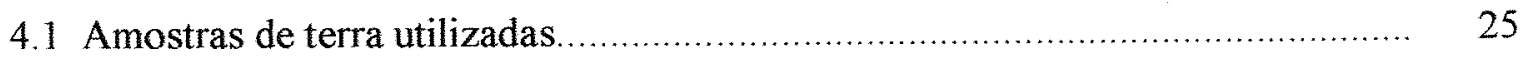

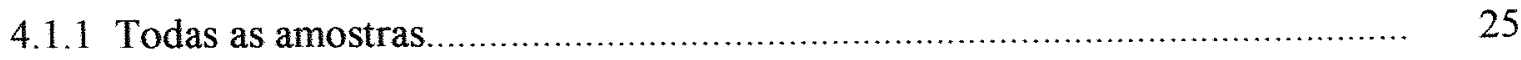

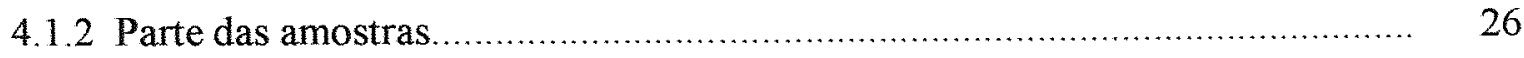

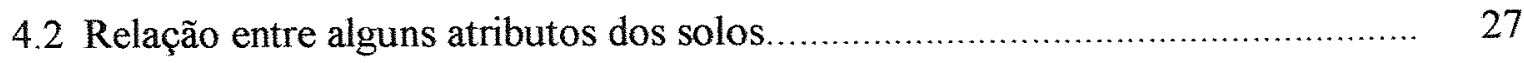

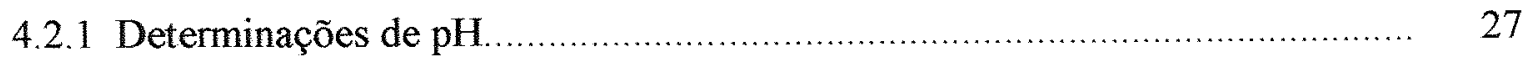

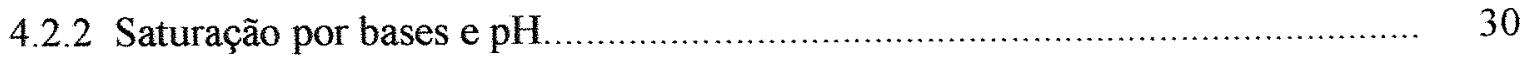

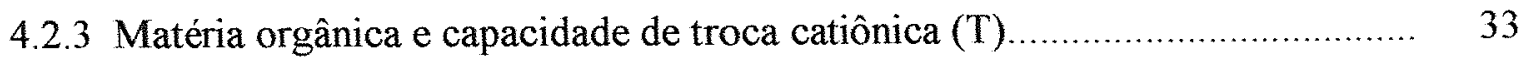




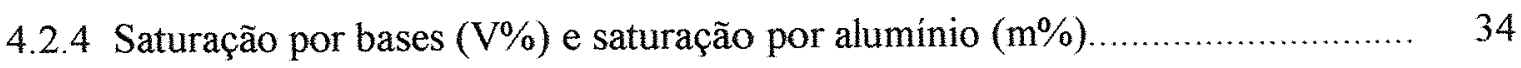

4.3 Relação entre acidez potencial $(\mathrm{H}+\mathrm{Al})$ e o pH SMP................................. 35

4.4 Relação entre pH da suspensão de acetato de cálcio e acidez potencial............. 39

4.5 Incubação com carbonato de cálcio .................................................... 42

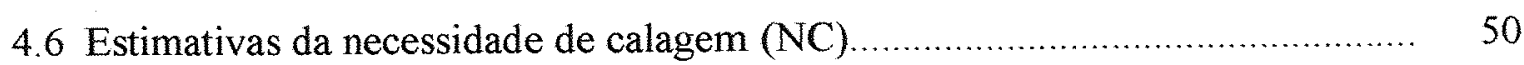

4.7 Avaliação agronômica dos métodos de recomendação de calagem.................... 56

4.7.1 Características químicas das amostras de terra ................................... 56

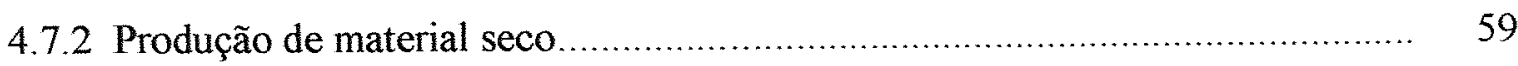

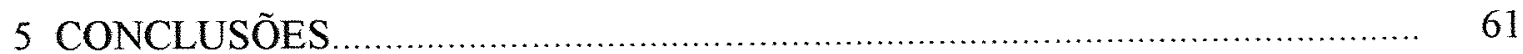

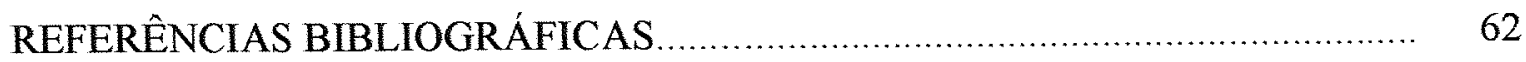

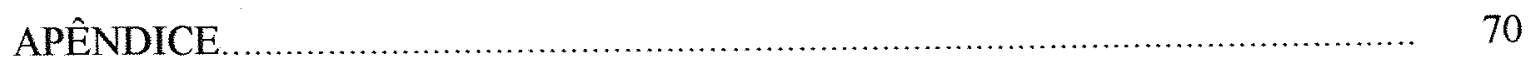




\title{
DETERMINAÇÃO DA ACIDEZ POTENCIAL E DA NECESSIDADE DE CALAGEM EM SOLOS DO NORDESTE PARAENSE
}

\author{
Autor: MARCOS ANDRÉ PIEDADE GAMA \\ Orientador: Prof. Dr. LUÍS IGNÁCIO PROCHNOW
}

\section{RESUMO}

No Estado do Pará há predominância de solos ácidos e com baixa fertilidade. Nesse Estado, a determinação da acidez potencial é realizada através do método de extração com acetato de cálcio, que é trabalhoso. As recomendações de calcário, quando realiza-se a análise da terra, são calculadas através de métodos que utilizam o alumínio trocável, ou então indicando o uso de $2 \mathrm{Mg} \mathrm{ha}^{-1}$ de calcário, no caso de não ser feita a análise da terra.

Em vinte e sete amostras de terra do nordeste paraense, coletadas da camada de 0 a $20 \mathrm{~cm}$, foram avaliadas a relação entre alguns atributos do solo, como: $\mathrm{pH}$ em água x pH em solução de $\mathrm{CaCl}_{2}, \mathrm{pH} \times \mathrm{V} \%$, T x Matéria orgânica, $\mathrm{V} \%$ x m\%. Nessas amostras de terra, também estudou-se a utilização do método do $\mathrm{pH}$ SMP e da determinação do pH da suspensão de acetato de cálcio - terra, para a determinação da acidez potencial $(\mathrm{H}+\mathrm{Al})$.

Realizou-se a incubação com carbonato de cálcio em quatro das amostras de terra, para a elaboração das curvas de neutralização e a posterior determinação da necessidade de calcário para atingir valores de $\mathrm{pH}$ em água de 5,5 e 6,0. Essas necessidades de calcário também foram utilizadas para a comparação com as obtidas por 
outros métodos de recomendação de calagem. Realizou-se ainda uma avaliação agronômica das recomendações de calcário fornecidas por quatro métodos de recomendação da necessidade de calagem para três amostras de terra.

Observaram-se correlações elevadas para os atributos analisados, como entre $\mathrm{pH}$ em água e $\mathrm{pH}$ em $\mathrm{CaCl}_{2}(\mathrm{r}=0,95)$, de $\mathrm{pH}$ em $\mathrm{H}_{2} \mathrm{O}$ e V\% $(\mathrm{r}=0,88)$, de $\mathrm{pH}$ em $\mathrm{CaCl}_{2}$ e V\% $(\mathrm{r}=0,94)$, e de capacidade de troca cationnica e matéria orgânica $(r=0,84)$.

Observou-se a possibilidade de utilização dos dois métodos estudados (pH da suspensão terra-tampão SMP e pH da suspensão terra-solução de acetato de cálcio) para a determinação indireta da acidez potencial, no entanto, devido à maior amplitude observada nos resultados das leituras de pH SMP, em relação àqueles observados para o $\mathrm{pH}$ da suspensão de acetato de cálcio, torna-se mais seguro a utilização do primeiro como forma de determinação dos valores de $\mathrm{H}+\mathrm{Al}$.

Em três das amostras de terra utilizadas, verificou-se grandes variações de pH com pequenas doses aplicadas de $\mathrm{CaCO}_{3}$. Entre os métodos de recomendação de calcário analisados, observou-se que as quantidades de calcário obtidas pela saturação por bases a $70 \%$ e pH SMP para atingir pH em água 6,0 foram as quantidades que mais aproximaram-se das obtidas na incubação com $\mathrm{CaCO}_{3}$.

$\mathrm{Na}$ avaliação agronômica dos métodos de recomendação de calagem, não observaram-se diferenças de produção de matéria seca de caupi em função das recomendações obtidas pelos métodos utilizados. As maiores produções de matéria seca ocorreram, quando utilizou-se as doses recomendadas pelo método do Al trocável, diferindo, no entanto, somente daquelas obtidas pela testemunha. $\mathrm{Na}$ análise das características químicas das amostras de terra, ao final dessa avaliação, observou-se que para o $\mathrm{pH}$ os maiores valores ocorreram quando da utilização do método da saturação por bases a $70 \%$, que recomendou as maiores doses de calcário. Esse método apresentou também os melhores efeitos sobre os teores de cálcio e magnésio. 


\title{
DETERMINATION OF THE POTENTIAL ACIDITY AND OF THE LIMING NEED IN SOILS OF THE NORTHEAST PARAENSE
}

\author{
Author: MARCOS ANDRÉ PIEDADE GAMA \\ Adviserr: Prof. Dr. LUÍS IGNÁCIO PROCHNOW
}

\section{SUMMARY}

Soils in the state of Para are generally acid and with low fertility. In that state, the determination of the potential acidity is accomplished through the extraction of $\mathrm{H}+\mathrm{Al}$ by the calcium acetate method (traditional method). Lime recommendations are obtained by the exchangeable aluminum method, when soil analysis is utilized, or indicating the use of $2 \mathrm{Mg} \mathrm{ha}^{-1}$ of lime when the farmer does not have a soil analysis result.

In twenty-seven soil samples, collected from the 0 to $20 \mathrm{~cm}$ layer, of representative soils of the northeast of Pará, studies were accomplished to evaluate the relationship among some attributes of the soil, as: $\mathrm{pH}$ in water $\mathrm{x} \mathrm{pH}$ in solution of $\mathrm{CaCl}_{2}$, $\mathrm{pH} \times \mathrm{V} \%, \mathrm{~T} \times$ organic matter, $\mathrm{V} \% \mathrm{x} \mathrm{m} \%$. Two alternative methods for the determination of the potential acidity were also studied.

In four of the soil samples, the incubation of rates of calcium carbonate ( 0 to $10 \mathrm{Mg} \mathrm{ha}{ }^{-1}$ ) was promoted in order to elaborate the curves of neutralization and posterior determination of the need of lime to reach $\mathrm{pH}$ values in water of 5.5 and 6.0. Those needs of lime were also used for comparison with quantities obtained by utilizing some other methods of recommendation used in Brazil. A greenhouse experiment was also conducted in order to gain information about which, of four of the most popular 
methods utilized, for lime recommendation, was best applied to the soil samples from northeast of Pará.

High correlation were found between some attributes of the soil samples, as: $\mathrm{pH} \mathrm{H}_{2} \mathrm{O} \times \mathrm{pH} \mathrm{CaCl}_{2}(\mathrm{r}=0.95), \mathrm{pH} \mathrm{H}_{2} \mathrm{O} \times \mathrm{V} \%(\mathrm{r}=0.88), \mathrm{pH} \mathrm{CaCl}_{2} \times \mathrm{V} \%(\mathrm{r}=0.94)$ and cation exchange capacity $x$ organic matter $(r=0,84)$.

It was observed a high relation between the $\mathrm{H}+\mathrm{Al}$ obtained by the traditional method and the values of $\mathrm{pH}$ for the soil sample-acetate method and $\mathrm{pH}$ SMP. In consequence those methods could be used in order to evaluate indirectly the potential acidity of the soils studied. The higher amplitude of those data found for the pH SMP qualifies these method as more precise than the first determination proposed.

For three soil samples it was verified a great $\mathrm{pH}$ variation, even when small rates of $\mathrm{CaCO}_{3}$ were applied. Among the recommendation methods of lime studied, it was observed that those quantities obtained to increase base saturation to $70 \%$ and the SMP method to reach $\mathrm{pH}$ in water 6.0 were the ones that recommended quantities close to those obtained by the incubation with $\mathrm{CaCO}_{3}$.

In the agronomic evaluation of the four methods, differences of production of dry matter of Vigna unguiculata were not observed among the recommendations obtained by the methods. The largest dry matter yield was obtained with the utilization of the exchangeable aluminum method, however, with statistical difference only when related to the control. The soil analysis realized with soil samples collected after the crop was harvested showed higher $\mathrm{pH}$ and concentrations of $\mathrm{Ca}$ and $\mathrm{Mg}$ when the base saturation method was utilized. 


\section{INTRODUÇÃo}

A agricultura ainda vem sendo praticada, em várias partes da Amazônia, no sistema tradicional de corte e queima, também denominado de itinerante, que necessita sempre de novas áreas para sua continuidade. Esse itinerantismo é comum em praticamente toda a região, sendo utilizada por diversos motivos, entre os quais, a grande disponibilidade de terra e por diminuir prejuízos com a perda de fertilidade do solo, que é crescente com o tempo de uso e, que também pode ser verificado na pecuária, pelo abandono de pastagens. Tais situações têm contribuído para as produções baixas por unidade de área agrícola e para o aumento na área desmatada.

A transformação desse sistema agrícola, através da utilização de técnicas mais racionais e adaptáveis ao meio, permitiria um aumento da produtividade e, também, uma maior fixação do homem à terra. Além disso, possibilitaria uma diminuição das áreas desmatadas, que têm aumentado consideravelmente nas últimas décadas, principalmente na região nordeste do Estado do Pará.

Um dos fatores que podem contribuir para essa transformação está relacionado à melhoria e posterior manutenção da fertilidade dos solos da região, que na sua maioria apresentam baixa fertilidade. De uma forma geral, esse problema de fertilidade é solucionado, ou amenizado, através do uso de corretivos, fertilizantes e outras práticas de manejo (ex: sistemas agroflorestais e agrossilviculturais). Com as duas primeiras opções, a questão da fertilidade seria tratada de forma mais imediata, pelo menor tempo de resposta a essas práticas.

A correção e a fertilização dos solos são práticas comuns e que são estudadas na maior parte do Brasil, principalmente, quanto à eficiência que é condição 
básica para uso dessas práticas. Essa questão do uso eficiente de fertilizantes não tem sido estudada e nem levada em consideração, em várias recomendações de adubação realizadas no Estado do Pará. Essa eficiência é afetada por vários fatores, entre os quais a acidez dos solos amazônicos. Este problema de acidez pode ser resolvido através do uso de corretivos agrícolas, como o calcário.

No Pará, como na maior parte da Amazônia, o uso de calcário é muito restrito, o que é devido a alguns fatores, tais como: baixo nível de conhecimento técnico dos agricultores e altos preços do corretivo.

Além do uso restrito de calcário, há também fatores que influenciam na eficiência dos mesmos quando utilizados. A determinação ou estimativa da necessidade de calcário $(\mathrm{NC})$ é um desses fatores. Pesquisas que visem o estudo da eficiência dos métodos para a determinação da necessidade de calagem são raras na região nordeste do Pará. No Brasil, vários métodos tem sido utilizados para estimar a necessidade de calcário, sendo que para um mesmo solo, podem haver diferenças significativas nas quantidades recomendadas por métodos distintos.

A recomendação correta de calcário tem grande importância, principalmente para que se tenha uma correção eficiente de acidez e também uma eficiência maior dos fertilizantes. Além disso, evita-se o uso de quantidades acima (supercalagem) ou abaixo da que realmente é necessária, as quais não permitem o alcance dos benefícios esperados com a calagem. Outro fato a ser levado em consideração, é que ao se escolher um método, é necessário conhecer-se o seu comportamento com os solos da região.

Um exemplo de método que depende do comportamento do solo é o da saturação por bases (V\%), o qual necessita da determinação de soma de bases e da acidez potencial $(\mathrm{H}+\mathrm{Al})$ para a indicação da necessidade de calcário. Para a determinação da V\%, não há grandes dificuldades na sua realização nos laboratórios de rotina. Para a obtenção da acidez potencial, a dificuldade aumenta, pois em grande parte do Brasil ainda é utilizado o método de extração com acetato de cálcio, que é um processo muito trabalhoso, devido à necessidade de titulação e o tempo maior para sua execução, além de outras desvantagens, tais como, o uso de acetato de cálcio com baixa 
qualidade, o preparo diário de soluções de acetato e problemas de nitidez no ponto de viragem, quando os solos são ricos em matéria orgânica.

No entanto, para esse problema já existe uma opção, sugerida por Raij et al (1979) e Quaggio et al. (1985), que é a utilização do pH de equilíbrio da suspensão tampão SMP-terra, para determinação de $\mathrm{H}+\mathrm{Al}$. Uma outra opção, sugerida por Pereira et al. (1998), é a leitura do pH da solução de acetato de cálcio após o contato com a amostra de terra. Isso evitaria a titulação com $\mathrm{NaOH}$.

O Pará ainda é um dos estados brasileiros que utiliza o método do acetato de cálcio para a determinação da acidez potencial, que como já foi citado é muito trabalhoso. Quanto à recomendação de calagem, se a análise de solo for realizada, os laboratórios de rotina determinam a necessidade de calcário, escolhendo a maior entre as quantidades encontradas pelos métodos do Alumínio trocável e Alumínio + cálcio e magnésio, ou a média das recomendações obtidas pelos dois critérios. Se a análise de solo não é realizada, fato mais comum, recomenda-se, geralmente, a aplicação de $2 \mathrm{Mg}$ $\mathrm{ha}^{-1}$ do corretivo, o que pode levar ao excesso ou a falta de corretivo por gleba.

As hipóteses desse trabalho são de que: i) é possivel a utilização do $\mathrm{pH}$ SMP e do $\mathrm{pH}$ da solução de acetato de cálcio para a determinação da acidez potencial em solos do nordeste paraense; ii) existe uma relação entre alguns atributos desses solos já citados; iii) as quantidades de calcário recomendadas, atualmente, para os solos da região nordeste do Pará são inadequadas.

Diante dos problemas expostos, o presente trabalho teve por objetivos:

a) Estudar o uso do pH SMP e do pH da solução de acetato de cálcio, após contato com as amostras de terra, para a determinação indireta dos valores de $\mathrm{H}+\mathrm{Al}$ em solos representativos da região nordeste paraense;

b) Verificar a relação entre alguns atributos dos mesmos solos;

c) Determinar a necessidade de calcário, pelo método da incubação com $\mathrm{CaCO}_{3}$, comparando-a com as determinadas por alguns métodos de recomendação de calagem;

d) Avaliar a eficiência agronômica de quatro métodos de recomendação de calagem para as mesmas amostras de terra utilizadas na incubação. 


\section{REVISÃO DE LITERATURA}

\subsection{O Nordeste Paraense}

\subsubsection{A agricultura}

A ocupação desta parte do Estado do Pará teve início a partir do século XVII, em áreas hoje identificadas como Região Metropolitana de Belém (IBGE, 1991). O nordeste paraense pode ser dividido em sete microrregiões (Salgado, Bragantina, Cametá, Tomé-Açu, Guamá, Castanhal e Paragominas). É a região mais afetada pelas práticas de uso da terra - agricultura, pecuária, extração madeireira - principalmente em relação a sua vegetação. Isso pode ser justificado pelo fato de cerca de $90 \%$ de suas sedes municipais estarem interligadas por rodovias asfaltadas (IBGE, 1991). Rocha et al. (1992) relataram que a região Nordeste, em 1970, já era a região mais alterada daquele Estado, apresentando a microrregião Bragantina com $51 \%$ de vegetação modificada.

A agricultura é a atividade mais importante do nordeste paraense, o que pode ser comprovado pelo fato de que $59 \%$ da produção agrícola do Estado do Pará em 1994 foi proveniente dessa região (IBGE, 1994). No entanto, a agricultura é desenvolvida pela maioria dos agricultores da região através do sistema tradicional de cultivo denominado de "corte e queima". Sioli (1984)", citado por Burger (1986), relatou que esse tipo de sistema é característico da pequena agricultura ${ }^{2}$ na Amazônia e, quando

\footnotetext{
${ }^{1}$ SIOLI, H. Present "development" of Amazonia in the light of the ecological aspects of life, an alternative concept. In: SIOLI, $\mathrm{H}$. ed. The Amazon. Limnology and landscape ecology of a mighty tropical river and its basin. Lancaster, W. Lunk, 1984, p.737-47.

2 A pequena agricultura é caracterizada pela utilização do cultivo de corte e queima ou itinerante, utilizando mão-de-obra exclusivamente familiar, sendo sua produção utilizada para subsistência e somente o excesso destinado à venda.
} 
praticado em pequenas áreas, e com pousios suficientemente longos, é muito bem adaptado às condições ecológicas.

O pousio é de grande importância para a reacumulação de nutrientes, no entanto, quando tende a ser curto, o sistema começa a entrar em declínio com a diminuição das produtividades e empobrecimento do solo. Por isso, o pousio tem se tornado uma grande preocupação em áreas como a do nordeste paraense, onde tem ocorrido diminuição do tamanho das propriedades dos pequenos agricultores, crescimento do número de grandes fazendas de pecuária e dificuldades cada vez maiores em se obter novas áreas para produção agrícola.

Apesar da predominância do sistema de corte e queima no nordeste paraense há, em alguns importantes Municípios dessa região, como Castanhal, Capitão Poço, Tomé-Açu e Bragança, também a ocorrência de sistemas que utilizam tecnologias visando o aumento da produtividade agrícola, principalmente das culturas perenes.

\subsubsection{Os solos}

Vieira et al. (1971) classificaram os solos do Estado do Pará em três grandes grupos: solos bem drenados, solos hidromórficos e solos em desenvolvimento. Os solos "bem drenados", que também podem ser chamados de terra firme, ocupam as maiores áreas dentro do Estado, tendo grande potencial para cultivos de culturas anuais e perenes, sendo por isso, os solos que apresentam o maior potencial para uso de calcário. São exemplos deste grupo: os latossolos e podzólicos. No grupo dos "hidromórficos" também são encontrados alguns solos de grande importância, como os Gley Húmico e Pouco Húmico, de ocorrência principalmente nas várzeas amazônicas e que possuem grande potencial para o cultivo das culturas de arroz e cana-de-açúcar.

No Nordeste Paraense, predominam os latossolos amarelos, ocorrendo com menor intensidade os Latossolos Vermelho-Amarelo, o Concrecionário Laterítico e os Gley Húmico e Pouco Húmico. 
Vieira (1975) relatou que Latossolos Amarelos são solos envelhecidos, ácidos a fortemente ácidos e de boa drenagem. São solos com B latossólico (óxico). Apresentam-se com textura variando de média (17 - 35\% de argila) a muito argilosa (> $70 \%$ de argila).

Os Latossolos Vermelho-Amarelos possuem horizonte B latossólico e características análogas as do Latossolo Amarelo, diferenciando-se dos mesmos pelo maior teor de óxido de ferro. Os Concrecionários Lateríticos são solos de média profundidade, formados por uma mistura de partículas minerais finas e concreções de um arenito ferruginoso de diâmetros diferenciados. Podem apresentar no perfil um B latóssolico ou um B textural. São normalmente argilosos, pobres em bases trocáveis e com capacidade de troca e saturação por bases baixas. Os Gley Húmicos são solos hidromórficos, poucos desenvolvidos, apresentando superficialmente um horizonte A com teor elevado de matéria orgânica, sempre acima de 5\%, de espessura variável, assentado sobre um horizonte gleizado mineral. As características morfológicas no perfil são típicas de condições redutoras, proporcionadas pela influência do lençol freático próximo ou mesmo à superficie, durante parte do ano. Podem ser eutróficos ou distróficos. Os Gley Pouco Húmicos, são bastante semelhantes aos Gley Húmicos, diferindo-se por apresentarem no horizonte A uma coloração bem mais clara e teores de matéria orgânica nunca superiores a 5\%. Quando seco, na região amazônica, esse conteúdo pode ser baixo, com cerca de $2,5 \%$ no horizonte A (Vieira, 1987).

Levando-se em consideração os tipos de solos que ocorrem na região nordeste paraense, na sua maioria ácidos e de baixa fertilidade, fica evidente o grande potencial que esta região apresenta para utilização da prática da calagem.

\subsection{Acidez dos Solos}

De acordo com Kinjo (1983) a acidez do solo pode ser inicialmente melhor entendida através do conceito de ácido-base de Bronsted e Lowry (1923), no 
qual é considerado ácido uma substância que tende a doar prótons (ions $\mathrm{H}^{+}$) e base a substância que tende a aceitar tais prótons.

Verifica-se em vários trabalhos relacionados ao tema, como os de Quaggio (1983) e Almeida (1984), que durante muito tempo houve grande variação nas definições sobre a verdadeira causa da acidez dos solos. Sanchez (1981) relatou que a acidez dos solos apresentava definição duvidosa. Atualmente, tal definição é bem mais clara, assim como sua importância. Fassbender \& Bornemisza (1987) relataram que entre os processos de grande importância, regulados pela reação do solo, encontram-se a intemperização dos minerais e formação de argilas, a decomposição da matéria orgânica e a disponibilidade de muitos nutrientes.

Ainda segundo Fassbender \& Bornemisza (1987), a reação do solo depende do conteúdo de hidrogênio ionizável, do Al em diferentes formas dissociáveis e, em grau menor, dos íons de manganês e ferro, todos em equilibrio com a solução do solo, onde ocorrem várias reações de hidrólise.

Melo (1985) considerou que o processo de acidificação do solo é iniciado ou acentuado devido à remoção de bases da superficie dos colóides e aumento de íons $\mathrm{H}^{+}$(quanto mais $\mathrm{H}^{+}$, mais ácido o solo vai se tornando). $\mathrm{O}$ autor cita ainda alguns exemplos de processos que podem fornecer $\mathrm{H}^{+}$ao solo, tais como: dissociação do ácido carbônico; dissociação dos ions $\mathrm{H}^{+}$de grupos carboxilicos e fenólicos da matéria orgânica; hidrólise de cátions trocáveis; monômeros e polímeros de alumínio; uso de fertilizantes, principalmente amoniacais e uréia. Fassbender \& Bornemisza (1987) também citaram alguns desses mecanismos como fontes de acidez dos solos. Hue et al. (1987) consideraram como principais efeitos adversos da acidez do solo os níveis tóxicos de $\mathrm{Al}$ e $\mathrm{Mn}$, bem como a deficiência de $\mathrm{Ca}$.

Para a região nordeste paraense, a acidez deve ser o fator limitante mais importante a ser superado para obtenção de melhores produções agricolas, já que há predominância de solos altamente intemperizados como é o caso do Latossolo Amarelo, que é um oxissol. Em geral, os oxissolos apresentam elevada acidez, com elevados teores de alumínio trocável e de ferro, além de baixa saturação de cálcio e magnésio (Fox et al., 1991; Fontes et al., 1995). 
Malavolta (1985), classificando o grau de acidez dos solos nas quatro regiôes do Brasil, citou que cerca de $75 \%$ dos solos da Amazônia são considerados de alta acidez, condicionando-os a necessidade de práticas corretivas ou de calagem quando se deseja obter melhores produtividades.

\subsection{A avaliação da acidez dos solos}

A acidez dos solos pode ser divida em: acidez ativa e acidez potencial. A primeira, é a fração ou parte do hidrogênio que está dissociada na forma de $\mathrm{H}^{+}$na solução do solo e é quimicamente ativa, exercendo grande influência na vida das plantas. É determinada por meio de sua atividade, através do índice $\mathrm{pH}$.

A acidez potencial está relacionada ao hidrogênio e alumínio que permanecem na fase sólida, na forma não dissociada. Como se pode observar a reação dos solos obedece os princípios químicos de um ácido, sendo que como a maior parte do $\mathrm{H}^{+}$está na fase sólida pode-se associar com um ácido fraco.

Essa acidez pode ser divida em: (i) acidez trocável, referente, basicamente, ao aluminio trocável que está ligado por força eletrostática a superficie dos colóides e, que pode ser extraída pelo uso de solução de $\mathrm{KCl}$; (ii) acidez não trocável, referente ao hidrogênio ligado covalentemente aos colóides. $O$ hidrogênio, nessa forma, não é trocável sendo dissociado somente com a elevação do pH do meio (Raij, 1981; Kinjo, 1983; Quaggio, 1986; Raij, 1991).

, Brady (1989) denominou acidez potencial, devido ao fato de que o hidrogênio e o alumínio adsorvidos passam para solução do solo quando esta se reduz: Esse deslocamento do íon $\mathrm{H}$ da fase sólida para a líquida mantêm o equilíbrio entre as duas fases, não permitindo assim grandes variações nas concentrações desse ín na solução do solo, havendo por conseguinte, uma determinada resistência à mudanças bruscas no valor de $\mathrm{pH}$. A esta resistência a mudança de $\mathrm{pH}$ se dá o nome de poder tampão do solo. 
A determinação da acidez potencial tem grande importância. Adicionando-se a soma de bases aos valores de $\mathrm{H}+\mathrm{Al}$ é possível se chegar a capacidade de troca de cátions (CTC), que é utilizada, por exemplo, na determinação da necessidade de calcário pelo método de saturação por bases. Raij (1991), relata que a acidez potencial é determinada integralmente, incluindo hidrogênio e alumínio e, que as soluções utilizadas são cloreto de bário tamponada com trietanolamina a pH 8,2, acetato de cálcio $0,5 \mathrm{~mol} \mathrm{~L}^{-1}$ a $\mathrm{pH} 7$ e a solução tampão SMP. As duas últimas são as mais utilizadas no Brasil.

O método do acetato de cálcio, apesar de ser muito utilizado pelos laboratórios de rotina, tem a desvantagem de ser trabalhoso. O método que utiliza a solução tampão SMP resolve esse problema, pois é possível estimar $\mathrm{H}+\mathrm{Al}$ através de uma regressão que correlaciona os valores obtidos de $\mathrm{H}+\mathrm{Al}$ por acetato de cálcio com os do pH de equilíbrio da solução tampão SMP com a amostra de terra, por meio de leituras potenciométricas (Raij et al., 1979; Quaggio, 1983).

Raij et al. (1979), para solos do Estado de São Paulo e utilizando uma relação 10:20:10 para solo - água - tampão SMP, foram os primeiros a sugerirem a utilização desse método na determinação do $\mathrm{H}+\mathrm{Al}$, o que também foi verificado por Quaggio (1983), trabalhando com um maior número de amostras de terra do mesmo Estado. Esse autor encontrou a equação $\ln Y=7,76-1,053 \mathrm{X}$, que é ainda hoje utilizada para determinar indiretamente a acidez potencial em solos do Estado de São Paulo.

Embora saiba-se da simplicidade e rapidez que o método SMP possui para determinação dos valores de $\mathrm{H}+\mathrm{Al}$, há sempre a necessidade de avaliação da relação entre as variáveis e da determinação de novas curvas de regressão para cada grupo de solos.

Com base nisso e após os primeiros trabalhos com o método, vários outros têm sido realizados em alguns Estados brasileiros. Desse modo, têm se obtido novas equações e correlações altamente significativas entre os valores de $\mathrm{H}+\mathrm{Al}$ determinados pelo método do acetato de cálcio e os de $\mathrm{pH}$ da solução de equilíbrio do tampão SMP com a amostra de terra (Almeida, 1984; Sousa et al, 1989; Pavan et al., 1996; Maeda, 1997; Pereira et al., 1998). 
Pavan et al. (1996), trabalhando com solos do Estado do Paraná, encontraram alta correlação entre $\mathrm{H}+\mathrm{Al}$ (determinado pelo método do acetato) e pH da solução de equilíbrio do tampão SMP-solo, no entanto, utilizaram uma metodologia diferente da utilizada por Quaggio (1983) quanto a quantidade de tampão SMP, tempo de agitação e repouso antes da leitura potenciométrica. Após a leitura do $\mathrm{pH}$ em solução de $\mathrm{CaCl}_{2}$ os autores adicionaram $4 \mathrm{ml}$ da solução tampão SMP e colocaram para agitar por 20 minutos, deixando em seguida esse material em repouso por uma noite. $\mathrm{Na}$ manhã seguinte, agitou-se por 10 minutos, deixando por mais 30 minutos em repouso, após o que fez-se a leitura do $\mathrm{pH}$.

Verifica-se que a metodologia utilizada por Pavan et al. (1996), apesar de simples, é mais demorada, igualando-se ao tempo necessário para determinar $\mathbf{H}+\mathrm{Al}$ pelo método do acetato de cálcio. A metodologia de Quaggio (1983) é simples e rápida, pois a agitação é de 15 minutos, com repouso da solução por cerca de 30 minutos, antes da leitura do $\mathrm{pH}$.

No Estado do Pará a determinação de $\mathrm{H}+$ Al é feita pela extração com acetato de cálcio, seguido de titulação do sobrenadante com hidróxido de sódio, que como já citado é bastante trabalhoso, além de ter outros problemas como a qualidade do acetato utilizado. Por isso, justifica-se o estudo de opções de metodologias capazes da determinação da acidez potencial de forma mais simples e rápida, agilizando assim as práticas laboratoriais.

\subsection{A correção da acidez dos solos}

\subsubsection{Considerações gerais}

O efeito da calagem decorre da neutralização de alumínio e manganês, sendo o fornecimento de cálcio e magnésio também relevantes (Raij, 1991). Sumner (1997) considerou que além desses beneficios, a calagem deve: criar condições ótimas

para uma performance benéfica da fauna e flora, particularmente na rizosfera; no caso de 
leguminosas, criar um ambiente que promova infecção e nodulação de raizes com rizóbio; e facilitar a absorção de nutrientes requeridos para produção ótima.

Apesar de ser uma prática comum, há a necessidade de que se tenha bons critérios para definição das doses. Sanchez (1981) relatou que na calagem devem ser considerados os seguintes fatores: i) a quantidade necessária de calcário para diminuir a porcentagem de saturação de alumínio a um nível adequado para o crescimento das plantas, ii) a qualidade do calcário e iii) o método de aplicação.

No Brasil, muitos trabalhos sobre calagem, de forma isolada ou não, em vários solos, têm sido desenvolvidos com resultados que demonstram melhoria à níveis adequados de alguns atributos do solo de grande importância como pH, CTC efetiva, saturação por bases, saturação por alumínio, além de significativos aumentos de produção das culturas (Oliveira \& Medeiros, 1983; Ferreira \& Santos, 1988; Miranda, 1993; Spehar, 1993; Cruz et al., 1994).

Silva et al. (1994) trabalhando com sete solos da região Sul de Minas Gerais verificaram que a mineralização de nitrogênio foi influenciada positivamente pela calagem e que o processo de nitrificação foi mais intenso com a correção da acidez do solo. Paiva et al (1993) verificaram o efeito do calcário e da matéria orgânica sobre algumas propriedades químicas de um latossolo e, observaram que a concentração de $\mathrm{Ca}$ e $\mathrm{Mg}$ aumentaram com a elevação do valor V2 e com o tempo de incubação com calcário, enquanto a acidez potencial e a trocável, diminuíram. Lima \& Bohnen (1993), estudando a dinâmica de nutrientes em solos arenosos em função da calagem, observaram que houve elevação do $\mathrm{pH}$ devido à calagem, o que provocou aumento da CTC efetiva. Houve ainda aumento da concentração, na fase trocável, dos cátions que foram adicionados pelo corretivo.

$\mathrm{Na}$ Amazônia, são poucos os estudos sobre calagem. Entre eles há o de Bastos \& Smyth (1984), no qual verificou-se resultados significativos devido ao efeito do calcário em Latossolo Amarelo muito argiloso na redução da saturação de alumínio (com $1 \mathrm{Mg} \mathrm{ha}^{-1}$ a $\mathrm{m} \%$ reduziu de 42 para 16\%) e na produção de culturas anuais. Com a mesma quantidade de calcário, o milho apresentou um aumento de produção de cerca de $673 \%$ em relação a testemunha. Foi observado ainda, que a saturação de alumínio acima 
de $40 \%$ exerceu efeito negativo na produtividade do milho. Esse efeito tornou-se quase nulo com $20 \%$ de saturação de alumínio.

Alfaia et al. (1988) encontraram resultados similares para saturação de Al, quando realizaram uma pesquisa para verificar o efeito da aplicação de calcário e micronutrientes em Latossolo Amarelo da Amazônia Central, utilizando a soja como cultura teste. Esses autores utilizaram tratamentos com calagem, calagem + micronutrientes, sendo os tratamentos aplicados em três sistemas de manejo do solo (floresta primária queimada, floresta primária retirada por mecanização e vegetação de capoeira queimada). Em termos de produção de soja, observou-se que não houve aumento significativo quando da utilização de calagem de forma isolada para nenhum dos níveis testados e formas de manejo. No entanto, quando houve adição de calcário + micronutrientes, obteve-se aumentos significativos de produção em relação aos outros.

Devido a elevada acidez e baixa fertilidade natural inerente a maioria dos solos da Amazônia, e também aos benefícios que se consegue com uso de calcário, fica evidente que a calagem de solos, como os da região nordeste paraense, propicia melhores produtividades das culturas, permitindo assim uma exploração contínua destes solos.

\subsubsection{Métodos para determinar a necessidade de calagem}

A correta estimativa da necessidade de calcário (NC) a ser aplicado aos solos, é fator básico para o sucesso de qualquer programa de correção dos mesmos. $\mathrm{O}$ termo "necessidade de calagem" indica a quantidade de corretivo de acidez necessária para neutralizar a acidez do solo, de uma condição inicial até outra desejada. (Rojas, 1974; Raij, 1987).

Kaminski \& Bohnen (1976) relataram que a indicação de corretivos para elevar o $\mathrm{pH}$ dos solos, ou neutralizar a acidez, é feita por diversos métodos. A escolha de um determinado método depende do seu comportamento nos solos (Defelipo, 1972). 
Raij \& Quaggio (1997) relataram que a quantidade requerida de corretivo depende da propriedade tampão do solo.

Outros fatores que devem ser levados em consideração são a cultura, o sistema de produção a ser utilizado e a questão do retorno econômico. Este último fator, nas condições do nordeste paraense, é o fator mais importante e dificil de ser resolvido já que o preço do calcário é bastante elevado. Sumner (1997) citou que a performance das culturas deveriam determinar a necessidade de calagem e não os critérios ou parâmetros atualmente utilizados.

Comparando alguns métodos rápidos para determinação da $\mathrm{NC}$ em solos do Estado de São Paulo, Freitas et al. (1968) dividiram os mesmos em dois grupos. O primeiro, consiste em utilizar calcário para elevar o $\mathrm{pH}$ até uma faixa de valores préfixada (SMP, Saturação por bases). Outra forma, trata de aplicar calcário até neutralizar o $\mathrm{Al}$ trocável e assegurar um suprimento adequado de $\mathrm{Ca}+\mathrm{Mg}$, não importando o $\mathrm{pH}$ final que seja alcançado (método do alumínio trocável)

Há inúmeros métodos de recomendação de calagem. No Brasil, em uso nos laboratórios de rotina de análise de solo, há três métodos e algumas variações locais dos mesmos (Raij, 1987; Raij \& Quaggio, 1997). Os métodos mais utilizados no Brasil são da saturação por bases, do alumínio trocável e SMP, os quais podem ser enquadrados nos grupos citados por Freitas et al. (1968).

Os principais métodos utilizados no Brasil estão descritos a seguir:

\section{Método de incubação com $\mathrm{CaCO}_{3}$}

É o método de recomendação de corretivo considerado padrão, servindo inclusive para a calibração de outros métodos, mas não é utilizado em rotina por apresentar a inconveniência de ser demorado e trabalhoso.

Neste método, porções de amostra de terra são misturadas com quantidades crescentes de $\mathrm{CaCO}_{3}$. As amostras devidamente umedecidas são deixadas em incubação durante um período de aproximadamente três meses para que o carbonato adicionado neutralize a acidez. Findo esse período o $\mathrm{pH}$ de cada porção de terra 
incubada é determinado e com os dados se faz um gráfico com dados de quantidades de corretivo adicionados na ordenada e os valores de $\mathrm{pH}$ finais obtidos na abscissa. Por interpolação determina-se a dose de $\mathrm{CaCO}_{3}$ necessária para atingir o pH desejado (Malavolta, 1981).

\section{Método do alumínio trocável}

Trata-se de um método que visa a neutralização do alumínio trocável. Kamprath (1970) estudando o alumínio trocável como um critério para recomendação de calagem, sugeriu que a dose de calcário fosse calculada multiplicando os miliequivalentes de $\mathrm{Al}$ pelo fator 1,5. Segundo o autor, para as culturas mais sensiveis ao Al pode-se utilizar o fator 2 .

Há uma variação deste método que utiliza, além da neutralização do alumínio trocável, a elevação dos teores de cálcio e magnésio a um mínimo de 20 ou 30 $\mathrm{mmol}_{\mathrm{c}} \mathrm{dm}^{-3}$. Raij et al. (1983) verificaram que este método não era adequado para recomendação de calagem, pois a diminuição dos teores de alumínio trocável no solo não apresentou relação linear com a produção e nem acompanhou a elevação da soma de bases.

Vários trabalhos têm demonstrado que as recomendações de calcário obtidas por esse método, geralmente inferiores aos demais critérios, não conseguem promover elevações de $\mathrm{pH}$ em água superiores a 5,5 e da saturação por bases além de 40 a $50 \%$, sendo no entanto, suficiente para neutralizar o aluminio trocável (Amedee \& Peech, 1976; Rojas, 1977; Mendez \& Kamprath, 1978; Quaggio, 1983; Sousa et al., 1989; Costa et al., 1996). Esses resultados concordam com a classificação de Freitas et al. (1968), os quais colocaram esse método no grupo daqueles que servem apenas para neutralizar o $\mathrm{Al}^{+3}$, não importando o $\mathrm{pH}$ final obtido.

O fato das recomendações de calagem obtidas por esse método serem sempre inferiores aos demais, poderia justificar sua utilização em áreas em que o preço do corretivo seja muito elevado, como é o caso da região do presente estudo. Apesar de 
muitas restrições, ainda é um método bastante utilizado pela maioria dos estados brasileiros.

Esse método é utilizado no Estado do Pará da seguinte forma: calcula-se a NC pelo método do Alumínio trocável $\left(\mathrm{Al}^{3+} \times 1,5\right)$ e pelo alumínio + cálcio e magnésio $\left(2 \times \mathrm{Al}^{3+}+\left[2-\left(\mathrm{Ca}^{2+}+\mathrm{Mg}^{2+}\right)\right]\right)$, escolhendo-se a maior quantidade obtida ou em alguns casos optando pela média entre os valores obtidos para os dois métodos.

\section{Métodos que utilizam solução tampão}

São métodos que medem a depressão em $\mathrm{pH}$ verificada numa solução tampão depois que lhe é adicionada uma amostra de terra ácida (Freitas et al., 1968). Como exemplo desses métodos tem-se: o teste de Woodruff e o SMP (Shoemaker et al., 1961). Após a publicação do trabalho que desenvolveu o método SMP, outros têm sido realizados em vários países com objetivo de ajustá-lo ou adaptá-lo às condições locais.

Entre os métodos tampões, o SMP é o mais comum em uso nos laboratórios de rotina de análise de solo. Webber et al. (1977), para solos ácidos do Canadá, indicaram o método SMP como índice diagnóstico para recomendação da necessidade da calagem pela sua rapidez e simplicidade. No Brasil é utilizado nos Estados do Rio Grande do Sul e Santa Catarina.

Raij et al. (1979) atribuiu duas grandes vantagens ao método SMP: é de fácil execução no laboratório e apresenta um fundamento teórico muito bom. Kaminski \& Bohnen (1976) trabalhando com amostras representativas de solos do Rio Grande do Sul, encontraram alta correlação entre o pH SMP e a necessidade de corretivo de acidez. A mesma correlação foi obtida por outras pesquisas, como a de Ernani \& Almeida (1986), quando trabalharam com solos de Santa Catarina e de Sousa et al. (1989) utilizando solos dos cerrados.

Esses trabalhos evidenciam que as recomendações obtidas por esse método são, geralmente, superiores quando comparadas aos demais. Esse fato pode ser a 
principal dificuldade para o uso deste método na recomendação de calcário para solos do nordeste paraense, devido aos altos preços do corretivo praticados naquela região.

\section{Método da saturação por bases}

O princípio deste método está baseado na relação entre o pH e a saturação por bases. Este método começou a ter repercussão no Brasil com a trabalho de Catani \& Galo (1955). Foram utilizadas 85 amostras de solo do Estado de São Paulo, obtendo-se uma relação linear entre pH e saturação por bases. A correlação entre essas duas variáveis também foi determinada em outros trabalhos (Raij, 1968; Castro, 1972; Sousa et al., 1989; Vasconcellos, 1994).

Para o uso deste método há a necessidade da determinação da soma de bases $(\mathrm{K}, \mathrm{Ca}, \mathrm{Mg})$, da acidez potencial $(\mathrm{H}+\mathrm{Al})$ e da CTC. Quaggio (1983) e Almeida (1984) relataram que o problema deste método, que foi proposto por Catani \& Galo (1955), estava na determinação do $\mathrm{H}+\mathrm{Al}$, que é realizada pelo método do acetato de cálcio, bastante trabalhoso, o que foi resolvido com o trabalho de Raij et al. (1979), no qual os autores encontraram excelente correlação entre o pH da solução SMP (na relação proposta de 10:20:10 para solo:água:solução tampão) e os valores de $\mathrm{H}+\mathrm{Al}$. Isso demonstrou a possibilidade de utilização das leituras potenciométricas do $\mathrm{pH}$ de equilíbrio do tampão SMP com a amostra de solo para determinação de $\mathrm{H}+\mathrm{Al}$.

Uma outra condição importante para utilização dessa metodologia é verificação da relação entre $\mathrm{pH}$ e saturação por bases para cada região. De uma forma geral as recomendações obtidas por esse método são semelhantes com as obtidas com as do $\mathrm{pH}$ SMP.

Atualmente, a necessidade de calcário por este método pode ser determinada pela seguinte fórmula:

$\mathrm{NC}=\mathrm{T}\left(\mathrm{V}_{2}-\mathrm{V}_{1}\right) / 10 . \mathrm{PRNT}, \quad$ sendo:

$\mathrm{NC}=$ necessidade de calcário, expressa em $\mathrm{Mg} \mathrm{ha}^{-1}$

$\mathrm{T}=$ capacidade de troca de cátions total $\left(\mathrm{mmol}_{\mathrm{c}} \mathrm{dm}^{-3}\right)$

$\mathrm{V}_{1}=$ saturação por bases atual do solo

$\mathrm{V}_{2}=$ saturação por bases que se pretende alcançar. 


\section{MATERIAL E MÉTODOS}

\subsection{Relação entre alguns atributos de amostras de terra do nordeste paraense.}

Utilizaram-se 27 amostras de terra representativas da região em estudo, sendo que as mesmas foram coletadas da camada superficial desses solos $(0$ a $20 \mathrm{~cm}$ de profundidade). A identificação dessas amostras encontra-se na Tabela 1.

Após a coleta, as amostras foram secas ao ar, destorroadas e passadas em moinho com peneira de $2 \mathrm{~mm}$, sendo então submetidas à análise de fertilidade no laboratório de Ciência do Solo da ESALQ/USP.

Entre as determinações realizadas encontram-se: $\mathrm{pH}$ em água, $\mathrm{pH}$ em solução de $\mathrm{CaCl}_{2}$ 0,01 mol L $\mathrm{L}^{-1}, \mathrm{pH}$ em $\mathrm{KCl} 1 \mathrm{~mol} \mathrm{~L}^{-1}$, fósforo, cálcio, magnésio e teores de matéria orgânica de acordo com a metodologia citada em Raij et al. (1987). Foram calculadas a soma de bases, saturação por bases (V\%) e saturação por alumínio (m\%). Os resultados dessas análises estão apresentadas na Tabela 2.

De posse dos resultados, determinaram-se as relações entre alguns atributos das amostras de terra como, por exemplo: $\mathrm{pH} \mathrm{H}_{2} \mathrm{O} \times \mathrm{pH} \mathrm{CaCl}$, $\mathrm{pH} \mathrm{H}_{2} \mathrm{O} \times \mathrm{V} \%$, $\mathrm{pH} \mathrm{CaCl} 2 \times \mathrm{V} \%, \mathrm{~V} \% \times \mathrm{m} \%$, Matéria Orgânica $\times \mathrm{T}$. 
Tabela 1. Identificação das vinte e sete amostras de terra utilizadas.

\begin{tabular}{|c|c|}
\hline Número das Amostras & Nome \\
\hline 1 & Podzólico Vermelho-Amarelo \\
\hline 2 & Gley Pouco Húmico \\
\hline 3 & Podzólico Vermelho-Amarelo \\
\hline 4 & Podzólico Vermelho-Amarelo \\
\hline 5 & Podzólico Vermelho-Amarelo \\
\hline 6 & Podzólico Vermelho-Amarelo \\
\hline 7 & Podzólico Vermelho-Amarelo \\
\hline 8 & Latossolo Vermelho-Amarelo \\
\hline 9 & Latossolo Amarelo \\
\hline 10 & Podzólico Vermelho- Amarelo fase cascalhenta I \\
\hline 11 & Gley Pouco Húmico \\
\hline 12 & Podzólico Vermelho-Amarelo \\
\hline 13 & Podzólico Vermelho-Amarelo cascalhento \\
\hline 14 & Latossolo Vermelho-Amarelo \\
\hline 15 & Podzólico Vermelho-Amarelo \\
\hline 16 & Podzólico Vermelho-Amarelo \\
\hline 17 & Latossolo Amarelo \\
\hline 18 & Podzólico Vermelho-Amarelo \\
\hline 19 & Latossolo Vermelho-Amarelo \\
\hline 20 & Latossolo Vermelho-Amarelo \\
\hline 21 & Podzólico Vermelho-Amarelo \\
\hline 22 & Latossolo Amarelo textura média \\
\hline 23 & Podzólico Vermelho-Amarelo \\
\hline 24 & Latossolo Amarelo muito argiloso \\
\hline 25 & Gley Pouco Húmico \\
\hline 26 & Latossolo Vermelho-Amarelo \\
\hline 27 & Concrecionário Laterítico \\
\hline
\end{tabular}




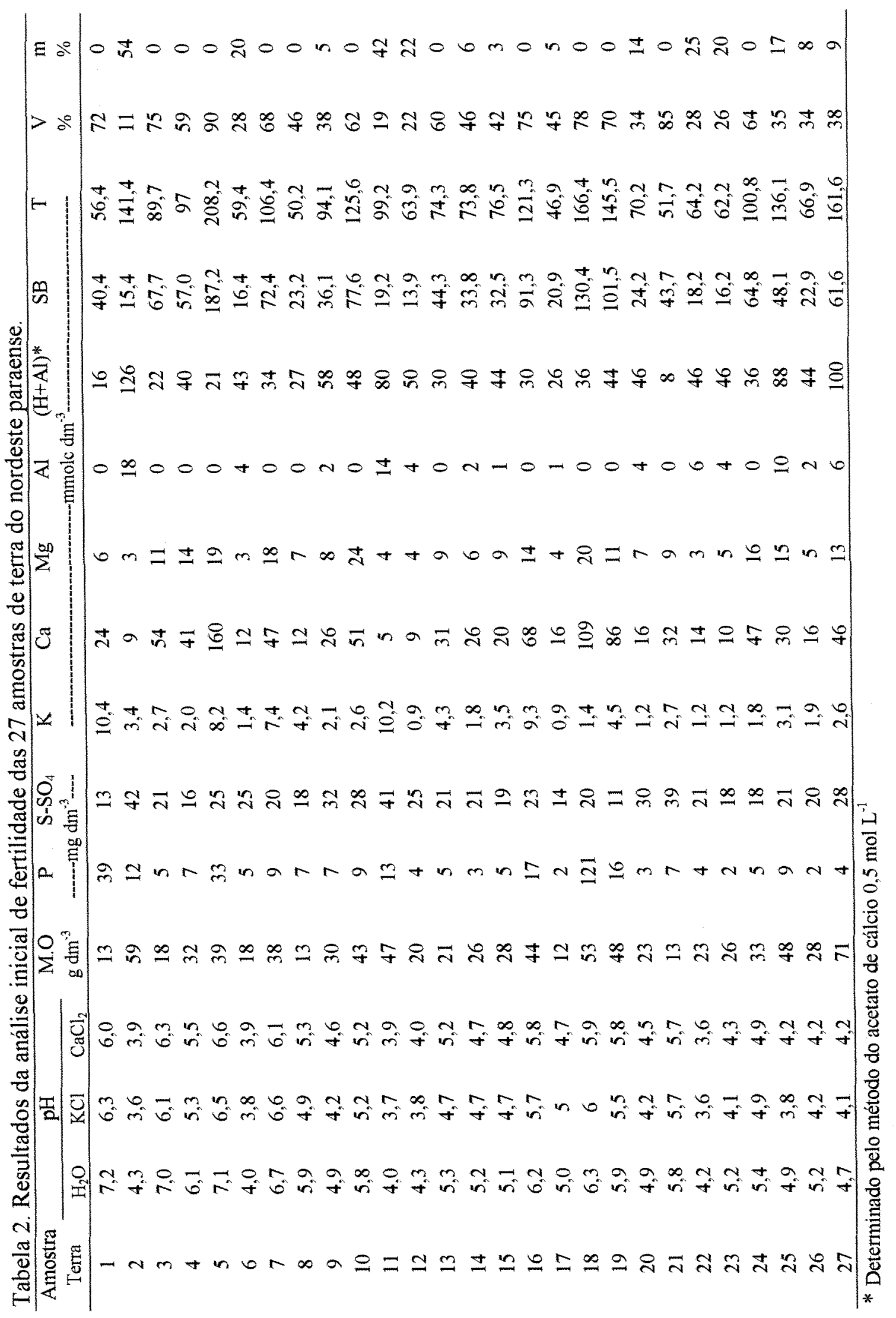




\subsection{Relação entre o pH SMP e a acidez potencial $(\mathbf{H}+\mathbf{A I})$}

Para a avaliação dessa relação foram utilizadas as mesmas amostras de terra do item 3.1, as quais estão apresentadas nas tabelas 1 e 2. Para tanto, a acidez potencial $(\mathrm{H}+\mathrm{Al})$ nessas amostras foi extraida com acetato de cálcio a $\mathrm{pH} 7,0$ e determinada por titulação com hidróxido de sódio (Raij et al., 1987).

A extração da acidez potencial foi realizada com uso de acetato de cálcio $0,5 \mathrm{~mol} \mathrm{~L}^{-1}$ a pH 7,0 e determinada por titulação com $\mathrm{NaOH} 0,025 \mathrm{~mol} \mathrm{~L}^{-1}$. Para isso, utilizaram-se erlenmeyer de $250 \mathrm{~mL}$, ao qual foi adicionado $5 \mathrm{~cm}^{3}$ de terra e $50 \mathrm{~mL}$ de solução extratora, agitando-se por 15 min e, deixando esse material em repouso por uma noite. Preparou-se também uma prova em branco. Após esse período, retiraram-se 25 $\mathrm{mL}$ do líquido sobrenadante, ao qual adicionou-se três gotas de solução alcoólica de fenolftaleína a $3 \%$, realizando em seguida a titulação com $\mathrm{NaOH} 0,025 \mathrm{~mol} \mathrm{~L}^{-1}$, até a viragem para a cor rosa permanente. Subtraindo do volume gasto na titulação da amostra o volume gasto na titulação da prova em branco, chegou-se aos valores de acidez potencial, expressos em $\mathrm{mmol}_{\mathrm{c}} \mathrm{dm}^{-3}$.

Nas mesmas amostras foram realizadas as leituras do $\mathrm{pH}$ quando em contato com a solução tampão SMP, seguindo metodologia proposta por Raij et al. (1987). A solução SMP foi preparada da seguinte forma: Para um balão volumétrico de $1 \mathrm{~L}$, foram transferidos $106,2 \mathrm{~g}$ de cloreto de cálcio $\left(\mathrm{CaCl}_{2} \cdot 2 \mathrm{H}_{2} \mathrm{O}\right), 6 \mathrm{~g}$ de cromato de potássio $\left(\mathrm{K}_{2} \mathrm{CrO}_{4}\right), 4 \mathrm{~g}$ de acetato de cálcio $\left(\mathrm{CaCH}_{3} \mathrm{OO}\right)_{2}$ e $5 \mathrm{ml}$ de trietanolamina. Em seguida adicionaram-se água destilada até obter um volume de cerca de $700 \mathrm{~mL}$. Separadamente em um béquer, dissolveram-se $3,6 \mathrm{~g}$ de p-nitrofenol em cerca de $200 \mathrm{~mL}$ de água destilada quente $\left(80\right.$ a $\left.90^{\circ} \mathrm{C}\right)$, sendo essa solução transferida para o balão volumétrico. Após isso, completou-se o volume e agitou-se manualmente. No dia seguinte o pH foi ajustado para 7,5 .

Após essas determinações e através de análise de regressão, estudou-se a relação entre os valores de $\mathrm{H}+\mathrm{Al}$ determinada através do método do acetato de cálcio $0,5 \mathrm{~mol} \mathrm{~L}^{-1}$ e $\mathrm{pH}$ SMP. 


\subsection{Relação entre pH da suspensão de acetato de cálcio e a acidez potencial}

Foram utilizadas também as mesmas amostras do item 3.1, apresentadas nas tabelas 1 e 2 . Nessas amostras, durante a determinação da acidez potencial pelo método do acetato de cálcio, foram realizadas as leituras de $\mathrm{pH}$ da solução sobrenadante, resultante da agitação entre o acetato de cálcio e cada uma das amostras de terra. Em seguida determinaram-se os valores de $\mathrm{H}+\mathrm{Al}$ através da titulação dessa solução sobrenadante com hidróxido de sódio.

Foram realizados estudos de regressão para verificar a relação entre o $\mathrm{pH}$ da suspensão de acetato de cálcio-terra e os valores de $\mathrm{H}+\mathrm{Al}$. Foi avaliado ainda a relação entre as leituras de pH SMP e pH da suspensão de acetato de cálcio-terra na determinação indireta da acidez potencial.

\subsection{Curva de neutralização com $\mathrm{CaCO}_{3}$}

Esse experimento foi realizado em laboratório do Departamento de Ciência do Solo da ESALQ/USP, utilizando-se delineamento experimental inteiramente casualizado. Cada unidade experimental foi composta por amostra de $500 \mathrm{~g}$ de terra.

Os tratamentos constaram de quatro amostras de terra (Número 22, 23, 25 e 26 das tabelas 1 e 2) e sete doses de carbonato de cálcio $\left(0,1,2,4,6,8\right.$ e $\left.10 \mathrm{Mg} \mathrm{ha}^{-1}\right)$. Para os cálculos dos níveis de $\mathrm{CaCO}_{3}$ considerou-se a massa de um hectare como sendo igual a $2000 \mathrm{Mg}$. Foram utilizadas 3 repetições, totalizando 84 unidades experimentais. A incubação ocorreu por 60 dias em copos plásticos.

As amostras de terra foram secas ao ar e peneiradas, seguindo-se de uma mistura de $500 \mathrm{~g}$ de terra com as respectivas doses de $\mathrm{CaCO}_{3}$. As quantidades de água nos copos para cada amostra de terra equivaleram a $100 \%$ da quantidade determinada pelo método do torrão separado pela frente de molhamento (TSFM), proposto por Costa (1983). O controle da umidade durante a incubação foi realizado através de pesagens 
periódicas (a cada 4 ou 5 dias) dos copos e adição de água. As determinações de pH em água e em solução de $\mathrm{CaCl}_{2} 0,01 \mathrm{~mol} \mathrm{~L}^{-1}$ foram realizadas quinzenalmente até o final do periodo de incubação.

Ao final, construíram-se os gráficos que relacionaram doses de $\mathrm{CaCO}_{3}$ utilizadas (eixo das abscissas) vs. $\mathrm{pH}$ final (eixo das ordenadas), sendo também realizadas as análises de regressão para cálculos das necessidades de calcário $(\mathrm{NC})$ para atingir determinados valores de $\mathrm{pH}(5,5$ e 6,0$)$ em cada solo estudado. Também foram construídos os gráficos que demonstram a evolução dos valores de $\mathrm{pH}$ durante o período de incubação.

\subsection{Avaliação agronômica dos métodos de recomendação de calagem}

Foi realizado em casa-de-vegetação do Departamento de Ciência do solo da ESALQ, sendo conduzido em delineamento inteiramente casualizado. Os tratamentos constaram de três amostras de terra (Números 23, 25 e 26 das tabelas 1 e 2), nas quais foram aplicadas as doses de calcário determinadas pelos seguintes métodos: $\mathrm{Al}$ x 0,15 ; média entre $\mathrm{Al} \times 0,15$ e $0,2 \times \mathrm{Al}+[2-0,1(\mathrm{Ca}+\mathrm{Mg})]^{1}$, saturação por bases a $70 \%$ e SMP para atingir um pH 5,5, segundo tabela proposta em Raij (1991). Esses métodos mais a testemunha (para cada amostra de terra) foram dispostos em quatro repetições, perfazendo um total de 60 unidades experimentais, sendo cada uma composta por $2 \mathrm{~kg}$ de amostra de terra em vasos plásticos.

O calcário utilizado foi um dolomítico com as seguintes características: óxido de cálcio $=280 \mathrm{~g} \mathrm{~kg}^{-1}$; óxido de magnésio $=173 \mathrm{~g} \mathrm{~kg}^{-1}$; ślica e insolúveis $=5,05$ $\mathrm{g} \mathrm{kg}^{-1} ;$ PRNT $=96,28 \%$.

Realizou-se uma incubação prévia das amostras de terra com as doses de calcário, recomendadas de acordo com os quatro métodos utilizados, nos próprios vasos por cerca de 20 dias. Em seguida, realizou-se uma adubação básica com 100, 200, 250, 
$5,10,10,10,5$ e $1 \mathrm{mg} \mathrm{kg}^{-1}$, respectivamente de $\mathrm{N}$ (uréia), $\mathrm{P}$ (superfosfato triplo), $\mathrm{K}$ (cloreto de potássio), B (ácido bórico), Fe (sulfato de ferro heptahidratado), Mn (sulfato de manganês tetrahidratado), $\mathrm{Zn}$ (sulfato de zinco heptahidratado), $\mathrm{Cu}$ (sulfato de cobre pentahidratado) e Mo (molibdato de sódio dihidratado), todos em mistura com o volume total de terra do vaso.

A quantidade de água adicionada aos vasos equivaleu a quantidade determinada pelo método do TSFM proposto por Costa (1983). O controle da umidade foi realizada através da anotação dos pesos dos vasos após a adição da água, os quais foram mantidos aproximadamente constante com novas adições de água até 22 dias da emergência. A partir desse período a umidade foi controlada através da observação do secamento da superfície da terra nos vasos.

Em cada unidade experimental, foram semeadas quatro sementes de feijão caupi, variedade BR 17 Gurgueia. Aos 15 dias da germinação, realizou-se um desbaste deixando apenas duas plantas que foram cultivadas até o final do experimento.

Realizaram-se três adubações de cobertura. A primeira, logo após o surgimento do primeiro par de folhas definitivas, com $50 \mathrm{mg} \mathrm{kg}^{-1}$ de $\mathrm{N}$ na forma de uréia em solução. A segunda, após o surgimento do terceiro par de folhas, com aplicação de $150 \mathrm{mg} \mathrm{kg}^{-1}$ de $\mathrm{N}$ (uréia) em solução. A terceira, 25 dias após a germinação, com aplicação de $21 \mathrm{mg} \mathrm{kg}^{-1}$ de $\mathrm{K}(\mathrm{KCl})$ em solução.

Com intuito de se evitar o aparecimento de doenças e pragas aplicou-se, aos 7 dias após a germinação, o fungicida Benlate na proporção de $7 \mathrm{~g}$ para $10 \mathrm{~L}$ de água e, o inseticida Temik na proporção de $1 \mathrm{~g} / \mathrm{vaso}$, aplicado na superficie da amostra de terra de cada vaso.

Sessenta dias após a semeadura realizou-se o corte das plantas rente à terra, as quais foram acondicionadas em sacos de papel, secas em estufa e pesadas para determinação do material seco. Nas amostras terra, após o corte das plantas, foram determinados os teores de cálcio, magnésio, $\mathrm{pH}$ em água e em solução de $\mathrm{CaCl}_{2} 0,01$

\footnotetext{
${ }^{1}$ Metodologia utilizada na Faculdade de Ciências Agrárias do Pará para recomendação de calagem.
} 
mol $\mathrm{L}^{-1}$ e calculado a saturação por bases. Com esses resultados e utilizando-se da análise de variância e teste de Tukey, analisaram-se a produção de material seco, $\mathrm{pH}$, $\mathrm{V} \%$ e teores de $\mathrm{Ca}$ e $\mathrm{Mg}$ em função dos métodos de recomendação de calcário e das amostras de terra utilizadas. 


\section{RESULTADOS E DISCUSSÃO}

\subsection{Amostras de terra utilizadas}

\subsubsection{Todas as amostras}

Para o conjunto das 27 amostras de terra (Tabela 2) utilizadas para o estudo de relações entre alguns atributos dos solos e para avaliação da relação entre acidez potencial, determinada pelo método do acetato de cálcio, e valores de pH SMP e $\mathrm{pH}$ da suspensão de acetato de cálcio (itens 3.1 a 3.3), observa-se que os valores de $\mathrm{pH}$ em água variaram de 4,2 a 7,2 e os de $\mathrm{pH}$ em $\mathrm{CaCl}_{2}$ de 3,6 a 6,6 , demonstrando a grande amplitude no grau de acidez dessas amostras.

A acidez potencial, determinada pelo método do acetato de cálcio, apresentou uma variação entre 8 e $126 \mathrm{mmol}_{\mathrm{c}} \mathrm{dm}^{-3}$. Os teores de matéria orgânica oscilaram entre 12 e $71 \mathrm{~g} \mathrm{dm}^{-3}$. A capacidade de troca catiônica (T) dessas amostras acompanha também a grande amplitude encontrada para os valores de acidez potencial e matéria orgânica. Isso evidencia diferentes intensidades de poder tampão dessas amostras de terra

Utilizando a classificação de Raij et al. (1996), verifica-se que os teores das bases trocáveis variaram dentro de faixas consideradas como baixa a alta. Para o cálcio, encontraram-se teores variando de médio a muito alto. 


\subsubsection{Parte das amostras}

Para os estudos de incubação com carbonato de cálcio e avaliação agronômica dos métodos de recomendação de calagem utilizaram-se as amostras de terra de número $22,23,25$ e 26 apresentadas na Tabela 2. Verifica-se que, entre essas amostras, o pH inicial em $\mathrm{H}_{2} \mathrm{O}$ variou numa faixa de 4,2 a 5,2 e de 3,6 a 4,3 para o $\mathrm{pH}$ em $\mathrm{CaCl}_{2}$, o que evidencia a condição ácida dessas amostras de terra.

O conteúdo de matéria orgânica é mais alto para a amostra de gley pouco húmico (GPH) com $48 \mathrm{~g} \mathrm{dm}^{-3}$, a qual apresentou também os maiores valores para fósforo, acidez potencial $(\mathrm{H}+\mathrm{Al})$, soma de bases $(\mathrm{SB})$, saturação por bases $(\mathrm{V} \%)$ e capacidade de troca de cátions (T). Esse solo, além de possuir o maior conteúdo de matéria orgânica, enquadra-se na classe textural argilosa.

Raij et al. (1996) citaram que os teores de matéria orgânica são úteis para dar uma idéia da textura do solo e que na faixa de 31 a $60 \mathrm{~g} \mathrm{dm}^{-3}$ indicam solos com características argilosas.

Pela análise física realizada nessas quatro amostras de terra, verificou-se uma textura arenosa para o latossolo amarelo e podzólico vermelho-amarelo, média argilosa para latossolo vermelho-amarelo e argilosa para o gley pouco húmico, o que confirma as expectativas iniciais antes da coleta desse material.

Essas análises evidenciam que as amostras utilizadas apresentavam características ácidas e de baixa fertilidade, como os apresentados por Vieira (1988), e que são representativas dos principais solos do nordeste paraense. 


\subsection{Relação entre alguns atributos dos solos}

\subsubsection{Determinações de $\mathrm{pH}$}

Os resultados de $\mathrm{pH}$ obtidos de quatro formas diferentes (em água, $\mathrm{KCl}$, $\mathrm{CaCl}_{2}$ e SMP) são apresentados na Tabela 3. Para as diferenças entre os valores de pH em $\mathrm{KCl}$ e $\mathrm{pH}$ em $\mathrm{H}_{2} \mathrm{O}$, também chamada de $\Delta \mathrm{pH}$, observa-se que as mesmas são negativas em praticamente todas as amostras de terra, indicando que há um balanço de cargas negativas e que a capacidade de troca catiônica é maior que a aniônica (CTC > CTA).

Para as diferenças entre $\mathrm{pH}$ em $\mathrm{H}_{2} \mathrm{O}$ e $\mathrm{pH}$ em $\mathrm{CaCl}_{2} 0,01 \mathrm{~mol} \mathrm{~L}$, observa-se que a diferença variou de 0,1 a 1,2 unidades. No entanto, verifica-se que os valores de $\mathrm{pH}$ determinados em água foram em média 0,5 unidades superiores aos obtidos em solução de $\mathrm{CaCl}_{2}$ 0,01 mol L ${ }^{-1}$. Essa diferença é cerca de 0,1 unidade menor do que aquelas observadas por Quaggio (1983) e Almeida (1984).

Observou-se um alto coeficiente de correlação $(r=0,95)$ entre as variáveis $\mathrm{pH}$ em água e $\mathrm{pH}$ em $\mathrm{CaCl}_{2} 0,01 \mathrm{~mol} \mathrm{~L}^{-1}$. Na Figura 1 apresenta-se a relação e a equação ajustada entre essas variáveis. A equação linear que se ajustou aos resultados foi $\mathrm{pHCaCl}_{2}=0,1868+0,8783 \mathrm{pHH}_{2} \mathrm{O}$.

Utilizando-se essa equação e os valores de $\mathrm{pH}$ em $\mathrm{H}_{2} \mathrm{O}$, estimaram-se os valores de $\mathrm{pH}$ em solução de $\mathrm{CaCl}_{2}$, os quais são apresentados na Tabela 4. As diferenças entre as duas variáveis foram de 0,3 a 0,7 unidades, sendo maior com o aumento dos valores de $\mathrm{pH}$. 
Tabela 3. Valores de $\mathrm{pH}$ determinados em $\mathrm{H}_{2} \mathrm{O}, \mathrm{KCl} 1 \mathrm{~mol} \mathrm{~L}^{-1}, \mathrm{CaCl}_{2} 0,01 \mathrm{~mol} \mathrm{~L} \mathrm{~L}^{-1} \mathrm{e}$ SMP em 27 amostras de terra do nordeste paraense.

\begin{tabular}{|c|c|c|c|c|c|c|c|c|c|c|c|c|c|}
\hline \multirow{2}{*}{$\begin{array}{c}\mathrm{N}^{\mathrm{o}} \\
\text { Amostra } \\
\end{array}$} & \multicolumn{4}{|c|}{$\mathrm{pH}$} & \multicolumn{2}{|c|}{$---\Delta p H---$} & \multirow{2}{*}{$\begin{array}{c}\mathrm{N}^{0} \\
\text { Amostra } \\
\end{array}$} & $\mathrm{pH}$ & \multirow[b]{2}{*}{$\mathrm{KCl}$} & \multirow[b]{2}{*}{$\mathrm{CaCl}_{2}$} & \multirow[b]{2}{*}{ SMP } & \multicolumn{2}{|c|}{$---\Delta p H$} \\
\hline & $\mathrm{H}_{2} \mathrm{O}$ & $\mathrm{KCl}$ & $\mathrm{CaCl}_{2}$ & SMP & $\mathrm{A}$ & $\mathrm{B}$ & & $\mathrm{H}_{2} \mathrm{O}$ & & & & $\mathrm{A}$ & $\mathrm{B}$ \\
\hline 1 & 7,2 & 6,3 & 6,0 & 7,6 & $-0,9$ & 1,2 & 15 & 5,1 & 4,7 & 4,8 & 6,5 & $-0,4$ & 0,3 \\
\hline 2 & 4,3 & 3,6 & 3,9 & 5,1 & $-0,7$ & 0,4 & 16 & 6,2 & 5,7 & 5,8 & 6,9 & $-0,5$ & 0,4 \\
\hline 3 & 7,0 & 6,1 & 6,3 & 7,2 & $-0,9$ & 0,7 & 17 & 5,0 & 5,0 & 4,7 & 7,2 & 0,0 & 0,3 \\
\hline 4 & 6,1 & 5,3 & 5,5 & 6,6 & $-0,8$ & 0,6 & 18 & 6,3 & 6,0 & 5,9 & 6,7 & $-0,3$ & 0,4 \\
\hline 5 & 7,1 & 6,5 & 6,6 & 7,2 & $-0,6$ & 0,5 & 19 & 5,9 & 5,5 & 5,8 & 6,6 & $-0,4$ & 0,1 \\
\hline 6 & 4,0 & 3,8 & 3,9 & 6,3 & $-0,2$ & 0,1 & 20 & 4,9 & 4,2 & 4,5 & 6,1 & $-0,7$ & 0,4 \\
\hline 7 & 6,7 & 6,6 & 6,1 & 6,8 & $-0,1$ & 0,6 & 21 & 5,8 & 5,7 & 5,7 & 7,1 & $-0,1$ & 0,1 \\
\hline 8 & 5,9 & 4,9 & 5,3 & 7,1 & $-1,0$ & 0,6 & 22 & 4,2 & 3,6 & 3,6 & 5,9 & $-0,6$ & 0,6 \\
\hline 9 & 4,9 & 4,2 & 4,6 & 6,1 & $-0,7$ & 0,3 & 23 & 5,2 & 4,1 & 4,3 & 6,0 & $-1,1$ & 0,9 \\
\hline 10 & 5,8 & 5,2 & 5,2 & 6,3 & $-0,6$ & 0,6 & 24 & 5,4 & 4,9 & 4,9 & 6,2 & $-0,5$ & 0,5 \\
\hline 11 & 4,0 & 3,7 & 3,9 & 4,9 & $-0,3$ & 0,1 & 25 & 4,9 & 3,8 & 4,2 & 5,2 & $-1,1$ & 0,7 \\
\hline 12 & 4,3 & 3,8 & 4,0 & 6,2 & $-0,5$ & 0,3 & 26 & 5,2 & 4,2 & 4,2 & 6,0 & $-1,0$ & 1,0 \\
\hline 13 & 5,3 & 4,7 & 5,2 & 7,0 & $-0,6$ & 0,1 & 27 & 4,7 & 4,1 & 4,2 & 5,1 & $-0,6$ & 0,5 \\
\hline 14 & 5,2 & 4,7 & 4,7 & 6,5 & $-0,5$ & 0,5 & & & & & & & \\
\hline
\end{tabular}

$\mathbf{A}=\mathrm{pH} \mathrm{KCl}-\mathrm{pH} \mathrm{H} \mathrm{H}_{2} \mathrm{O} ; \mathbf{B}=\mathrm{pH} \mathrm{H}_{2} \mathrm{O}-\mathrm{pH} \mathrm{CaCl}_{2}$ 


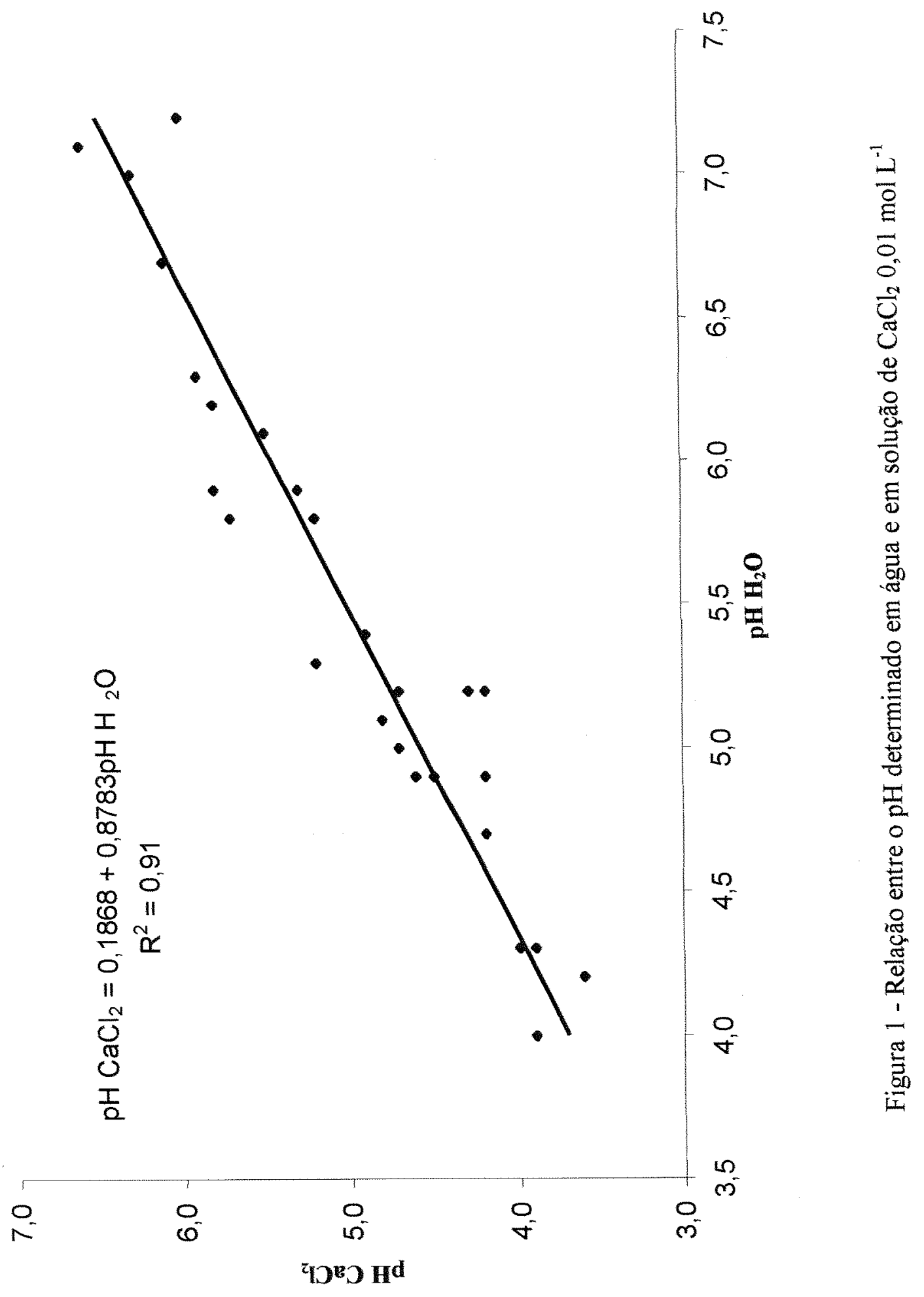


Tabela 4. Estimativas de $\mathrm{pH}$ em solução de $\mathrm{CaCl}_{2}$ em função dos valores de $\mathrm{pH}$ em $\mathrm{H}_{2} \mathrm{O}$ e da equação proposta, para solos do nordeste paraense.

\begin{tabular}{cc|cc|cc}
\hline $\mathbf{p H ~ H _ { 2 } \mathbf { O }}$ & $\mathbf{P H ~ C a C l}_{2}$ & $\mathbf{p H ~ \mathbf { H } _ { 2 } \mathbf { O }}$ & $\mathbf{p H ~ \mathbf { C a C l } _ { 2 }}$ & $\mathbf{p H ~ \mathbf { H } _ { 2 } \mathbf { O }}$ & $\mathbf{p H ~ \mathbf { C a C l } _ { 2 }}$ \\
\hline 4,0 & 3,7 & 5,1 & 4,7 & 6,2 & 5,6 \\
4,1 & 3,8 & 5,2 & 4,8 & 6,3 & 5,7 \\
4,2 & 3,9 & 5,3 & 4,8 & 6,4 & 5,8 \\
4,3 & 4,0 & 5,4 & 4,9 & 6,5 & 5,9 \\
4,4 & 4,1 & 5,5 & 5,0 & 6,6 & 6,0 \\
4,5 & 4,1 & 5,6 & 5,1 & 6,7 & 6,1 \\
4,6 & 4,2 & 5,7 & 5,2 & 6,8 & 6,2 \\
4,7 & 4,3 & 5,8 & 5,3 & 6,9 & 6,2 \\
4,8 & 4,4 & 5,9 & 5,4 & 7,0 & 6,3 \\
4,9 & 4,5 & 6,0 & 5,5 & 7,1 & 6,4 \\
5,0 & 4,6 & 6,1 & 5,5 & & \\
\hline
\end{tabular}

\subsubsection{Saturação por bases e pH}

A saturação por bases utilizada foi calculada através da determinação indireta da $T$, a qual foi calculada pela soma das bases trocáveis com os teores de $\mathrm{H}+\mathrm{Al}$ determinados pelo método da extração com acetato de cálcio. Quanto ao $\mathrm{pH}$, utilizaramse as leituras feitas em água e em solução de $\mathrm{CaCl}_{2}$.

A determinação da relação entre a saturação por bases e o pH é de grande importância, pois serve de base para estudos que verifiquem a possibilidade de uso futuro da V\% como método de determinação da necessidade de calagem em solos do nordeste paraense.

Coeficientes de correlações elevados foram obtidos para as relações entre $\mathrm{V} \% \times \mathrm{pH}$ em água $(\mathrm{r}=0,88)$ e $\mathrm{V} \% \mathrm{xpH}$ em $\mathrm{CaCl}_{2}(\mathrm{r}=0,94)$. Nas Figuras $2 \mathrm{a}$ e $2 \mathrm{~b}$ são apresentadas as relações e as equações de regressão obtidas entre os valores dessas 
variáveis. Os coeficientes de correlação foram elevados e maiores na relação entre $\mathrm{pH}$ em solução de $\mathrm{CaCl}_{2}$ e V\%. Quaggio (1983) e Regitano (1987), trabalhando com solos do Estado de São Paulo e de Minas Gerais, respectivamente, encontraram resultados semelhantes. Segundo esses autores, isso é uma indicação de que a determinação do $\mathrm{pH}$ em $\mathrm{CaCl}_{2}$ é mais confiável que a determinação em água. Quaggio (1983) argumenta que a razão principal para a maior confiabilidade na determinação do $\mathrm{pH} \mathrm{em} \mathrm{CaCl}_{2}$ é que nesta condição as amostras de terra não sofrem influência da concentração de sais.

Na Tabela 5 encontram-se os valores correspondentes de saturação por bases do solo e $\mathrm{pH}$ em água, obtidos através da equação apresentada na Figura 2a. Observa-se que para a saturação por bases do solo de 40 a $70 \%$ têm-se valores de $\mathrm{pH}$ em água de 5,1 a 6,2 .

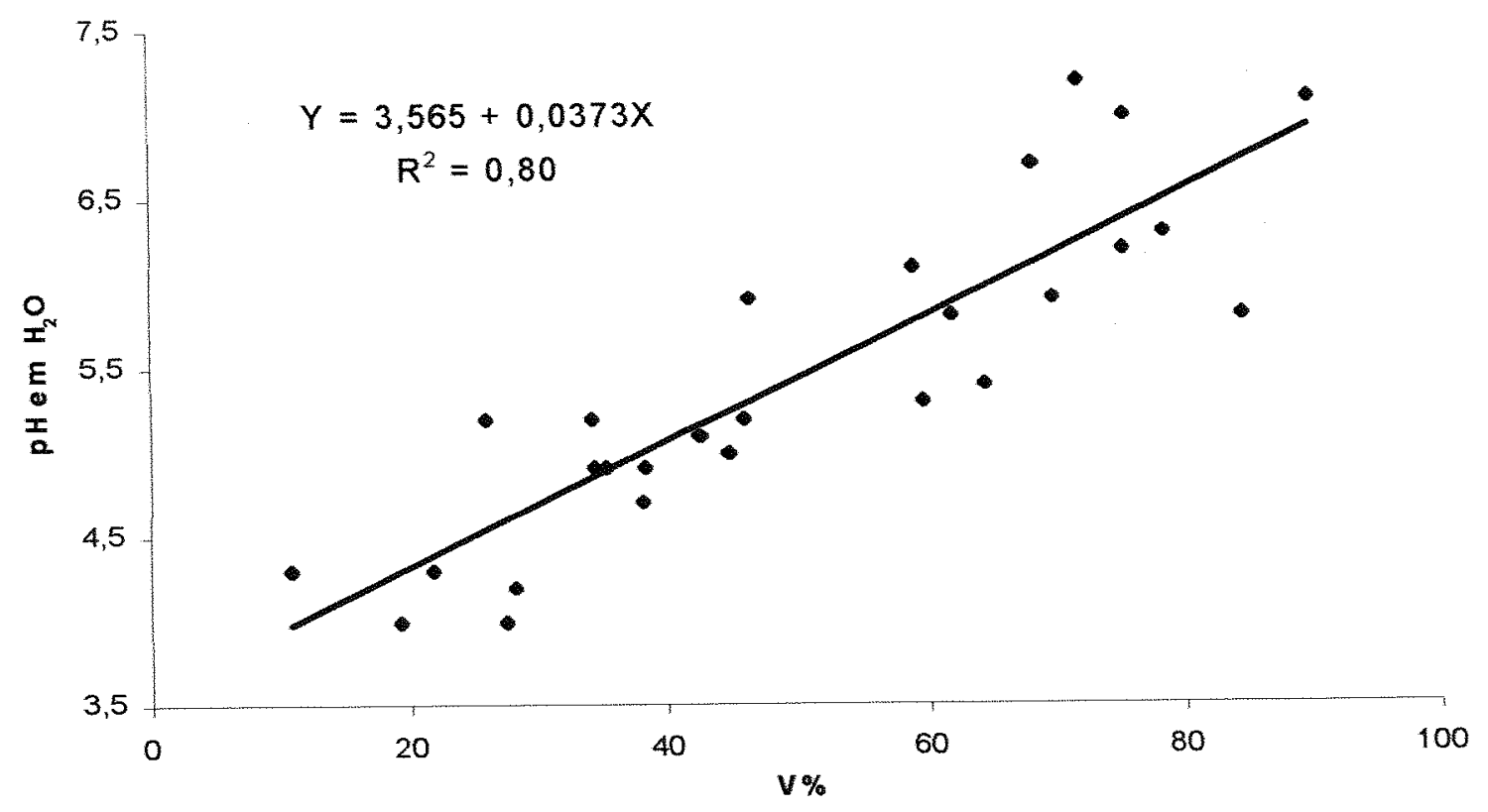

Figura $2 \mathrm{a}$ - Relação entre $\mathrm{pH}$ em $\mathrm{H}_{2} \mathrm{O}$ e a saturação por bases em 27 amostras de terra do nordeste paraense. 


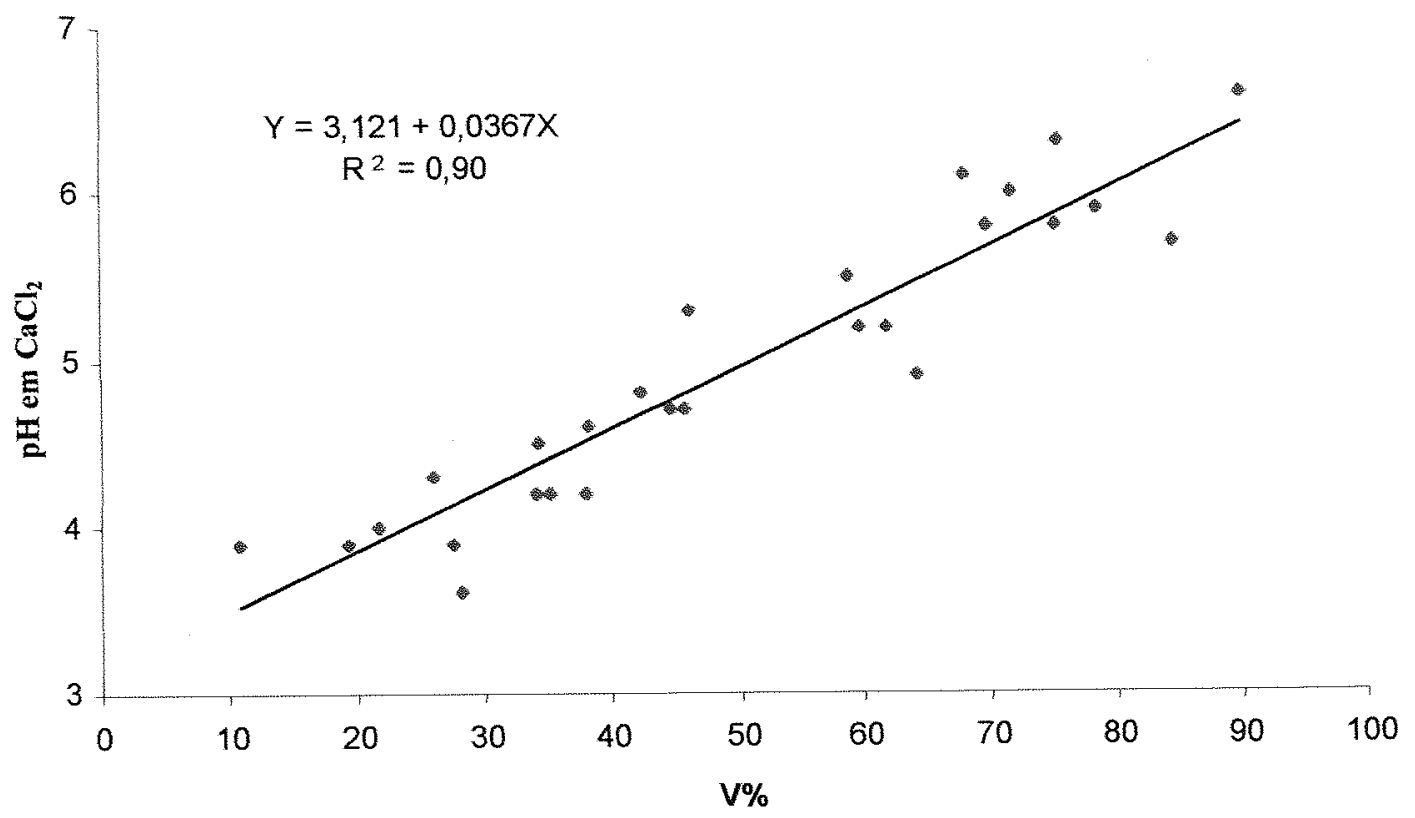

Figura $2 \mathrm{~b}$ - Relação entre $\mathrm{pH}$ em $\mathrm{CaCl}_{2} 0,01 \mathrm{~mol} \mathrm{~L}^{-1}$ e a saturação por bases em 27 amostras de terra do nordeste paraense.

Tabela 5. Estimativas de pH em água através da equação proposta.

\begin{tabular}{cccccccc}
\hline $\mathrm{V}$ & $\mathrm{pH} \mathrm{H}_{2} \mathrm{O}$ & $\mathrm{V}$ & $\mathrm{pH} \mathrm{H}_{2} \mathrm{O}$ & $\mathrm{V}$ & $\mathrm{pH} \mathrm{H}_{2} \mathrm{O}$ & $\mathrm{V}$ & $\mathrm{pH} \mathrm{H}_{2} \mathrm{O}$ \\
$\%$ & & $\%$ & & $\%$ & & 72 & 6,3 \\
\hline 11 & 4,0 & 32 & 4,8 & 52 & 5,5 & 74 & 6,3 \\
15 & 4,1 & 34 & 4,8 & 54 & 5,6 & 76 & 6,4 \\
16 & 4,2 & 36 & 4,9 & 56 & 5,7 & 58 & 6,5 \\
18 & 4,2 & 38 & 5,0 & 58 & 5,7 & 78 & 6,5 \\
20 & 4,3 & 40 & 5,1 & 60 & 5,8 & 80 & 6,6 \\
22 & 4,4 & 42 & 5,1 & 62 & 5,9 & 82 & 6,7 \\
24 & 4,5 & 44 & 5,2 & 64 & 6,0 & 84 & 6,8 \\
26 & 4,5 & 46 & 5,3 & 66 & 6,0 & 86 & 6,8 \\
28 & 4,6 & 48 & 5,4 & 68 & 6,1 & 88 & 6,9 \\
30 & 4,7 & 50 & 5,4 & 70 & 6,2 & 90 &
\end{tabular}




\subsubsection{Matéria orgânica e capacidade de troca catiônica (T)}

Para a avaliação dessa relação utilizaram-se os resultados de matéria orgânica em $\mathrm{g} \mathrm{dm}^{-3}$ e $\mathrm{T}$, que foi determinada indiretamente pela somatória da soma de bases (SB) e $\mathrm{H}+\mathrm{Al}$, em $\mathrm{mmol}_{\mathrm{c}} \mathrm{dm}^{-3}$, apresentados na Tabela 2.

Observou-se um coeficiente de correlação (r) de 0,84 entre essas variáveis. Na Figura 3 são apresentadas a relação e a equação $(Y=24,164+2,2537 X$, na qual $\mathrm{X}=$ M.O. e $\mathrm{Y}=\mathrm{T}$ ) entre essas variáveis. Esses resultados estão baseadas nas 27 amostras de terra apresentadas na Tabela 2, no entanto, quando não se considera os valores da amostra de número 5 , por apresentar um valor de $\mathrm{T}$ bem superior as demais, $\mathrm{o}$ coeficiente de correlação aumenta $(r=0,94)$, o que indica uma relação mais estreita entre as variáveis.

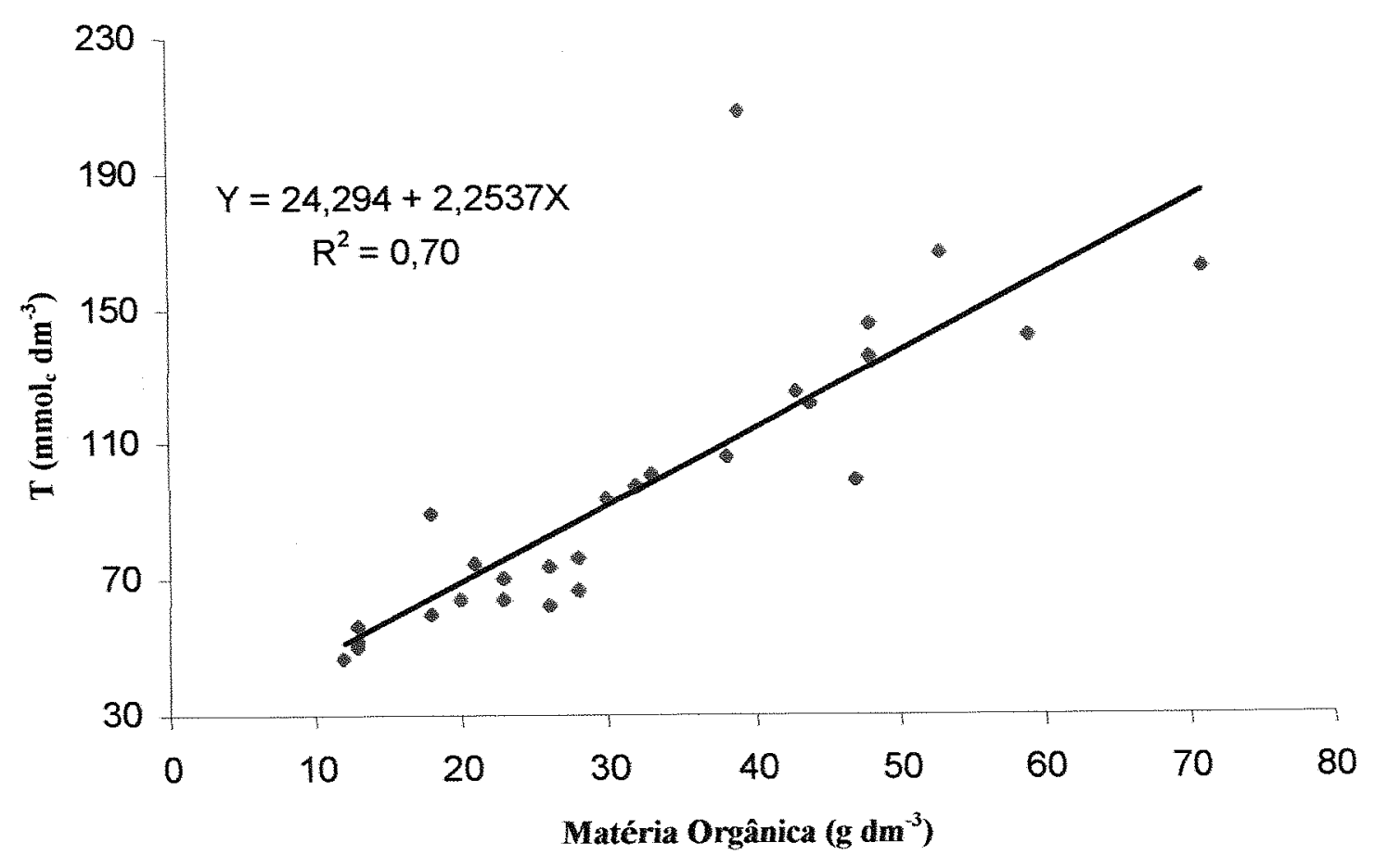

Figura 3 - Relação entre matéria orgânica e a T em 27 amostras de terra do nordeste paraense. 
Esses resultados indicam que a capacidade de troca catiônica $(\mathrm{T})$ depende muito do conteúdo de matéria orgânica desses solos, fato este comum em solos da região tropical, onde há predominância de argila 1:1 e óxidos de Fe e Al.

\subsubsection{Saturação por bases (V\%) e saturação por alumínio ( $\mathrm{m} \%)$}

A relação entre os resultados de saturação por bases e saturação por alumínio são apresentados na Figura 4. Observa-se, que com a saturação por bases em torno de $40 \%$, a saturação por alumínio é menor que $10 \%$ e atinge valor zero quando a V\% aproxima-se de $50 \%$.

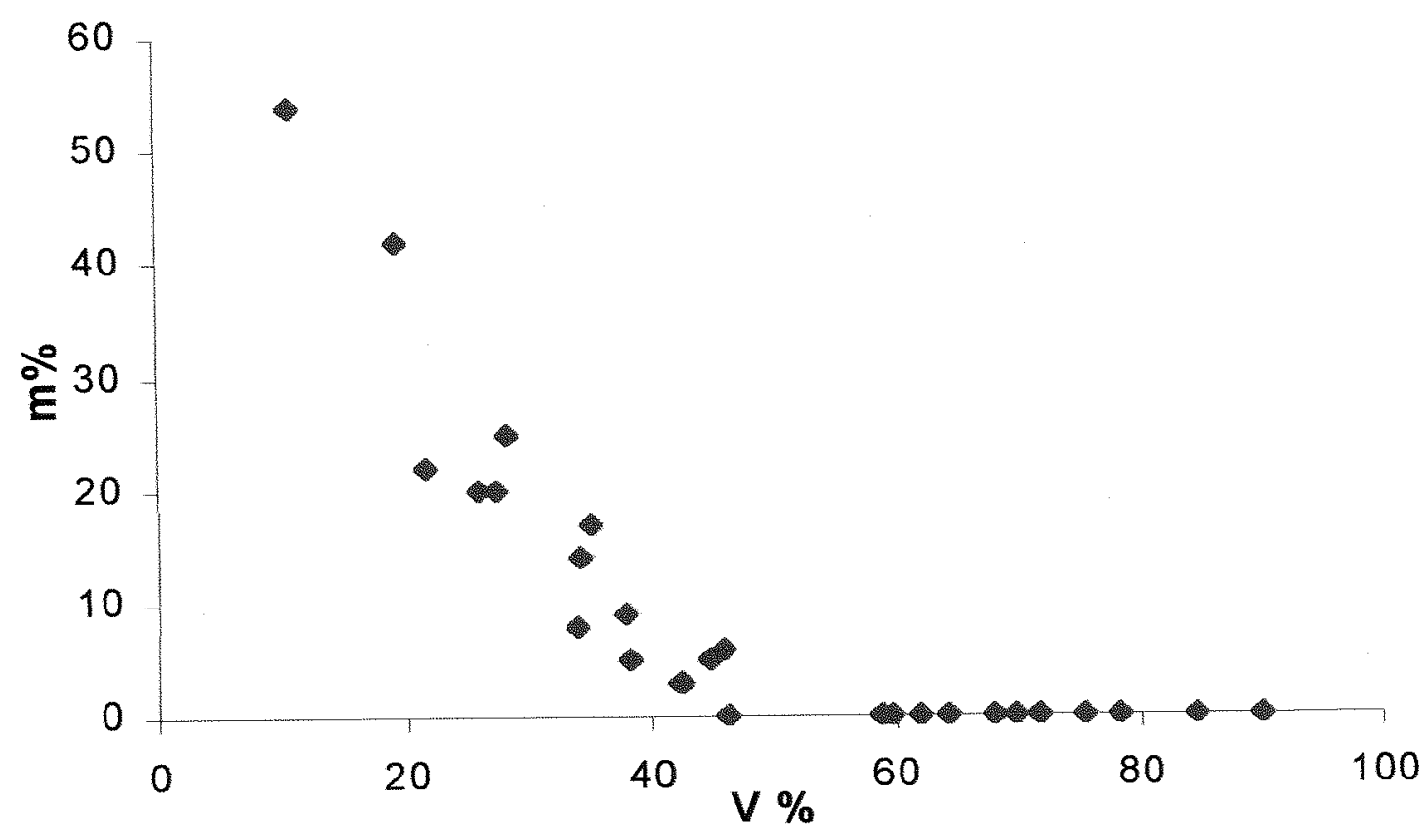

Figura 4 - Relação entre a saturação por bases (V\%) e a saturação por alumínio $(\mathrm{m} \%)$ em 27 amostras de terra do nordeste paraense. 


\subsection{Relação entre acidez potencial $(H+$ Al) e o pH SMP}

$\mathrm{Na}$ Tabela 2 encontram-se as características das 27 amostras de terra utilizadas para o estudo da relação entre acidez potencial extraída pelo método do acetato de cálcio e o pH de equilibrio da solução tampão SMP com a terra.

Os valores de acidez potencial $(\mathrm{H}+\mathrm{Al})$, extraídos por acetato de cálcio, variaram numa faixa de 8 a $126 \mathrm{mmol}_{\mathrm{c}} \mathrm{dm}^{-3}$ e os de $\mathrm{pH}$ SMP de 5,1 a 7,6. Verificou-se entre as duas variáveis uma alta correlação $(r=-0,91)$, inversamente proporcional, ou seja, com aumento do $\mathrm{pH}$ SMP observa-se um decréscimo nos valores de $\mathrm{H}+\mathrm{Al}$. Pela Figura 5, observa-se que o modelo quadrático ajustou-se aos resultados obtidos, através da equação $Y=786,3-201,73 X+13,294 X^{2}\left(R^{2}=0,90\right)$, na qual $Y$ representa os valores de $\mathrm{H}+\mathrm{Al}$ e $\mathrm{X}$ os de $\mathrm{pH}$ SMP.

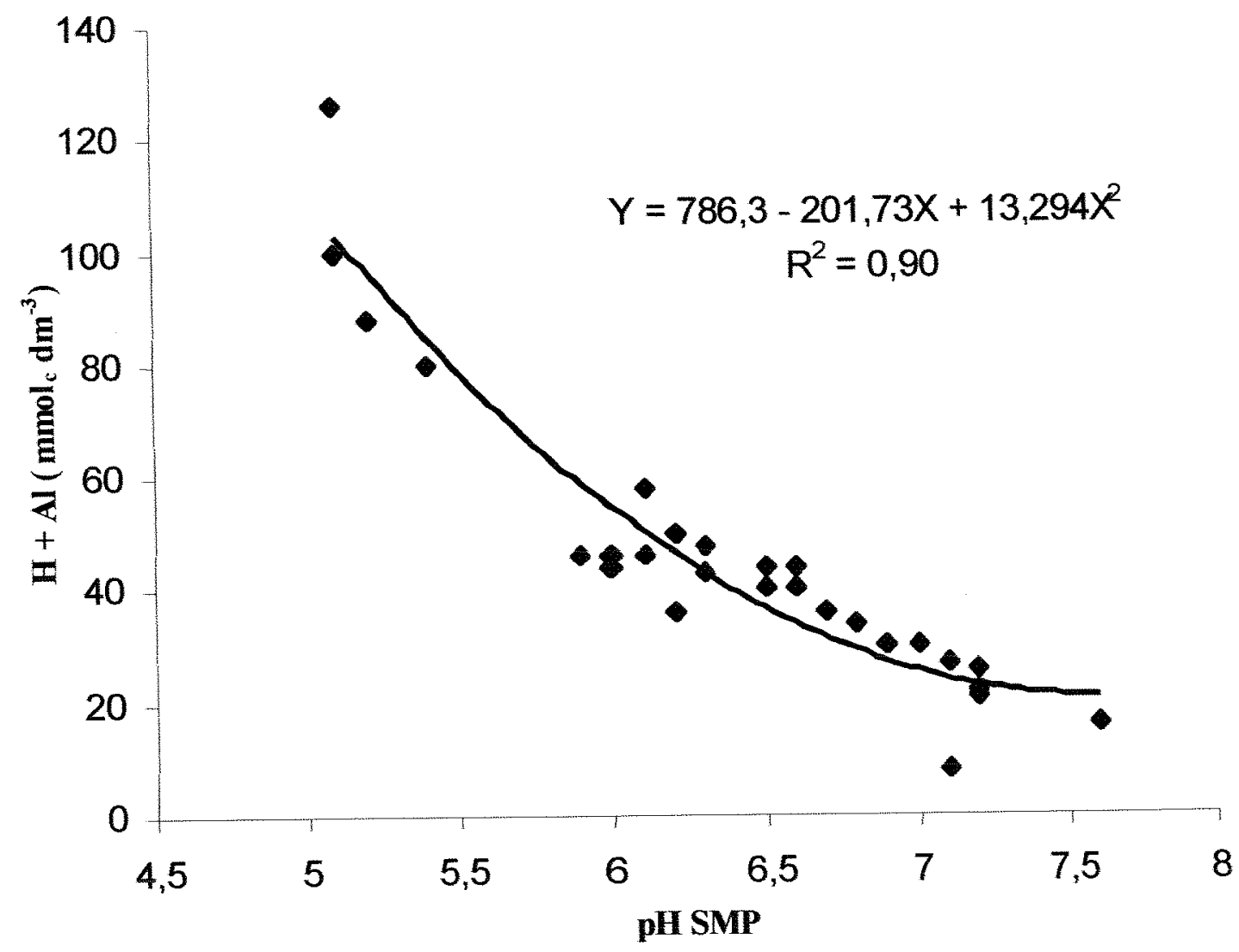

Figura 5 - Relação entre acidez potencial $(\mathrm{H}+\mathrm{Al})$ e pH SMP em 27 amostras de terra do nordeste paraense. 
$\mathrm{Na}$ Tabela 6 encontram-se as equações e os coeficientes de correlação obtidos nos trabalhos de Raij et al. (1979), Quaggio et al. (1985), Almeida (1984), Pereira et al. (1998) e neste estudo. Verifica-se que todas essas correlações foram negativas e inversamente proporcionais. Através dessa tabela nota-se a importância da necessidade de ajuste da curva de regressão e da relação entre valores de $\mathrm{H}+\mathrm{Al}$ e os de pH SMP para cada região do Brasil, já que para cada trabalho, foram obtidas equações diferentes.

Essa importância fica ainda mais evidente quando realiza-se uma comparação das médias dos valores de $\mathrm{H}+\mathrm{Al}$ (Tabela 7), que seriam obtidos, com os valores de pH SMP, para os solos da região nordeste paraense se fossem utilizadas as equações apresentadas na Tabela 6 , as quais foram desenvolvidas em outras condições de solo. Nota-se que, a equação proposta por Raij et al (1979) subestima os valores em cerca de $55 \%$ em relação àqueles obtidos pelo método do acetato de cálcio. Observa-se até valores negativos de $\mathrm{H}+\mathrm{Al}$ quando utilizou-se essa equação para os solos citados. Com as equações de Quaggio et al. (1985), Almeida (1984) e Pereira et al. (1998) a acidez potencial foi subestimada em 21,25 e $5 \%$ respectivamente.

Observa-se que o valor médio de $\mathrm{H}+\mathrm{Al}$ obtido pela equação da Figura 5 , proposta neste trabalho, é muito próximo daquele obtido pelo método do acetato de cálcio. Na Tabela 8 são apresentados os valores de $\mathrm{H}+\mathrm{Al}$, por amostra de terra, determinados pelo método padrão (Acetato), pela equação de Quaggio (1985) e pela equação proposta neste trabalho.

Na Tabela 9 são apresentados os valores da acidez potencial $(H+A 1)$ estimados pela equação proposta neste trabalho, dentro da faixa de pH SMP obtida entre as 27 amostras de terras utilizadas.

Os resultados apresentados na Figura 5 demonstram a possibilidade de utilização da leitura do $\mathrm{pH}$ da solução tampão SMP para a determinação dos valores de $\mathrm{H}+\mathrm{Al}$ em solos do nordeste paraense. 
Tabela 6. Equações obtidas em alguns trabalhos que relacionaram $\mathrm{H}+\mathrm{Al}$ e $\mathrm{pH}$ SMP.

Equação $\quad r \quad R^{2}$

Raij et al. (1979) $\quad \mathrm{Y}=28,8-4,18 \mathrm{X} \quad-0,975^{*}$

Quaggio et al. (1985)

$\operatorname{Ln} Y=7,76-1,053 X \quad-0,98^{*}$

Almeida (1984)

$Y=21,67-2,85 X$

$-0,977^{*}$

Pereira et al. (1998)

$\mathrm{Y}=\mathrm{e}^{10,05-1,02 \mathrm{X}}$

0,90

Apresentada neste trabalho $\quad Y=786,3-201,73 X+13,294 X^{2} \quad 0,90$

* Nesses trabalhos são apresentados apenas os coeficientes de correlação (r).

Tabela 7. Estimativa de valores de acidez potencial por diferentes equações propostas e pelo método do acetato de cálcio para as 27 amostras de terra do nordeste paraense.

\begin{tabular}{lcccc} 
& \multicolumn{3}{c}{$\mathrm{H}+\mathrm{Al}$} & \multirow{2}{*}{$\begin{array}{c}\text { Diferença } \\
\text { paraense. }\end{array}$} \\
\cline { 2 - 4 } & Máximo & Mínimo & Média & 100,00 \\
\cline { 2 - 4 }${\text { mmol } \mathrm{dm}^{-3}}^{\text {Acetato de Cálcio* }}$ & 126,00 & 8,00 & 45,52 & 44,66 \\
Raij et al. (1979) & 74,82 & $-29,68$ & 20,33 & 79,42 \\
Quaggio et al. (1985) & 109,00 & 10,00 & 36,15 & 75,11 \\
Almeida (1984) & 71,35 & 0,10 & 34,19 & \\
Pereira (1998) & 127,49 & 9,95 & 43,06 & 94,60 \\
Trabalho Atual & 103,25 & 21,01 & 45,53 & 100,02 \\
\hline
\end{tabular}

* Considerado como padrão. 
Tabela 8. Valores de $\mathrm{pH}$ SMP e $\mathrm{H}+\mathrm{Al}$ determinados por métodos diferentes, em 27 amostras de terra do nordeste paraense.

\begin{tabular}{|c|c|c|c|c|}
\hline \multirow[b]{2}{*}{ Amostras } & \multirow[b]{2}{*}{ pH SMP } & \multicolumn{3}{|c|}{$\mathrm{H}+\mathrm{Al}\left(\mathrm{mmol}_{\mathrm{c}} \mathrm{dm}^{-3}\right)$} \\
\hline & & 1 & 2 & 3 \\
\hline 1 & 7,6 & 10 & 21,01 & 16 \\
\hline 2 & 5,1 & 109 & 103,25 & 126 \\
\hline 3 & 7,2 & 12 & 23,00 & 22 \\
\hline 4 & 6,6 & 22 & 33,97 & 40 \\
\hline 5 & 7,2 & 12 & 23,00 & 21 \\
\hline 6 & 6,3 & 31 & 43,04 & 43 \\
\hline 7 & 6,8 & 18 & 29,25 & 34 \\
\hline 8 & 7,1 & 13 & 24,17 & 27 \\
\hline 9 & 6,1 & 38 & 50,42 & 58 \\
\hline 10 & 6,3 & 31 & 43,04 & 48 \\
\hline 11 & 5,4 & 88 & 84,61 & 80 \\
\hline 12 & 6,2 & 34 & 46,60 & 50 \\
\hline 13 & 7 & 15 & 25,60 & 30 \\
\hline 14 & 6,5 & 25 & 36,73 & 40 \\
\hline 15 & 6,5 & 25 & 36,73 & 44 \\
\hline 16 & 6,9 & 16 & 27,29 & 30 \\
\hline 17 & 7,2 & 12 & 23,00 & 26 \\
\hline 18 & 6,7 & 20 & 31,48 & 36 \\
\hline 19 & 6,6 & 22 & 33,97 & 44 \\
\hline 20 & 6,1 & 38 & 50,42 & 46 \\
\hline 21 & 7,1 & 13 & 24,17 & 8 \\
\hline 22 & 5,9 & 47 & 58,86 & 46 \\
\hline 23 & 6 & 42 & 54,50 & 46 \\
\hline 24 & 6,2 & 34 & 46,60 & 36 \\
\hline 25 & 5,2 & 98 & 96,77 & 88 \\
\hline 26 & 6 & 42 & 54,50 & 44 \\
\hline 27 & 5,1 & 109 & 103,25 & 100 \\
\hline
\end{tabular}

1 - Equação de Quaggio et al. (1985); 2 - Equação da Figura 5; 3 - Método do Acetato de cálcio 
Tabela 9. Estimativas de acidez potencial através da equação proposta neste trabalho.

\begin{tabular}{|c|c|c|c|c|c|}
\hline pH SMP & $\mathbf{H}+\mathbf{A l}$ & pH SMP & $\mathbf{H}+\mathbf{A l}$ & pH SMP & $\mathbf{H}+\mathbf{A l}$ \\
\hline & $\operatorname{mmol}_{c} \cdot \mathrm{dm}^{-3}$ & & $\mathrm{mmol}_{c} \cdot \mathrm{dm}^{-3}$ & & $\mathrm{mmol}_{c} \cdot \mathrm{dm}^{-3}$ \\
\hline 5,1 & 103,25 & 6,1 & 50,42 & 7,1 & 24,17 \\
\hline 5,2 & 96,77 & 6,2 & 46,60 & 7,2 & 23,00 \\
\hline 5,3 & 90,56 & 6,3 & 43,04 & 7,3 & 22,11 \\
\hline 5,4 & 84,61 & 6,4 & 39,75 & 7,4 & 21,48 \\
\hline 5,5 & 78,93 & 6,5 & 36,73 & 7,5 & 21,11 \\
\hline 5,6 & 73,51 & 6,6 & 33,97 & 7,6 & 21,01 \\
\hline 5,7 & 68,36 & 6,7 & 31,48 & & \\
\hline 5,8 & 63,48 & 6,8 & 29,25 & & \\
\hline 5,9 & 58,86 & 6,9 & 27,29 & & \\
\hline 6 & 54,50 & 7,0 & 25,60 & & \\
\hline
\end{tabular}

\subsection{Relação entre o pH da suspensão de acetato de cálcio e a acidez potencial}

Para essa relação utilizaram-se os mesmos valores de $\mathrm{H}+\mathrm{Al}$ utilizados no estudo anterior e os de $\mathrm{pH}$ da suspensão de acetato-terra, as quais variaram entre 6,1 e 6,8 .

Observou-se uma alta correlação entre as variáveis, sendo a mesma inversamente proporcional $(r=-0,93)$, demonstrando assim que para aumentos nos valores de $\mathrm{pH}$ da suspensão de acetato de cálcio há decréscimos nos valores de $\mathrm{H}+\mathrm{Al}$ obtidos após a titulação com $\mathrm{NaOH}$.

$\mathrm{Na}$ Figura 6 encontra-se a relação entre o $\mathrm{pH}$ da suspensão de acetato de cálcio-terra e a acidez potencial $(\mathrm{H}+\mathrm{Al})$ determinada pelo método do acetato de cálcio. $O$ modelo quadrático ajustou-se adequadamente aos resultados, obtendo-se a equação $Y$ $=6839,5-1976 \mathrm{X}+143,05 \mathrm{X}^{2}\left(\mathrm{R}^{2}=0,92\right)$, na qual $\mathrm{X}$ representa o $\mathrm{pH}$ da suspensão de acetato de cálcio e $\mathrm{Y}$ os valores de $\mathrm{H}+\mathrm{Al}$. 


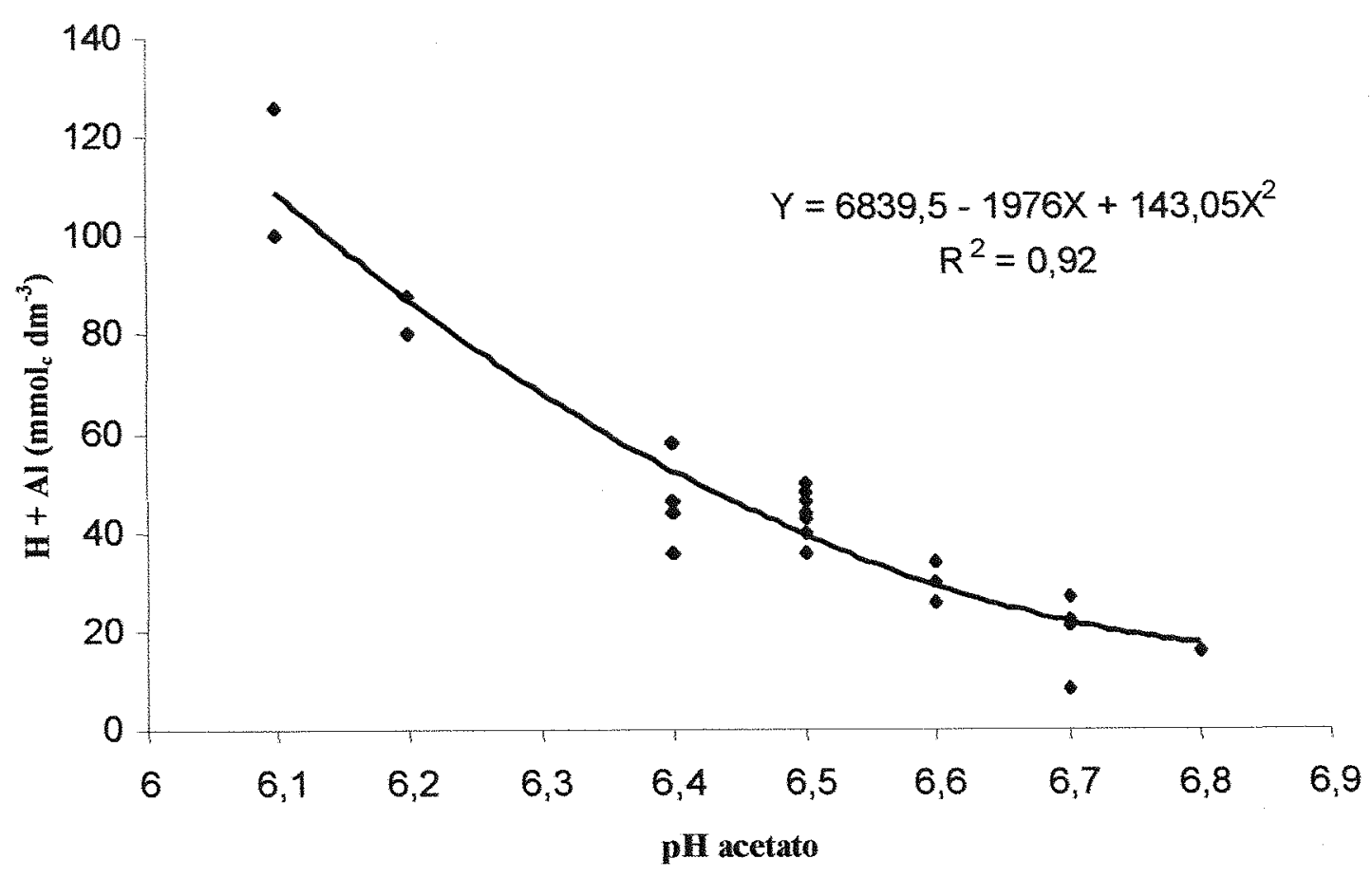

Figura 6 - Relação entre a acidez potencial $(H+A l)$ e o $p H$ da solução de acetato de cálcio em 27 amostras de terra do nordeste paraense.

Esses resultados demonstram a possibilidade de utilização da leitura do pH da suspensão do acetato de cálcio-terra para a determinação indireta dos valores de acidez potencial, através da equação proposta neste trabalho, para solos da região nordeste paraense. Isso resultaria também numa redução do tempo gasto para determinar os valores de $\mathrm{H}+\mathrm{Al}$, como ocorre com a leitura do $\mathrm{pH}$ da suspensão de solução tampão SMP com a terra, pois não haveria necessidade da titulação da suspensão de acetato de cálcio com $\mathrm{NaOH}$.

Pela Figura 7 verifica-se que há uma relação diretamente proporcional entre os valores de $\mathrm{pH}$ SMP e $\mathrm{pH}$ da suspensão de acetato de cálcio, ou seja, os aumentos nos valores de pH SMP são diretamente acompanhados pelos aumentos nos valores de $\mathrm{pH}$ da suspensão de acetato de cálcio. Isso demonstra a alta correlação que existe entre as duas variáveis ou metodologias possíveis de serem utilizadas para a determinação indireta dos valores de acidez potencial em solos do nordeste paraense. 
No entanto, é válido ressaltar que a amplitude dos valores de pH SMP é bem maior $(5,1$ a 7,6$)$ do que a observada para os valores de $\mathrm{pH}$ da suspensão de acetato de cálcio $(6,1$ a 6,8$)$, indicando assim maior segurança no uso do método do pH SMP para a determinação indireta da acidez potencial.

Pereira et al. (1998), trabalhando com amostras de terra do Estado do Rio de Janeiro também observaram a possibilidade de utilização da leitura do $\mathrm{pH}$ da suspensão de acetato de cálcio para a determinação da acidez potencial. Os autores encontraram entre essas duas variáveis uma correlação menor $(r=-0,82)$ quando comparada com a obtida neste trabalho $(r=-0,93)$, muito embora fosse também significativa. Os autores encontraram uma correlação idêntica $(r=0,95)$ à obtida neste trabalho entre as variáveis pH SMP e pH da suspensão de acetato de cálcio.

Os valores de $\mathrm{H}+$ Al estimados a partir da equação e relação obtida na Figura 6 são apresentados na Tabela 10, e podem ser obtidos a partir da leitura de pH da suspensão de acetato de cálcio - terra.

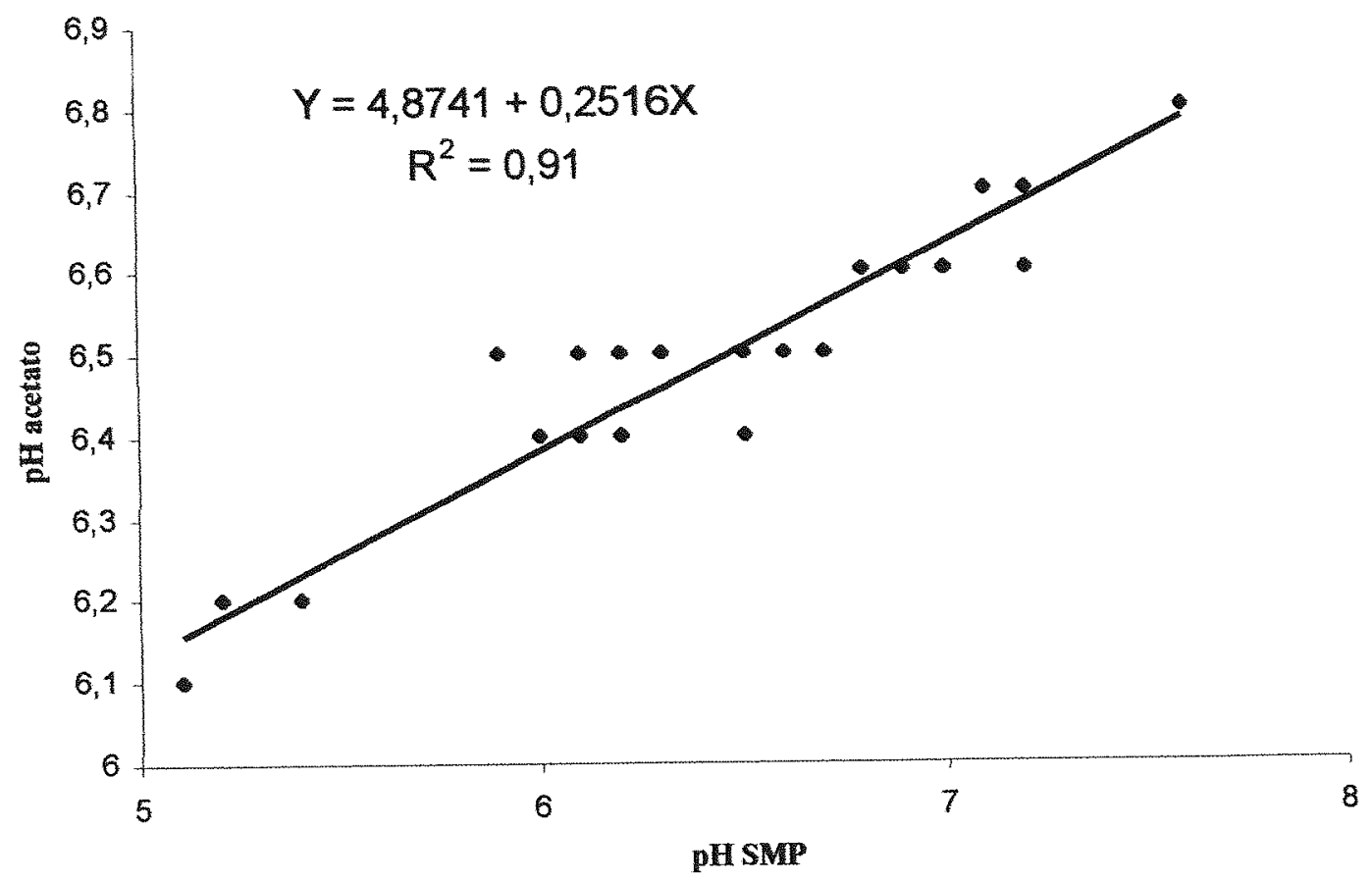

Figura 7 - Relação entre pH da solução de acetato de cálcio e pH SMP em 27 amostras de terra do nordeste paraense. 
Tabela 10. Estimativa da acidez potencial $\left(\mathrm{mmol}_{\mathrm{c}} \mathrm{dm}^{-3}\right)$ a partir da leitura do $\mathrm{pH}$ da suspensão de acetato de cálcio, para solos do nordeste paraense.

\begin{tabular}{cc|cc}
\hline $\begin{array}{c}\text { pH da supensão de } \\
\text { acetato de cálcio }\end{array}$ & $\mathbf{H}+\mathbf{A l}$ & $\begin{array}{c}\mathbf{p H} \text { da supensão de } \\
\text { acetato de cálcio }\end{array}$ & $\mathbf{H}+\mathbf{A l}$ \\
\hline 6,1 & 108,79 & 6,5 & 39,36 \\
6,2 & 87,14 & 6,6 & 29,16 \\
6,3 & 68,35 & 6,7 & 21,81 \\
6,4 & 52,43 & 6,8 & 17,33 \\
\hline
\end{tabular}

\subsection{Incubação com carbonato de cálcio}

As Figuras 8 a 15 expressam a evolução do $\mathrm{pH}$ em água e em $\mathrm{CaCl}_{2} 0,01$ mol L $\mathrm{L}^{-1}$ em função do tempo de incubação para as quatro amostras de terra utilizadas. Verificou-se um aumento do $\mathrm{pH}$ com o aumento das doses de carbonato de cálcio $\left(\mathrm{CaCO}_{3}\right)$ e do tempo de incubação, até um certo período. De uma forma geral, observase que os aumentos nos valores de $\mathrm{pH} \mathrm{em} \mathrm{H}_{2} \mathrm{O}$ e $\mathrm{CaCl}_{2}$ ocorreram até o $30^{\circ}$ dia, quando deu-se então a estabilização desses valores. Em alguns casos, houve até diminuição do pH quando atingiu-se o $30^{\circ}$ dia de incubação.

$\mathrm{O} \mathrm{pH}$ na amostra de gley pouco húmico, nas doses de 1 e $2 \mathrm{Mg} \mathrm{ha}^{-1}$ de $\mathrm{CaCO}_{3}$, não apresentou $\left(\mathrm{pH}\right.$ em $\left.\mathrm{H}_{2} \mathrm{O}\right)$ ou apresentou baixa variação $\left(\mathrm{pH} \mathrm{CaCl}_{2}\right)$ devido à aplicação do corretivo. Observa-se ainda, que o efeito da aplicação das doses de $\mathrm{CaCO}_{3}$ na variação de $\mathrm{pH}$ foi menor do que nas demais amostras de terra. As maiores variações ocorreram a partir do uso de $4 \mathrm{Mg} \mathrm{ha}^{-1}$ de $\mathrm{CaCO}_{3}$.

Para as demais amostras de terra houveram variações no $\mathrm{pH}$ devido à aplicação do $\mathrm{CaCO}_{3}$ em todos as doses utilizadas, indicando que com pequenas doses de calcário, grandes variações do $\mathrm{pH}$ podem ser obtidas. Isso pode ser exemplificado pela variação do $\mathrm{pH}$ em água da amostra de Latossolo Amarelo (Figura 9), que é predominante na região nordeste paraense. 


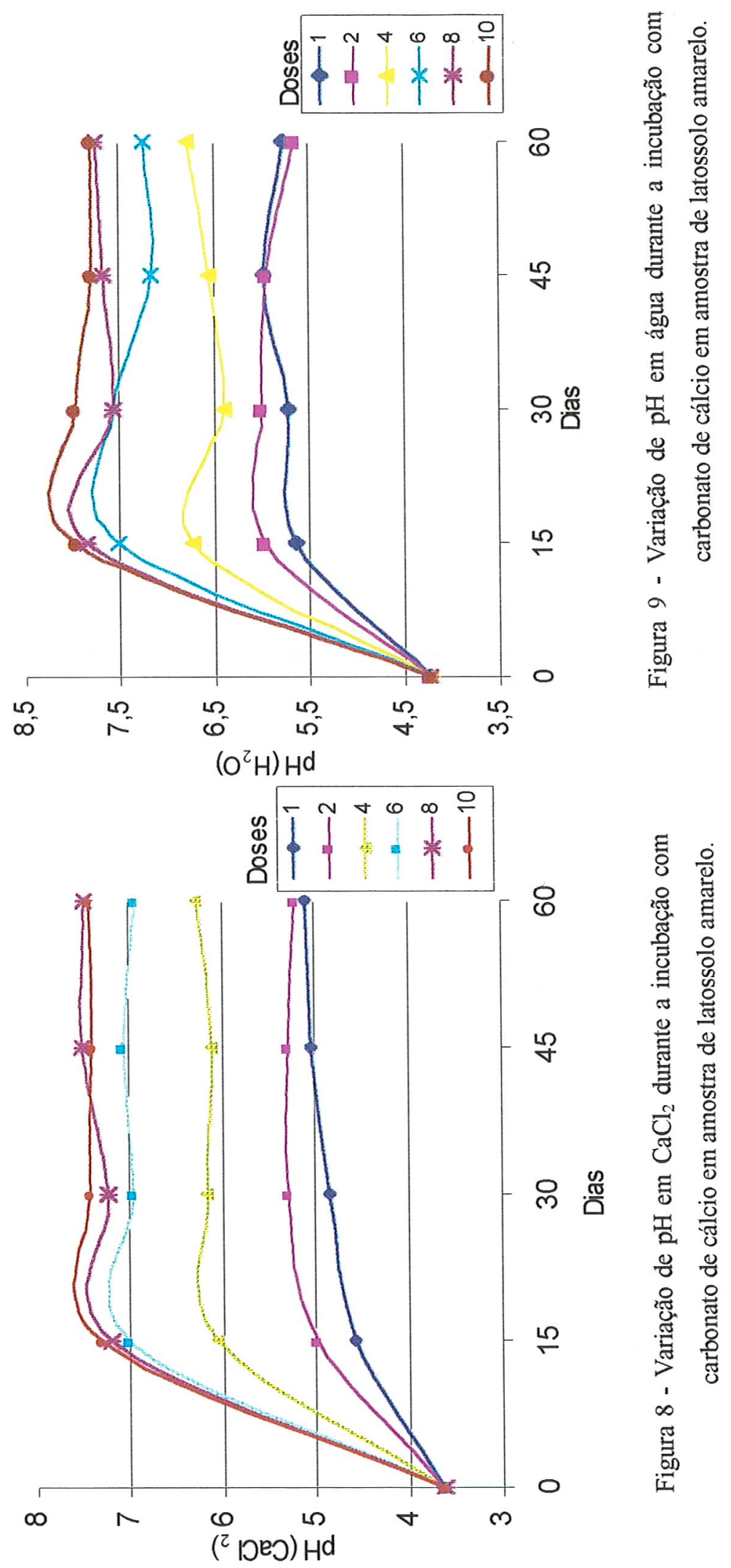



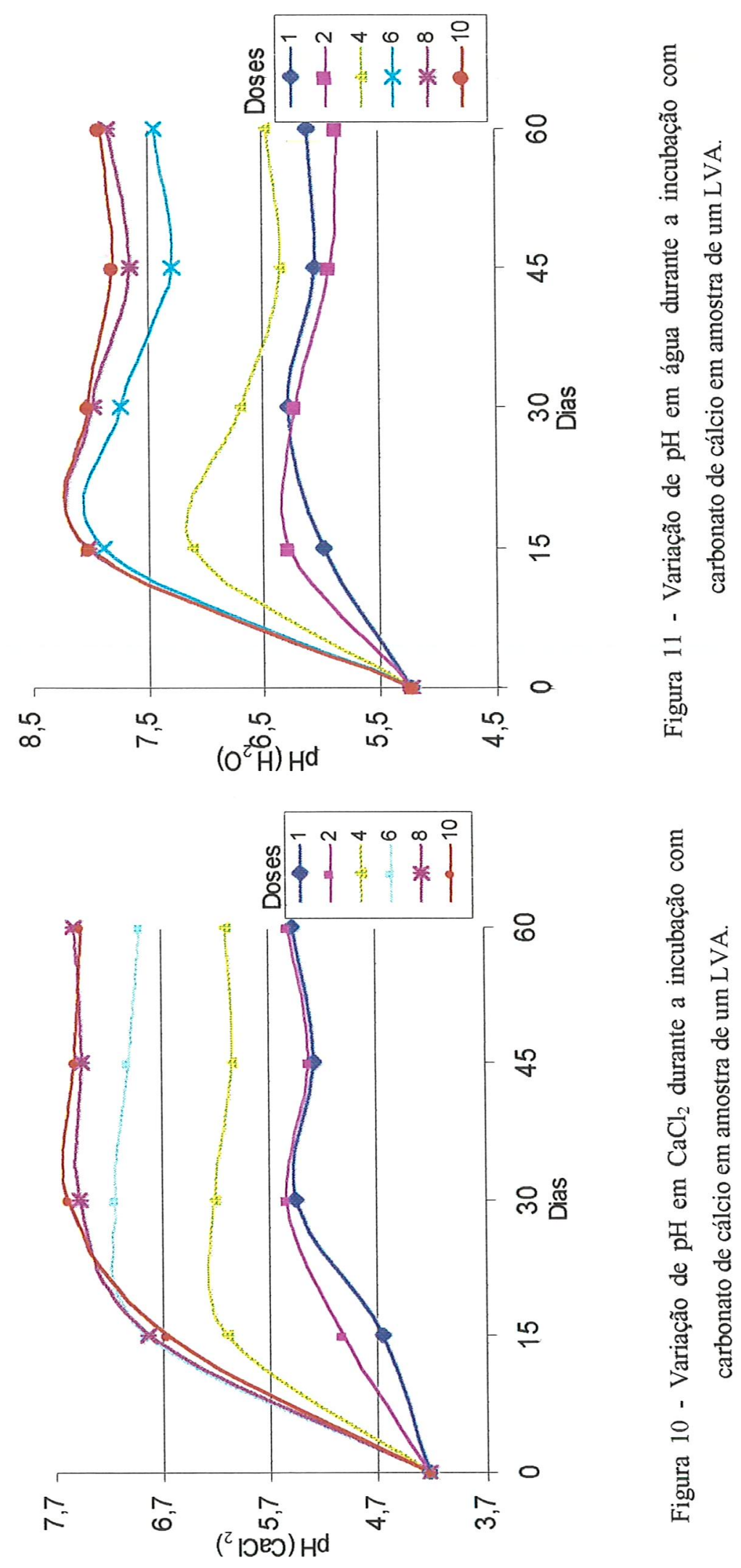

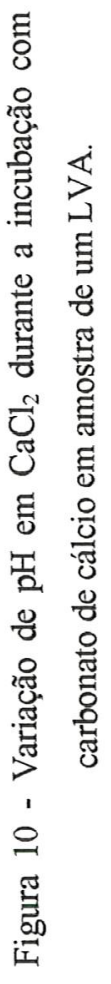



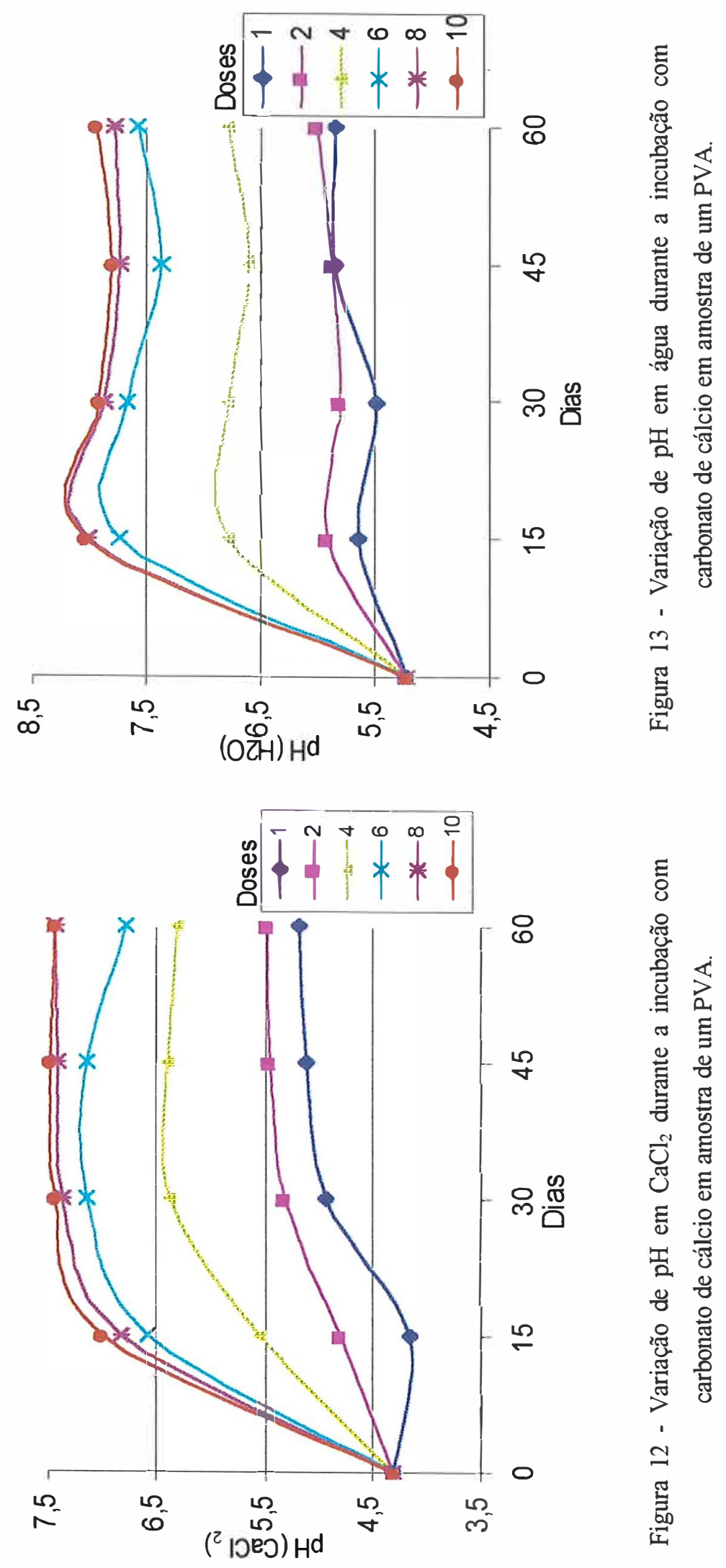

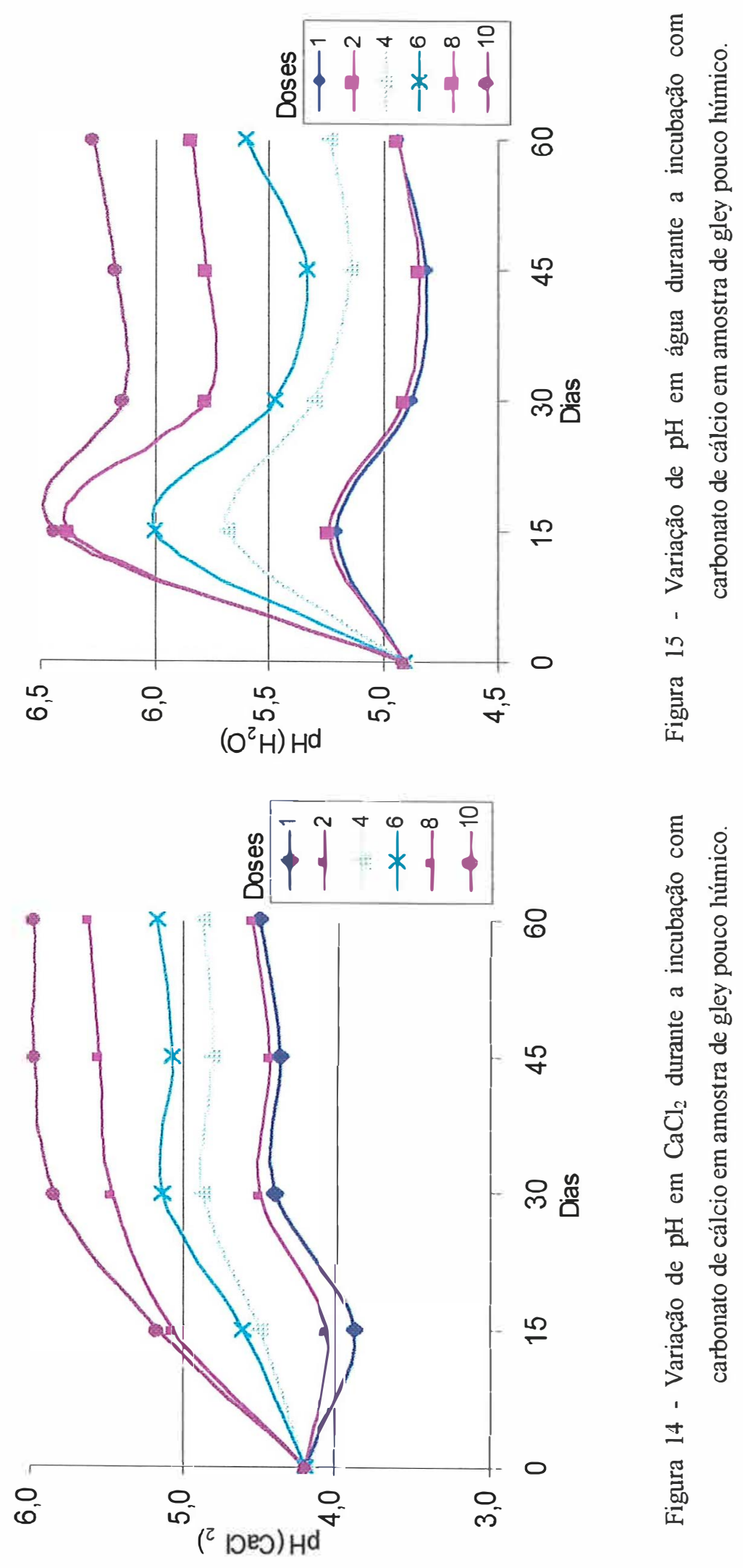
A baixa variação do $\mathrm{pH}$ na amostra de GPH pode ser explicado pelos mais altos teores de $\mathrm{MO}$ e argila presentes nesse solo e, consequentemente pelo maior poder tampão. Essa amostra apresentou ainda altos teores de $\mathrm{Al} \mathrm{e} \mathrm{H}+\mathrm{Al}$. Sabe-se que quanto maior o poder tampão, menores são as variações no $\mathrm{pH}$ e maiores as doses de corretivo recomendadas.

Nas Figuras 16 a 19 encontram-se as curvas de neutralização para as quatro amostras de terra, utilizando-se as determinações de $\mathrm{pH}$ em água e em $\mathrm{CaCl}_{2} 0,01$ mol L $\mathrm{L}^{-1}$. Observa-se que o modelo quadrático ajustou-se aos resultados obtidos, ao nível de $5 \%$, em quase todas as curvas de neutralização. Somente para $\mathrm{pH}$ em $\mathrm{H}_{2} \mathrm{O}$ no latossolo vermelho-amarelo e $\mathrm{pH}$ em $\mathrm{CaCl}_{2}$ no gley pouco húmico, utilizaram-se equações de $1^{\circ}$ grau. As equações estão resumidas na Tabela 11.

Com base nessas equações, determinou-se que, para atingir valores de $\mathrm{pH}$ em água 5,5 seriam necessários 1,$5 ; 0,5 ; 6,0$ e 0,2 $\mathrm{Mg} \mathrm{ha}^{-1}$ de $\mathrm{CaCO}_{3}$ para as amostras de LA, PVA, GPH e LVA respectivamente. Para atingir valores de $\mathrm{pH}$ em água de 6,0 seriam necessários $2,4,1,6,8,5$ e 2,0 $\mathrm{Mg} \mathrm{ha}^{-1}$ de $\mathrm{CaCO}_{3}$ para os mesmas amostras de terra.

Através dos resultados obtidos com o método de incubação dos solos com carbonato de cálcio, verificam-se os erros cometidos em muitas recomendações de calagem realizadas no nordeste paraense. Em geral, não há uma análise química prévia da terra e a recomendação é a de $2 \mathrm{Mg} \mathrm{ha}^{-1}$ de calcário, sem levar em consideração o solo e as características dos corretivos comercializados na região 


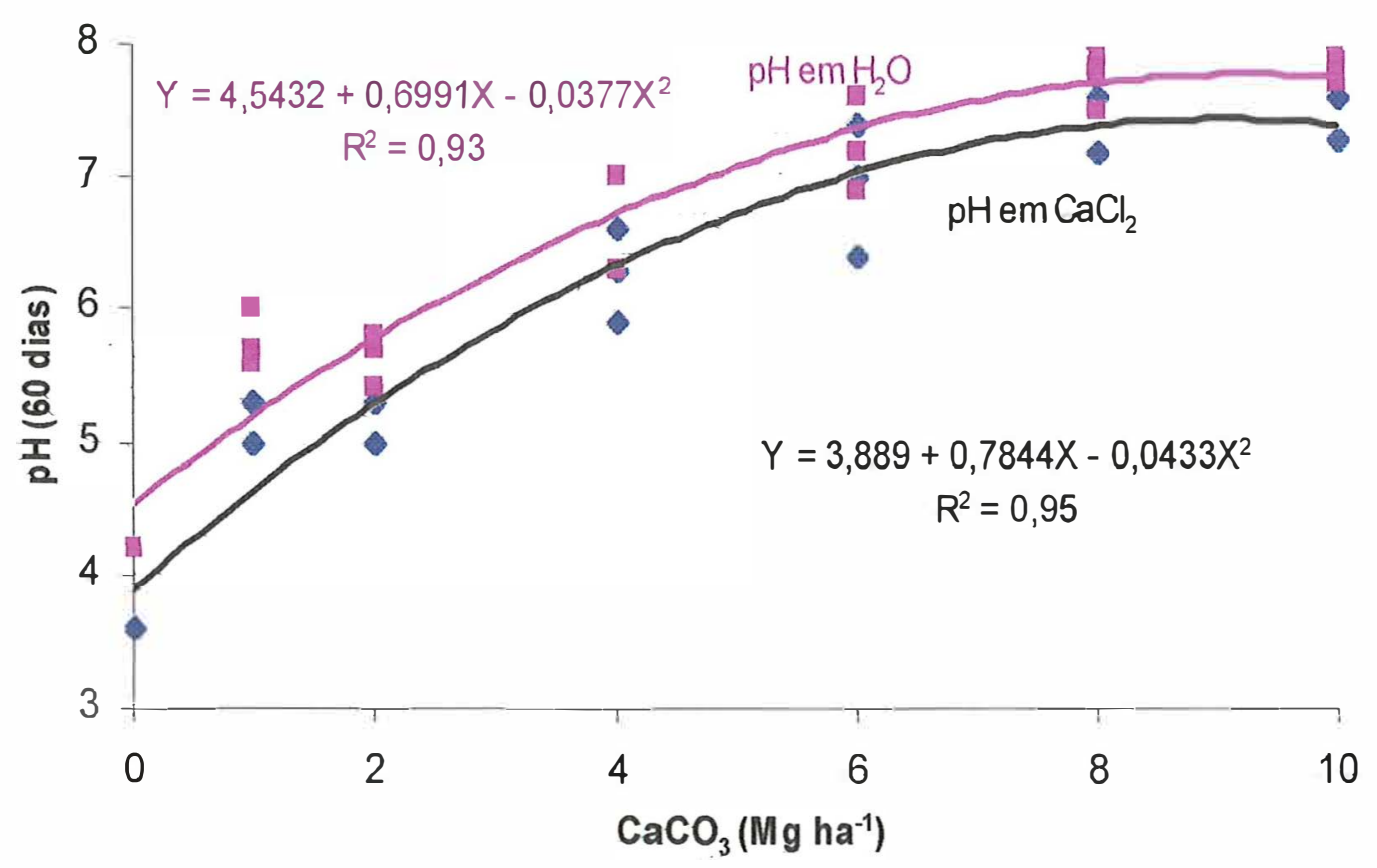

Figura 16 - Curva de neutralização com carbonato de cálcio para um latossolo amarelo coletado no nordeste paraense.

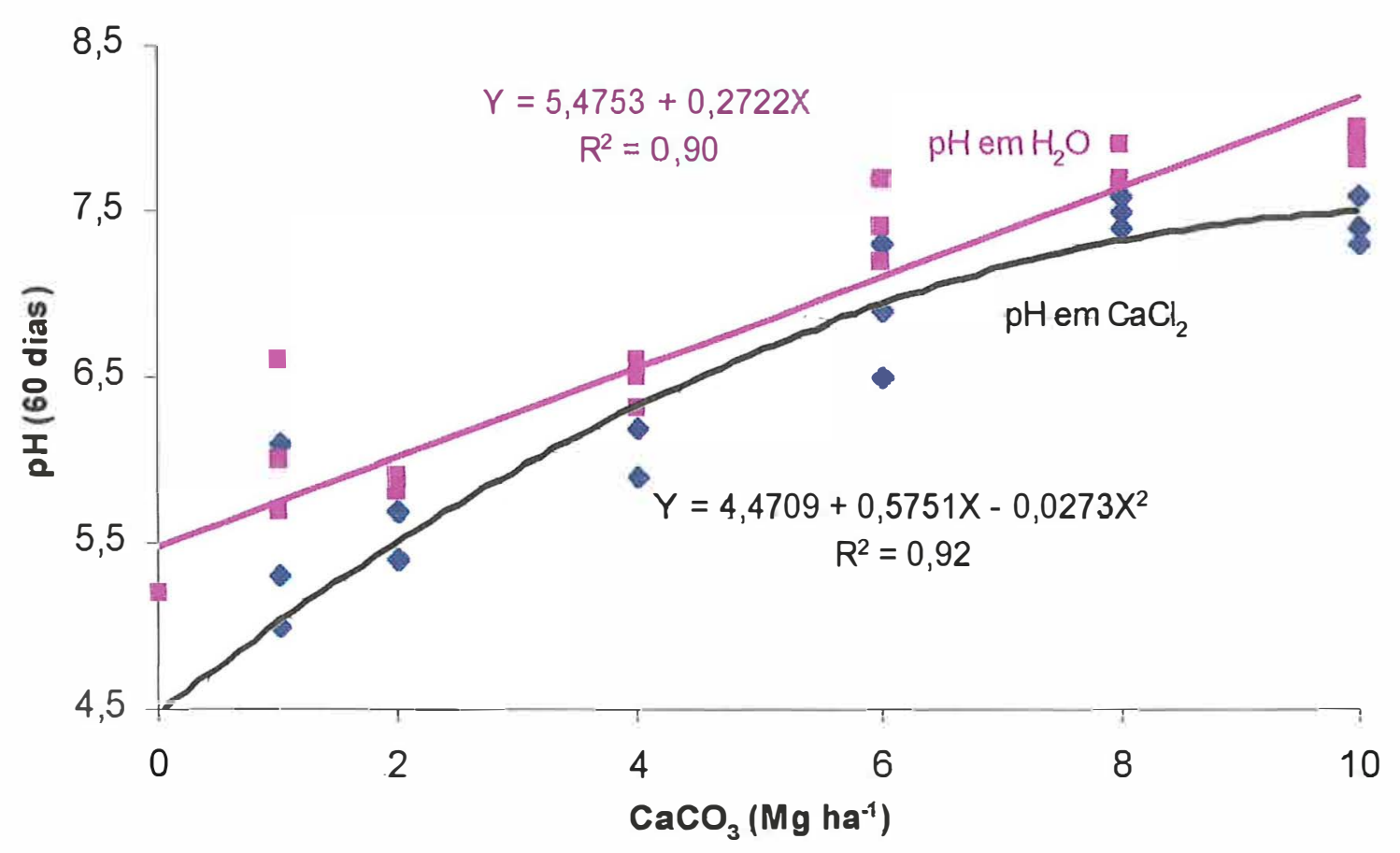

Figura 17 - Curva de neutralização com carbonato de cálcio para um latossolo vermelho - amarelo coletado no nordeste paraense. 


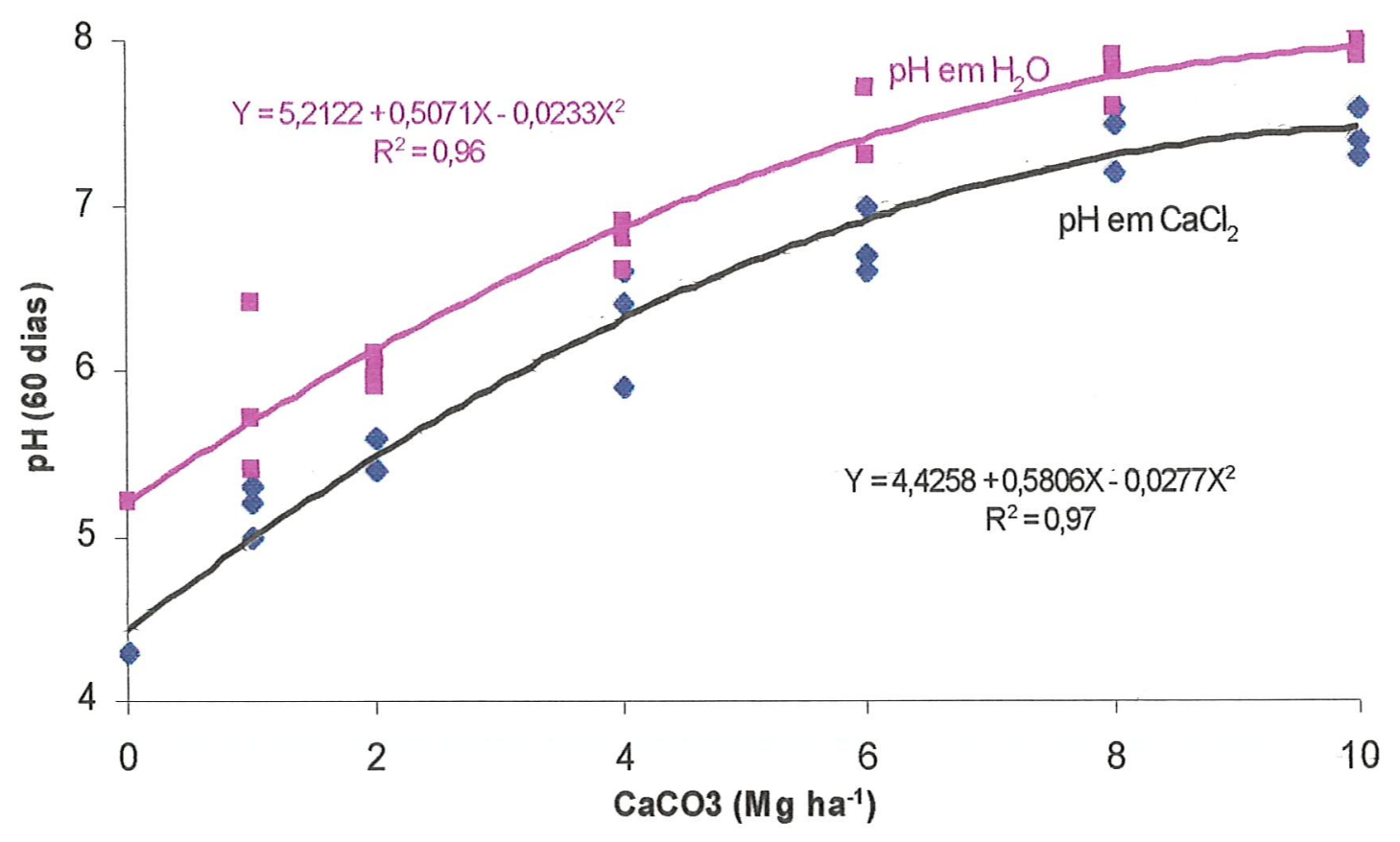

Figura 18 - Curva de neutralização com carbonato de cálcio para um podzólico vermelho - amarelo coletado no nordeste paraense.

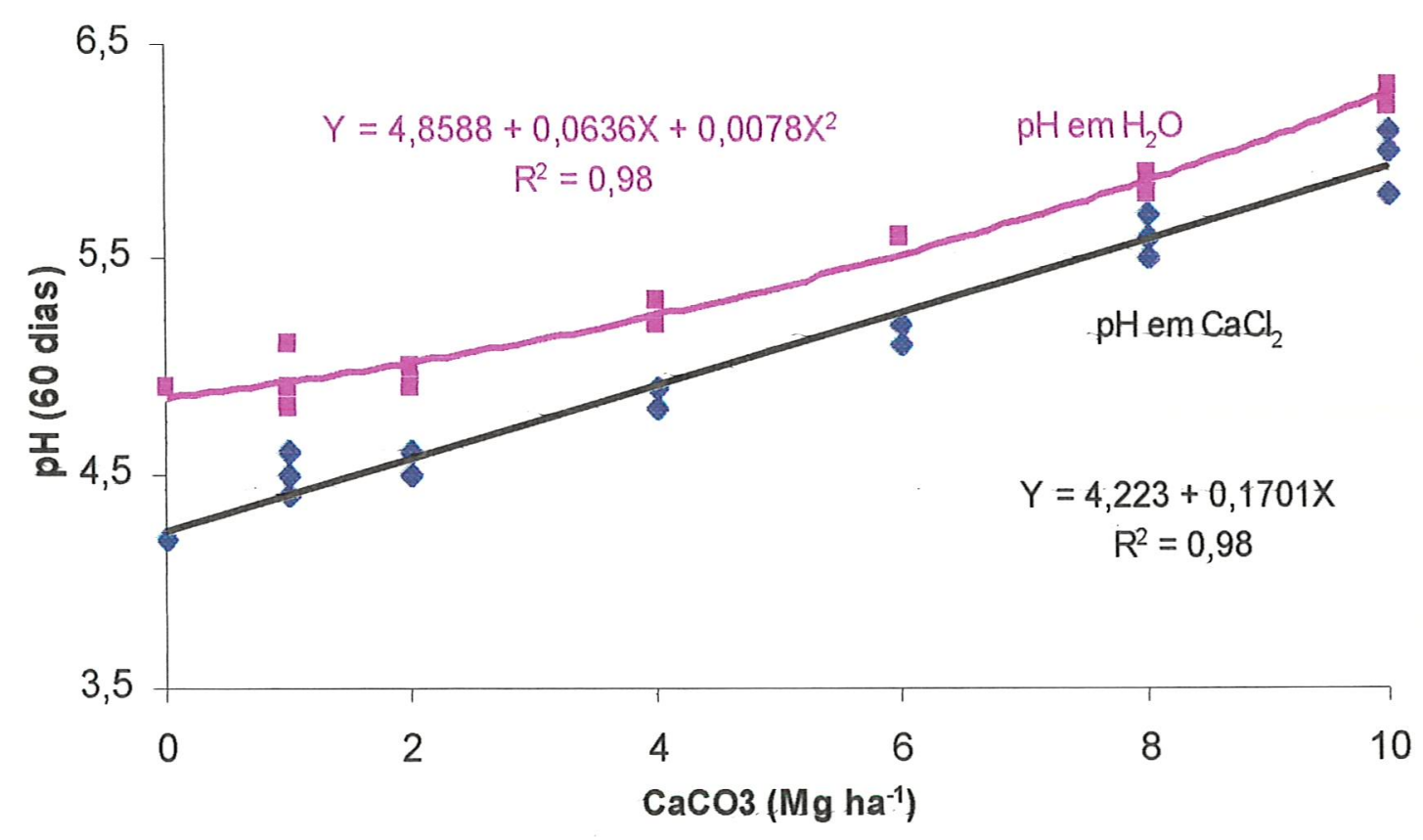

Figura 19 - Curva de neutralização com carbonato de cálcio para um gley pouco húmico coletado no nordeste paraense. 
Tabela 11. Equações de regressão para as relações entre pH final da incubação (Y) e doses de $\mathrm{CaCO}_{3}$ em tha (X).

\begin{tabular}{cccc}
\hline Solo & $\mathrm{PH}$ & Equação & $\mathrm{R}^{2}$ \\
\hline \multirow{2}{*}{$\mathrm{LA}$} & $\mathrm{H}_{2} \mathrm{O}$ & $\mathrm{Y}=4,5432+0,6991 \mathrm{X}-0,0377 \mathrm{X}^{2}$ & 0,93 \\
& $\mathrm{CaCl}_{2}$ & $\mathrm{Y}=3,889+0,7844 \mathrm{X}-0,0433 \mathrm{X}^{2}$ & 0,95 \\
LVA & $\mathrm{H}_{2} \mathrm{O}$ & $\mathrm{Y}=5,4753+0,2722 \mathrm{X}$ & 0,90 \\
& $\mathrm{CaCl}_{2}$ & $\mathrm{Y}=4,4709+0,5751 \mathrm{X}-0,0273 \mathrm{X}^{2}$ & 0,92 \\
PVA & $\mathrm{H}_{2} \mathrm{O}$ & $\mathrm{Y}=5,2122+0,5071 \mathrm{X}-0,0233 \mathrm{X}^{2}$ & 0,96 \\
& $\mathrm{CaCl}_{2}$ & $\mathrm{Y}=4,4258+0,5806 \mathrm{X}-0,0277 \mathrm{X}^{2}$ & 0,97 \\
$\mathrm{GPH}$ & $\mathrm{H}_{2} \mathrm{O}$ & $\mathrm{Y}=4,8588+0,0636 \mathrm{X}+0,0078 \mathrm{X}^{2}$ & 0,98 \\
& $\mathrm{CaCl}_{2}$ & $\mathrm{Y}=4,223+0,1701 \mathrm{X}$ & 0,98 \\
\hline
\end{tabular}

\subsection{Estimativas da necessidade de calagem (NC)}

Na Tabela 12 são apresentados os resultados das estimativas da necessidade de calagem, de acordo com os métodos utilizados nesse trabalho. Verificase que a maior diferença entre a maior e a menor recomendação de calagem ocorreu para a amostra de gley pouco húmico com variações de até $8 \mathrm{Mg}^{-1}$ de corretivo entre as recomendações. Para as demais amostras de solo a diferença entre as recomendações dos métodos oscilaram em torno de $2 \mathrm{Mg} \mathrm{ha}^{-1}$ de corretivo.

Utilizando-se as equações apresentadas na Tabela 11 e as quantidades de calcário recomendadas pelos métodos 1 a 7 da Tabela 12, foi possível o cálculo do $\mathrm{pH}$ em água que seriam obtidos, se fosse realizada uma incubação com as referidas quantidades de calcário recomendadas (Tabela 13).

Observou-se que as estimativas da $\mathrm{NC}$ do método de neutralização do alumínio trocável $(\mathrm{Al} \times 0,15)$, não promoveriam aumentos de $\mathrm{pH}$ em água para valores de 5,5 em duas amostras de terra (LA e GPH), sendo suficiente para as demais amostras ( PVA e LVA). Esse mesmo comportamento foi observado para o método 3 (Tabela 13). 


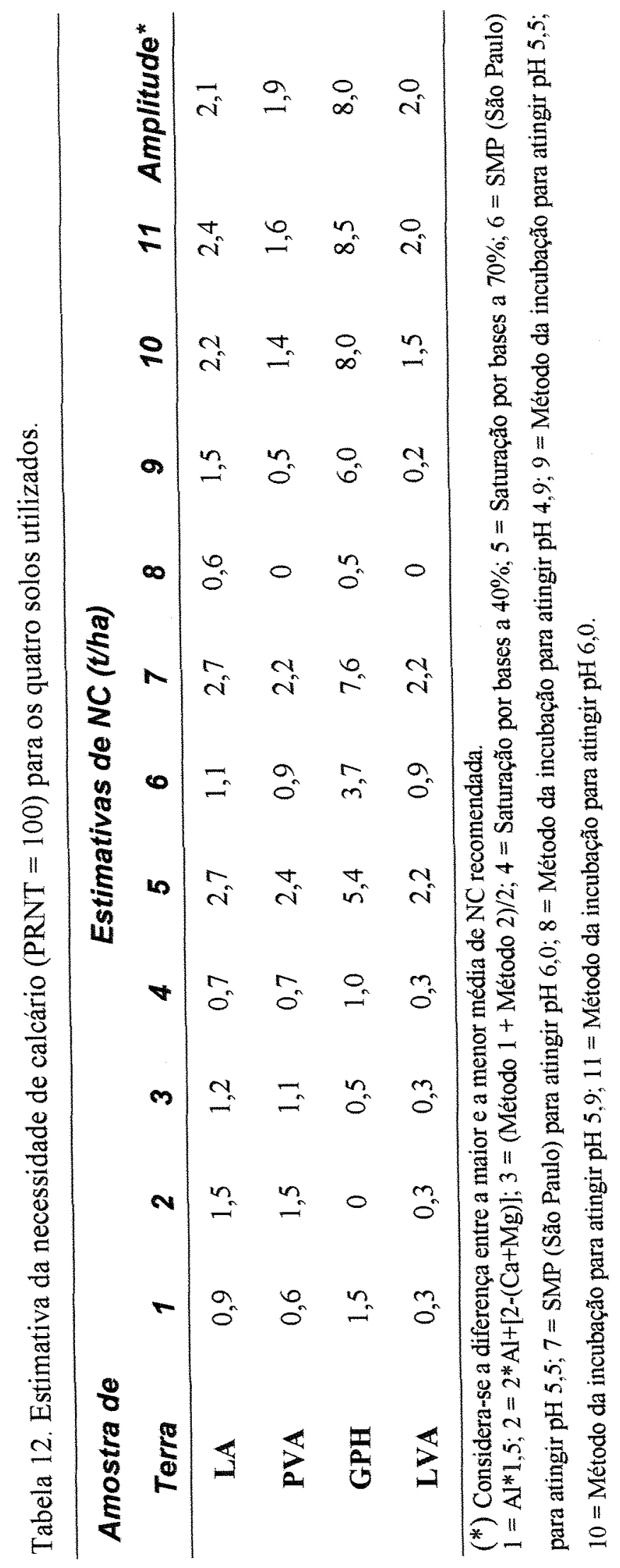




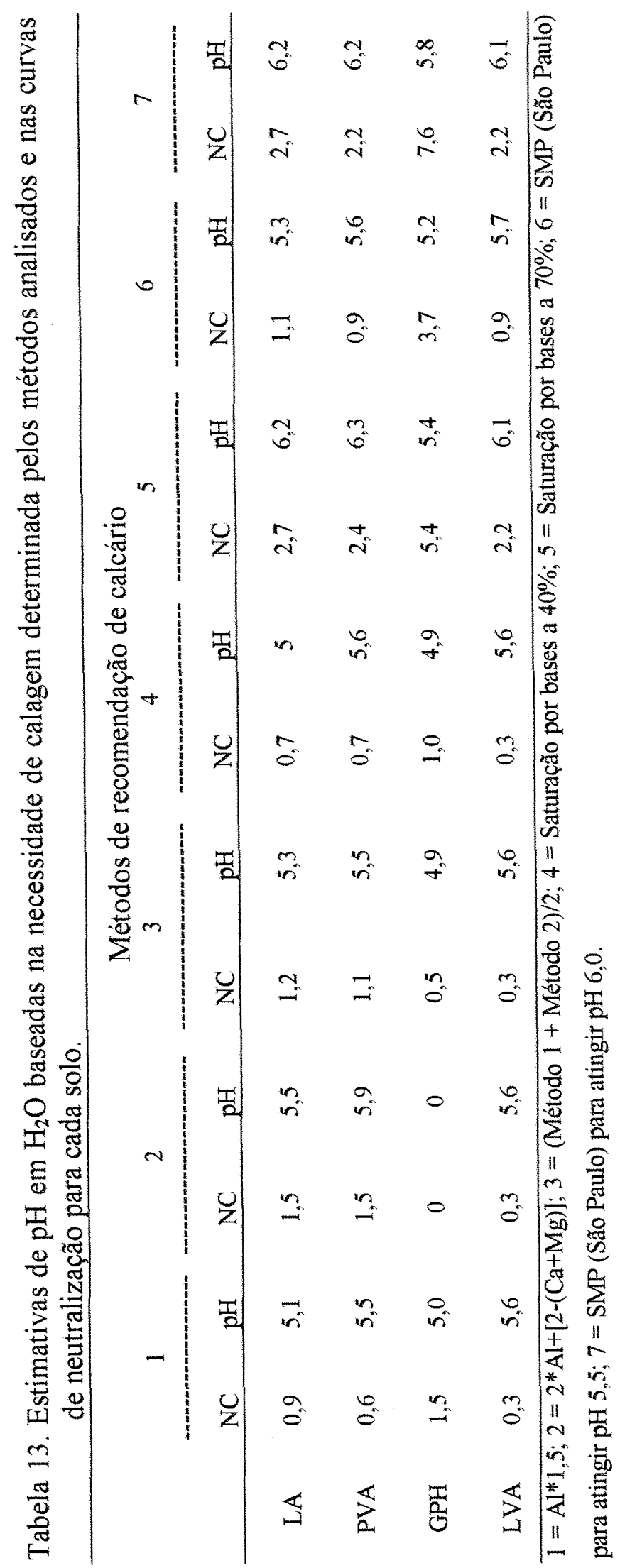


O método da neutralização do alumínio trocável mais adição de cálcio e magnésio, $0,2 \times \mathrm{Al}+[2-0,1(\mathrm{Ca}+\mathrm{Mg})]$, apresentou recomendações de calagem que seriam adequadas para alcançar $\mathrm{pH}$ em água de 5,5 nas amostras de LA, PVA e LVA. Para amostra de GPH o método não indicou necessidade de calagem, sendo a causa disso os altos teores de cálcio e magnésio encontrados nessa amostra de terra.

Os métodos da saturação por bases a 40\% e SMP para atingir $\mathrm{pH} 5,5$ (métodos 4 e 5) apresentaram comportamentos semelhantes aos métodos 1 e 3 . Pela Figura 4, que trata da relação entre V\% e m\%, observa-se que para uma saturação por bases de $40 \%$ corresponderia uma saturação por alumínio de aproximadamente $10 \%$. Os resultados do método $4 \mathrm{em}$ relação ao $\mathrm{pH}$ em água que poderiam ser obtidos, de certa forma aproximam-se daqueles obtidos na relação $\mathrm{V} \% \times \mathrm{pH} \mathrm{H} \mathrm{H}_{2} \mathrm{O}$, (Tabela 5).

A recomendação obtida pela saturação por bases a $70 \%$ (método 6) elevaria o $\mathrm{pH}$ em água até 5,4 na amostra de GPH, superestimando os valores de pH para os demais solos quando o objetivo fosse a elevação do pH em água a 5,5 e 6,0. Com as estimativas de $\mathrm{pH}$ em água que poderiam ser obtidas com essa recomendação, a saturação por bases chegaria a $70,72,50$ e $68 \%$ no LA, PVA, GPH e LVA, respectivamente (Tabela 5)

As recomendações obtidas pelo método SMP para atingir pH 6,0 (método 7) mostraram-se adequadas para três das amostras de terra, sendo subestimada para GPH. Os dois últimos critérios de recomendação de calagem (6 e 7) apresentaram os melhores resultados quanto a alcançar o pH em água até 5,5, e 6,0. Tais resultados são bem semelhantes aos obtidos por Costa et al. (1996), quando trabalharam com amostra de latossolo vermelho escuro álico. Quaggio (1983) observou também que o método do alumínio trocável e cálcio mais magnésio recomendavam pouco calcário, atingindo niveis próximos a $40 \%$ de saturação por bases do solo ou valores de $\mathrm{pH}$ nunca superiores a 5,5 .

Os resultados obtidos com o método do alumínio trocável neste trabalho e em outros aqui citados confirmam que, como citado por Freitas et al. (1968), este critério recomenda calcário suficiente para neutralizar o alumínio trocável, não importando o pH final obtido. 
$\mathrm{Na}$ comparação entre as recomendações de $\mathrm{NC}$ apresentadas na Tabela 12, observaram-se que o método SMP para atingir $\mathrm{pH} 5,5$ e 6,0 somente subestimou a NC na amostra de gley, superestimando para as demais amostras de terra, quando comparadas com a incubação para atingir valores de pH 5,5 e 6,0.

Através da Tabela 14 verificaram-se correlações positivas entre a maior parte das recomendações dos métodos analisados, o que indica uma certa aproximação nos comportamentos dos mesmos para as amostras de terra utilizadas, ou seja, um aumento ou diminuição da recomendação de calagem por um determinado método pode ser acompanhado por outro quando ocorre mudança de amostra. Isso é evidenciado quando compara-se, por exemplo, os métodos 1 e 4 ou 6 e 11 que apresentaram coeficientes de correlações de 0,951 e 0,999 , respectivamente.

Essas correlações, apresentadas na Tabela 14, não podem ser confundidas com a equiparação entre as recomendações de dois métodos, como ocorreu por exemplo, para os métodos 5 e 7 que apresentaram um alto coeficiente de correlação e uma grande semelhança nas estimativas de recomendação de calcário. 


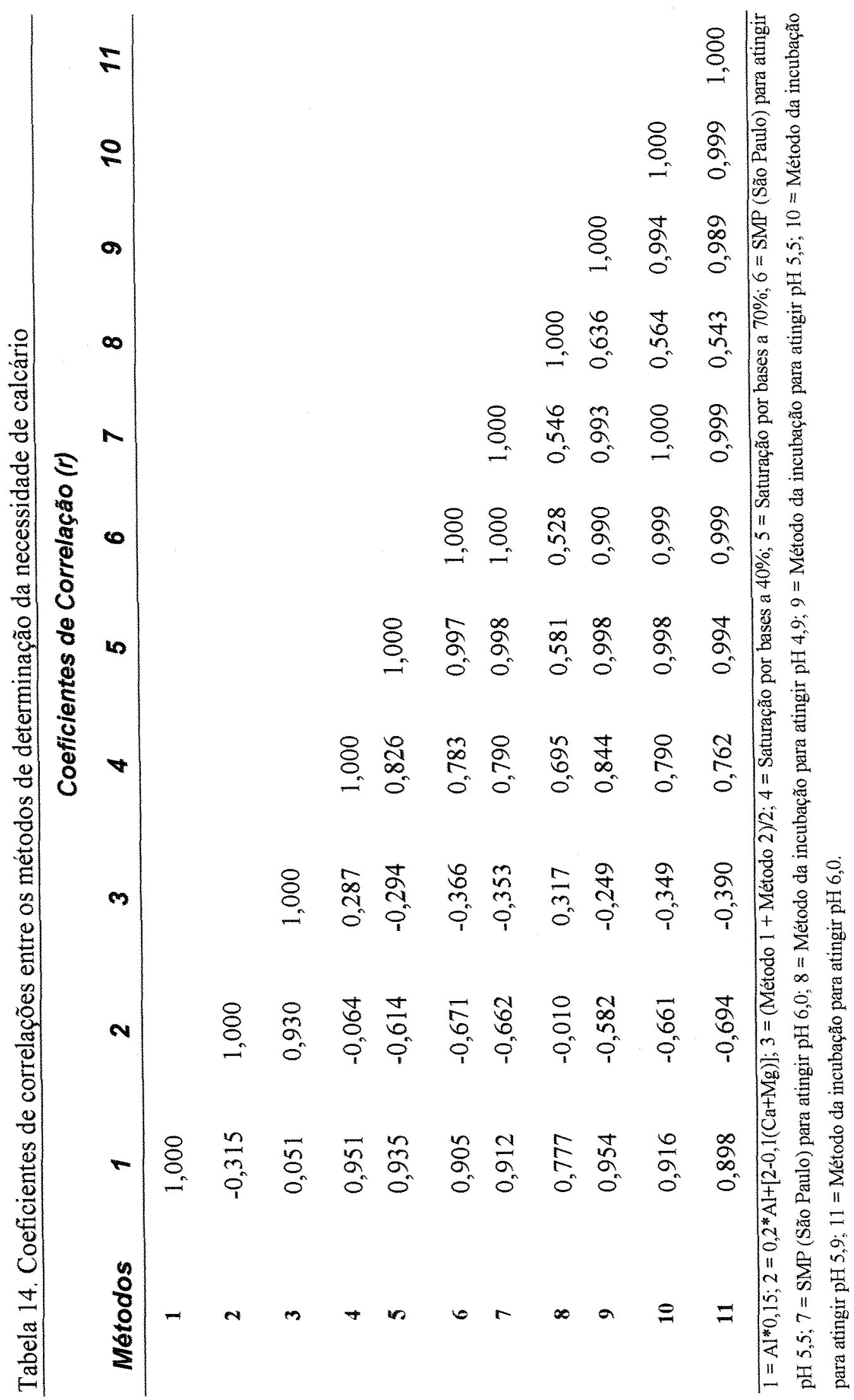




\subsection{Avaliação agronômica dos métodos de recomendação de calagem}

\subsubsection{Características químicas das amostras de terra}

Pelas análises de variância, apresentadas nas Tabelas 1 a 4, do apêndice, observa-se um efeito significativo dos métodos, dos solos e da interação método $\mathrm{x}$ solo para $\mathrm{pH}$ em $\mathrm{H}_{2} \mathrm{O}, \mathrm{pH}$ em $\mathrm{CaCl}_{2}$, cálcio e magnésio. A interação só não foi significativa para a saturação por bases, sendo nesse caso avaliado o efeito dos métodos utilizando-se da média geral para todas as amostras de terra.

\subsubsection{1 $\mathrm{pH}$ das amostras de terra}

Para a amostra de LVA, observou-se que as parcelas que receberam doses de calcário do método 4 (SMP para $\mathrm{pH} 5,5$ ) apresentaram as maiores médias de $\mathrm{pH}$ em água e em $\mathrm{CaCl}_{2}$, no entanto, esses valores não diferiram, ao nível de $5 \%$ pelo teste de tukey, das médias observadas nas parcelas que receberam os métodos $3(\mathrm{~V}=70 \%), 2$ e a testemunha. O método $1(\mathrm{Al} \times 0,15)$ apresentou o menor efeito sobre o $\mathrm{pH}$, igualando-se ao método 2 , conforme a Tabela 15 .

$\mathrm{Na}$ amostra de Gley, as parcelas que receberam calcário com base no método 3 apresentaram médias mais altas de $\mathrm{pH}$. No caso do $\mathrm{pH}$ em $\mathrm{CaCl}_{2}$, essas médias diferiram significativamente, ao nível de 5\%, dos demais métodos. Para o pH em água, essas médias só não diferiram daquelas apresentadas na utilização do método 4 . Os métodos 1 e 2 não conseguiram gerar efeitos sobre o $\mathrm{pH}$, que pudessem diferir daqueles apresentados na parcela testemunha (Tabela 15). 
Tabela 15. Resultados médios para $\mathrm{pH}$ em $\mathrm{H}_{2} \mathrm{O}$ e em $\mathrm{CaCl}_{2}$, no experimento envolvendo solos e métodos de determinação da $\mathrm{NC}$.

\begin{tabular}{|c|c|c|c|c|c|c|c|}
\hline \multirow{3}{*}{$\begin{array}{l}\text { Métodos }^{1} \\
\text { Testemunha }\end{array}$} & \multicolumn{3}{|c|}{ LVA $^{2}$} & \multicolumn{2}{|c|}{$\mathrm{GPH}^{2}$} & \multicolumn{2}{|c|}{$\mathrm{PVA}^{2}$} \\
\hline & \multicolumn{2}{|c|}{$\mathrm{pH} \mathrm{H}_{2} \mathrm{O}$} & \multirow{2}{*}{$\frac{\mathrm{PHCaCl}_{2}}{4,80 \mathrm{ab}}$} & \multirow{2}{*}{$\frac{\mathrm{pH} \mathrm{H} \mathrm{H}_{2} \mathrm{O}}{4,88 \mathrm{bc}}$} & \multirow{2}{*}{$\frac{\mathrm{pH} \mathrm{CaCl}}{4,45 \mathrm{~b}}$} & \multirow{2}{*}{$\frac{\mathrm{pH} \mathrm{H}_{2} \mathrm{O}}{5,35 \mathrm{a}}$} & $\mathrm{pHCaCl}_{2}$ \\
\hline & 5,38 & A & & & & & $4,68 \mathrm{~b}$ \\
\hline MI & 5,10 & $B$ & $4,73 \mathrm{~b}$ & $4,93 \mathrm{bc}$ & $4,50 \mathrm{~b}$ & $4,93 \mathrm{~b}$ & $4,50 \quad b$ \\
\hline $\mathrm{M} 2$ & 5,28 & $A b$ & $4,78 \mathrm{ab}$ & $4,80 \mathrm{c}$ & $4,43 \quad b$ & $5,00 \mathrm{~b}$ & $4,63 \mathrm{~b}$ \\
\hline M3 & 5,38 & A & 4,98 a & 5,20 a & $4,98 \mathrm{a}$ & $5,13 \mathrm{ab}$ & $4,93 \quad \mathrm{a}$ \\
\hline M4 & 5,45 & A & 4,98 a & $5,05 \mathrm{ab}$ & $4,65 \mathrm{~b}$ & $4,95 \mathrm{~b}$ & $4,53 \mathrm{~b}$ \\
\hline
\end{tabular}

Na Tabela 15, observa-se que para a amostra de PVA as maiores médias de $\mathrm{pH}$ em água ocorreram na testemunha, as quais só não diferiram significativamente daquelas ocorridas quando da utilização do método 3. No entanto, para o $\mathrm{pH} \mathrm{em} \mathrm{CaCl}_{2}$, observou-se que o método 3 apresentou as maiores efeitos médios, diferindo significativamente dos demais métodos.

Esses resultados evidenciam que os maiores efeitos sobre o $\mathrm{pH}$ ocorreram com a utilização do método que recomendou a maior dose de calcário, no caso o método $3(\mathrm{~V}=70 \%)$.

Nessas análises, um fato que deve ser levado em consideração é que na testemunha os valores de $\mathrm{pH}$, em $\mathrm{H}_{2} \mathrm{O}$ ou em $\mathrm{CaCl}_{2}$, em todas amostras de terra e após o cultivo das plantas, apresentaram-se sempre superiores aos determinados antes do início do experimento (Tabela 2). Esse fato, provavelmente evitou que houvessem diferenças significativas entre alguns métodos e a testemunha. 


\subsubsection{Cálcio, magnésio e a saturação por bases}

De uma forma geral, verificou-se que os melhores efeitos dos métodos de determinação da necessidade de calagem sobre os teores de cálcio, ocorreram quando utilizaram-se as doses provenientes dos métodos 3 e 4, no caso das amostras de latossolo vermelho-amarelo e gley pouco húmico. Para a amostra de podzólico, os melhores efeitos foram obtidos com a utilização das doses obtidos com o método 3 e 2 , que não diferiram significativamente entre sí (Tabela 16)

Para os teores de magnésio, o método 3 apresentou também os melhores efeitos, diferindo significativamente ao nível de $5 \%$, dos demais métodos de determinação da NC. Esses resultados são semelhantes aos obtidos para os teores de cálcio (Tabela 16)

Quando leva-se em consideração os solos, observa-se que os teores de cálcio e magnésio foram significativamente maiores nas parcelas compostas com amostras de GPH, que apresenta teores mais altos de matéria orgânica (Tabela 2).

Tabela 16. Resultados médios para teores de $\mathrm{Ca} \mathrm{e} \mathrm{Mg}$, em $\mathrm{mmol}_{\mathrm{c}} \mathrm{dm}^{-3}$, no experimento envolvendo solos e métodos de determinação da NC.

\begin{tabular}{|c|c|c|c|c|c|c|}
\hline \multirow[t]{2}{*}{ Métodos } & \multicolumn{2}{|c|}{$\mathrm{LVA}^{2}$} & \multicolumn{2}{|c|}{$\mathrm{GPH}^{2}$} & \multicolumn{2}{|c|}{$\mathrm{PVA}^{2}$} \\
\hline & $\mathrm{Ca}$ & $\mathrm{Mg}$ & $\mathrm{Ca}$ & $\mathrm{Mg}$ & $\mathrm{Ca}$ & $\mathrm{Mg}$ \\
\hline Testemunha & $24,25 \mathrm{ab}$ & $5,00 \mathrm{c}$ & $41,50 \mathrm{~B}$ & $19,75 d$ & $15,25 \mathrm{C}$ & $3,50 \mathrm{~d}$ \\
\hline M1 & $21,75 b$ & $6,25 \mathrm{c}$ & $46,75 \mathrm{~B}$ & $24,00 \mathrm{c}$ & $19,75 \mathrm{Bc}$ & $6,75 \mathrm{~cd}$ \\
\hline $\mathrm{M} 2$ & $22,75 b$ & $7,25 b c$ & $44,25 \mathrm{~B}$ & $21,50 \mathrm{~cd}$ & $25,25 \mathrm{Ab}$ & $10,75 b$ \\
\hline M3 & $31,00 \mathrm{a}$ & $15,00 \mathrm{a}$ & $63,00 \mathrm{~A}$ & $36,50 \mathrm{a}$ & $29.25 \mathrm{~A}$ & $16,00 \mathrm{a}$ \\
\hline M4 & $26,75 a b$ & $10,00 \mathrm{~b}$ & $58,75 \mathrm{~A}$ & $31,25 b$ & $21,25 \mathrm{BC}$ & $8,00 \mathrm{bc}$ \\
\hline
\end{tabular}


Pela Tabela 5, no apêndice, observou-se que não foram encontrados efeitos significativos da interação método $x$ solo sobre a saturação por bases nas amostras de terra utilizadas, mas houve efeito significativo do fator método sobre esse atributo. Os métodos 2,3 e 4 apresentaram as maiores médias de $\mathrm{V} \%$, não diferindo significativamente entre sí. O método 2 , no entanto, ocasionou uma média de saturação por bases que não diferiu significativamente do método 1 e da testemunha, que apresentaram os menores valores para esse atributo.

\subsubsection{Produção de material seco}

A média geral de produção de material seco da parte aérea foi de 3,41 g/vaso. A análise de variância e o teste $\mathrm{F}$ apresentados na Tabela 6 , do apêndice, possibilitaram verificar-se que os fatores método (nível de $5 \%$ ) e solo (nível de $1 \%$ ) apresentaram diferenças significativas sobre a produção de material seco, não havendo, no entanto, efeito significativo da interação desses dois fatores (método x solo).

Pela Tabela 17 observa-se que para o fator método, quando utilizou-se o teste de Tukey, ocorreram diferenças significativas ao nível de $5 \%$ somente entre as médias de produção de material seco do método $1(\mathrm{Al} \times 0,15)$ e da testemunha. Entre os métodos não verificaram-se diferenças significativas na produção de material seco. Maeda (1987) trabalhando com cultivares de soja, observou que o método do alumínio produziu os melhores efeitos sobre o rendimento de material seco da parte aérea.

Na Tabela 18, observa-se para o fator solo, quando utilizou-se o teste de Tukey, que a produção de material seco na amostra de gley pouco húmico diferiu significativamente ao nível de $1 \%$ das obtidas nas demais amostras de terra (PVA e LVA).

A baixa produção de material seco em todas as amostras de terra utilizadas, deveu-se ao pequeno desenvolvimento vegetativo das plantas de caupi, ocasionado pelo clima frio ocorrido durante a condução do experimento. A variedade 
utilizada é adaptada às condições de temperatura elevada, o que ocorreu poucas vezes durante o cultivo. Essa influência do clima frio, torna-se ainda mais evidente, quando observa-se que o ciclo da variedade utilizada é de 40 a 45 dias e, o período de cultivo no experimento foi de 60 dias, não havendo nesse tempo, na maioria das parcelas, nem emissão dos botões florais.

Esses resultados demonstraram que, no geral, não houve diferença entre os efeitos das quatro recomendações utilizadas para produção de matéria seca de caupi e, que somente através da recomendação do método do alumínio trocável $(\mathrm{Al} \times 0,15)$ obteve-se uma produção de matéria seca diferente estatisticamente da obtida com a testemunha.

Tabela 17. Médias de produção de material seco da parte aérea de caupi, de acordo com os métodos de determinação da NC utilizados.

\begin{tabular}{cc}
\hline Fator & Médias* $^{\star}$ \\
\hline Testemunha & $2,63 \mathrm{a}$ \\
Método 1 & $3,93 \mathrm{~b}$ \\
Método 2 & $3,63 \mathrm{ab}$ \\
Método 3 & $3,29 \mathrm{ab}$ \\
Método 4 & $3,59 \mathrm{ab}$ \\
\hline
\end{tabular}

* Médias seguidas por letras distintas diferem entre si ao nível de $5 \%$, pelo teste de Tukey.

Tabela 18. Médias de produção de material seco da parte aérea de caupi, de acordo com as amostras de terra utilizadas.

\begin{tabular}{cc}
\hline Solo & Médias* $^{*}$ \\
\hline GPH & $4,55 \mathrm{a}$ \\
LVA & $2,95 \mathrm{~b}$ \\
PVA & $2,74 \mathrm{~b}$ \\
\hline
\end{tabular}

* Médias seguidas por letras distintas diferem entre si ao nivel de $1 \%$, pelo teste de Tukey. 


\section{CONCLUSÕES}

Com os resultados deste trabalho conclui-se que:

- É possível a utilização dos dois métodos analisados (pH SMP e pH da suspensão da solução de acetato de cálcio) para a determinação da acidez potencial em solos do nordeste paraense, no entanto, devido à maior amplitude observada nos resultados das leituras de $\mathrm{pH}$ SMP, em relação àqueles observados para o $\mathrm{pH}$ da suspensão de acetato de cálcio, torna-se mais seguro a utilização do primeiro como forma de determinação dos valores de $\mathrm{H}+\mathrm{Al}$;

- Verificou-se relação elevada para $\mathrm{pH}$ em água $\times \mathrm{pH} \mathrm{CaCl}_{2}, \mathrm{pH} \times \mathrm{V} \%, \mathrm{~m} \% \mathrm{x}$ $\mathrm{V} \%$ e para capacidade de troca cationica $(\mathrm{T}) \mathrm{x}$ matéria orgânica nas amostras de terra estudadas;

- Os resultados obtidos nos estudos envolvendo métodos de recomendação de calagem evidenciam que as quantidades atualmente utilizadas são inadequadas;

- Novos estudos devem ser realizados para a definição do método que indique as doses de calcário adequadas a serem aplicadas nos solos da região nordeste do Pará. 


\section{REFERÊNCIAS BIBLIOGRÁFICAS}

ALFAIA, S.S.; MAGALHÃES, F.F.M.; YUYAMA, K. et al. Efeito da aplicação de calcário e micronutrientes em latossolo Amarelo da Amazônia Central. Acta Amazônica, v. 18, n.3/4, p.13-25, 1988.

ALMEIDA, J. A. de. Avaliação de métodos de recomendação de calagem em solos do Município de Piracicaba. Piracicaba, 1984. 84p. Dissertação (Mestrado) - Escola Superior de Agricultura Luiz de Queiroz, Universidade de São Paulo.

AMEDEE, G.; PEECH, M. Liming of highly weathered soils of the humid tropics. Soil Science, v. 121, n.5, p. 259-266, 1976.

BASTOS, J.B.; SMYTH, T.J. Efeito do calcário em latossolo Amarelo muito argiloso na produção de culturas anuais. Manaus: EMBRAPA; UEPAE de Manaus, 1984. 5p. (EMBRAPA. UEPAE. Pesquisa em Andamento, 61).

BRADY, N.C. Natureza e propriedades dos solos. 7 ed. Rio de Janeiro: Freitas Bastos, 1989. 878p.

BURGER, D. O uso da terra na Amazônia Oriental. In: EMPRESA BRASILEIRA DE PESQUiSA AGROPECUÁRIA. Centro de Pequisa Agroflorestal da Amazônia Oriental. Pesquisas sobre utilização e conservação do solo na amazônia oriental: relatório final do convênio EMBRAPA - CPATU - GTZ. Belém, 1986. p.71 - 97. (EMBRAPA . CPATU. Documentos, 40). 
CASTRO, A.F. de; BARRETO, W.O; ANASTÁCIO, M.L.A. Correlação entre pH e saturação de bases de alguns solos brasileiros. Pesquisa Agropecuária Brasileira, Sér. Agron., v.7, p.9-17, 1972.

CATANI, R.A.; GALLO, J.R. Avaliação da exigência em calcário dos solos do Estado de São Paulo, mediante correlação entre o $\mathrm{pH}$ e a porcentagem de saturação em bases. Revista de Agricultura, v.30, n.1/3, p.49-60, 1955.

COMISSÃO DE FERTILIDADE DO SOLO DO ESTADO DE MINAS GERAIS. Recomendação para uso de corretivos e fertilizantes no Estado de Minas Gerais: $3^{\mathrm{a}}$ aprox. Belo Horizonte: EPAMIG, 1978. 80p.

COSTA, A.; PARRA, M.S.; TOMAZ, M.L. Comparação de métodos para determinação da necessidade de calagem de um Latossolo Vermelho Escuro álico da região de Ponta Grossa. Arquivos de Biologia e Teenologia, v.39, n.2, p.333-342, 1996.

COSTA, M.P. Efeito da matéria orgânica em alguns atributos do solo. Piracicaba, 1983. 137p. Dissertação (Mestrado) - Escola Superior de Agricultura Luiz de Queiroz, Universidade de São Paulo.

CRUZ, M.C.P. da; FERREIRA, M.E.; LUCHETTA, S. Efeito da calagem sobre a produção de matéria seca de três gramíneas forrageiras. Pesquisa Agropecuária Brasileira, v.29, n.8, p.1303-1312, 1994.

DEFELIPO, B.V.; BRAGA, J.M.; SPIES, C. Comparação entre métodos de determinação da necessidade de calcário de solos de Minas Gerais. Experientiae, v.13, n.4, p.111-136, 1972.

ERNANI, P.R.; ALMEIDA, J.A. Comparação de métodos analíticos para avaliar a necessidade de calcário dos solos de Santa Catarina. Revista Brasileira de Ciência do Solo, v. 10, p.143-150, 1986. 
FASSBENDER, H.W; BORNEMISZ, E. Química de suelos com énfasis en suelos de America Latina. San José: IICA, 1987. cap.5, p.161-186: Reaccion del suelo.

FERREIRA, C.R.R.P.T.; SANTOS, Z.A.P.S. Avaliação do emprego de calcário agrícola pela agricultura paulista. São Paulo: Instituto de Economia Agrícola, 1988. 47p. (IEA. Relatorio de Pesquisa).

FONTES, M.P.F.; GJORUP, G.B.; ALVARENGA, R.C. et al. Calcium salts and mechanical stress effects on water-dispersible clay of oxisols. Soil Science Society of America Journal, v.59, p.224-227, 1995.

FOX, R.L.; HUE, N.V; JONES, R.C. et al. Plant-soil interactions associated with acid, weathered soils. Plant and Soil, v.134, p.65-72, 1991

FREITAS, L.M.M; PRATT, P.F.; VETTORI, L. Testes rápidos para estimar as necessidades em calcário de alguns solos de São Paulo. Pesquisa Agropecuária Brasileira, v.3, p.159-164, 1968.

FUNDAÇÃO INSTITUTO BRASILEIRO DE GEOGRAFIA E ESTATÍSTICA. Divisão regional do Brasil em mesorregiões e microrregiões geográficas. Rio de Janeiro, 1991. 2v.

FUNDAÇÃO INSTITUTO BRASILEIRO DE GEOGRAFIA E ESTATÍSTICA. Produção agrícola municipal. Rio de Janeiro, 1994.

HUE, N.V; FOX, R.L; McCALL, W.W. Aluminium, Ca, and Mn concentrations in Macadamia seedlings as affected by soil acidity na liming. Communications In Soil Science and Plant Analysis., v. 18, n.11, p.1253-1267, 1987.

KAMINSKI, J.; BOHNEN, H. Métodos para indicação da quantidade de corretivos da acidez em solos do Rio Grande do Sul. Revista da Faculdade de Agronomia da Universidade Federal do Rio Grande do Sul, v.1, n.2, p.85-98, 1976. 
KAMPRATH, E.J. Exchangeable aluminum as a criterion foi liming leached mineral soils. Soil Science Society American Proceedings, v.34, p.252-254, 1970.

KINJO, T. Conceitos de acidez dos solos. In: REUNIÃO BRASILEIRA DE FERTILIDADE DO SOLO, 15., Campinas, 1983. Resumos. Campinas: SBCS; IAC, 1983. p.23-31.

LIMA, M.R.de; BOHNEN, H. Dinâmica de nutrientes em solos arenosos em função da calagem. In: CONGRESSO BRASILEIRO DE CIÊNCIA DO SOLO, 24., Goiânia, 1993. Anais. Goiânia: SBCS, 1993. p.201-202.

MAEDA, S. Efeitos de quantidades de calcário, estimadas por três métodos, no comportamento de cultivares de soja Glycine max (L.) Merril. Lavras, 1987. 87p. Dissertação (Mestrado) - Escola Superior de Agricultura de Lavras.

MAEDA, S.; KURIHARA, C.H.; HERNANI, L.C. et al. Estimativa da acidez potencial de solos do Mato Grosso do Sul pelo método do pH SMP (compact disc). In: CONGRESSO BRASILEIRO DE CIÊNCIA DO SOLO, 26., Rio de Janeiro, 1997. Anais. Rio de Janeiro: SBCS, 1997.

MALAVOLTA, E. Manual de química agrícola: adubos e adubação. 3. ed. São Paulo: Ceres, 1981. 596p.

MALAVOLTA, E. A prática da calagem. In: SEMINÁRIO SOBRE CORRETIVO AGRíCOLA, Piracicaba, 1984. Campinas: Fundação Cargill, 1985. p.313-357.

MELO, F.A.F. Origem, natureza e componentes da acidez do solo: critérios para calagem. In: SEMINÁRIO SOBRE CORRETIVO AGRÍCOLA, Piracicaba, 1984. Campinas: Fundação Cargill, 1985. p.65-93.

MENDEZ, J.; KAMPRATH, E.J. Liming of Latosols and the effect on phosphorus response. Soil Science Society of America Journal, v.42, n.1, p.86-88, 1978. 
MIRANDA, L.N. de. Resposta da sucessão soja-trigo a doses e modos de aplicação de calcário em solos Gley Pouco Húmico. Revista Brasileira de Ciência do Solo, v. 17, n. 1, p. $75-82,1993$.

OLIVEIRA, J.N.S.; MEDEIROS, E. R. Viabilidade econômica da exploração de calcário de Pimenta Bueno. Porto Velho: EMBRAPA, UEPAE, 1983. 40p. (EMBRAPA. UEPAE. Documentos, 2)

PAIVA, A.Q; NASCIMENTO, A.P.S.; SANTOS, J.A.G. Efeito do calcário e da matéria orgânica sobre algumas propriedades químicas de um latossolo. In: CONGRESSO BRASILEIRO DE CIÊNCIA DO SOLO, 24., Goiânia, 1993. Anais. Goiânia: SBCS, 1993. p.181-182

PAVAN, M.A.; OLIVEIRA, E.L.de; MIYAZAWA, M. Determinação indireta da acidez extraível do solo $(\mathrm{H}+\mathrm{Al})$ por potenciometria com a solução tampão SMP. Arquivos de Biologia e Tecnologia, v.39, n.2, p.307-312, 1996.

PEECH, M.; BRADFIELD, R. Chemical methods for estimating lime needs of soils. Soil Science, v.65, p.35-55, 1948.

PEREIRA, M.G.; VALLADARES, G.S.; SOUZA, J.MP.F. et al. Estimativa da acidez potencial pelo método do pH SMP em solos do Estado do Rio de Janeiro. Revista Brasileira de Ciência do Solo, v.22, n. 1, p.159-162, 1998.

QUAGGIO, J. A. Critérios para calagem em solos do Estado de São Paulo. Piracicaba, 1983. 76p. Dissertação (Mestrado) - Escola Superior de Agricultura "Luiz de Queiroz", Universidade de São Paulo.

QUAGGIO, J.A. Reação do solo e seu controle. In: SIMPÓSIO AVANÇADO DE QUÍMICA E FERTILIDADE DO SOLO, Piracicaba, 1986. Anais. Campinas: Fundação Cargill, 1986. p.53-89. 
QUAGGIO, J.A.; RAIJ, B. van.; MALAVOLTA, E. Alternative use of the SMP-buffer solution to determine lime requirement of soils. Communications in Soil Science Plant Analysis, v.16, n.3, p.245-260, 1985.

RAIJ, B. van. Avaliação da fertilidade do solo. Piracicaba: POTAFOS, 1981. 142p.

RAIJ, B. van. Fertilidade do solo e adubação. Piracicaba: POTAFOS, 1991. 343p.

RAIJ, B.van.; QUAGGIO, J.A. Methods used for diagnosis and correction of soil acidity in Brazil: an overview. In: MONIZ, A.C.; FURLANI, A.M.C.; SCHAFFERT, R.E. et al. (Ed.) Plant-soil interactions at low pH: sustainable agriculture and forestry production. Campinas: Brasilian Soil Science Society, 1997. p. 205-214.

RAJ, B. van; SACCHETTO, M.T.D. Correlações entre o pH e o grau de saturação em bases nos solos com horizonte B textural e horizonte B latossólico. Bragantia, v. 27, n. 17, p. $193-200,1968$

RAIJ, B. van; CANTARELLA, H.; ZULLO, M.A.T. O método tampão SMP para determinação da necessidade de calagem de solos do Estado de São Paulo. Bragantia, v.38, n. 7, p.57-69, 1979.

RAIJ, B. van.; CAMARGO, A.P. de; CANTARELLA, H.; et al. Alumínio trocável e saturação em bases como critérios para recomendação de calagem. Bragantia, v.42, n.13, p.149-156, 1983

RAIJ, B.van.; CANTARELlA, H.; QUAGGIO, J.A. et al. Recomendações de adubação e calagem para o Estado de São Paulo. Campinas: IAC, 1996. p.285. (IAC. Boletim Técnico, 100).

RAIJ, B. van.; QUAGGIO, J.A.; CANTARELlA, H. et al. Análise química do solo para fins de fertilidade. Campinas: Fundação Cargill, 1987. 170p. 
REGITANO, J.B. Calagem em solos de várzeas de Minas Gerais: critérios de recomendação com base em parâmetros de acidez e/ou propriedades químicas do solo. Lavras, 1987. 116p. Dissertação (Mestrado) - Escola Superior de Agricultura de Lavras.

ROCHA, R.; UHL, C; McGRATH, D. Desmatamentos e usos da terra no Pará: tendências das microrregiões e municípios, de 1960 a 1985. Belém: IMAZON, 1992.

ROJAS, I.L.de. Evaluacion de metodos quimicos para determinar requerimientos de cal en suelos acidos del pais. Agronomia Tropical, v.24, n.4, p.259-278, 1974.

ROJAS, I.L.de. Biological evaluation of chemical methods for determination of lime requirement in acid soils of Venezuela. Agronomia-Tropical, v.27, n. 4, p.393-411, 1977.

SANCHEZ, P. A. Suelos del trópico: características e manejo. San José: IICA, 1981. $634 \mathrm{p}$.

SHOEMAKER, H.E.; McLEAN, E.O; PRATT, P.F. Buffer methods for determining lime requirements of soils with appreciable amounts of extractable aluminum. Soil Science Society American Proceedings, v.25, p.274-277, 1961.

SILVA, C.A.; VALE, F.R.; GUILHERME, L.R.G. Efeito da calagem na mineralização do nitrogênio em solos de Minas Gerais. Revista Brasileira de Ciência do Solo, v. 18, n.3, p. $471-476,1994$.

SKOLE, D; TUCKER, C. Tropical deforestation and habitat fragmentation in the Amazon: Satellite data from 1978 to 1988. Science, v.260, p. 1905-1909, 1993.

SOUSA, D. M. G. de; CARVAlHO, L. J. C. B; MIRANDA, L. N. Correção da acidez do solo - solos dos cerrados: tecnologias e estratégias de manejo. São 
Paulo: Nobel; Brasília: EMBRAPA, Centro de Pesquisa Agropecuária do Cerrado, 1985. p.99-125.

SOUSA, D.M.G. de; MIRANDA, L.N. de; LOBATO, E. et al. Métodos para determinar as necessidades de calagem em solos dos cerrados. Revista Brasileira de Ciência do Solo, v.13, p. 193-198, 1989.

SPEHAR, C.R. Composição mineral da soja cultivada em soo sob cerrado com dois niveis de calagem. Pesquisa Agropecuária Brasileira, v.28, n.5, p.645-648, 1993.

SUMNER, M.E. Procedures used for diagnosis and correction of soil acidity: A critical review. In: MONIZ, A.C.; FURLANI, A.M.C.; SCHAFFERT, R.E.; FAGERIA, N.K. et al. (Ed). Plant-soil interactions at low $\mathbf{p H}$ : sustainable agriculture and forestry production. Campinas: Brasilian Soil Science Society, 1997. p.195-204.

VASCONCELlOS, C.A; SANTANA, D.P.; FERREIRA, L. Métodos de determinação da necessidade de calagem e características físico-químicas de alguns solos de Minas Gerais. Pesquisa Agropecuária Brasileira, v.29, n.8, p. 1253-1263, 1994.

VIEIRA, L. S. Manual da ciência do solo. São Paulo: Ceres, 1975. 464 p.

VIEIRA, L. S. Manual da ciência do solo: com ênfase aos solos tropicais. São Paulo: Ceres, 1988. $464 \mathrm{p}$.

VIEIRA, L.S.; SANTOS, P.C. dos. Amazônia: seus solos e outros recursos naturais. São Paulo: Ceres, 1987. 416p.

VIEIRA, L. S.; OLIVEIRA, N.V.C. e; BASTOS, T. X. Os solos do Estado do Pará. Belém: Instituto de Desenvolvimento Econômico e Social do Pará, 1971. 175p. (Cadernos Paraenses, 8).

WEBBER, M.D; HOYT, P.B.; NYBORG, M. et al. A comparison of lime requirement methods for acid canadian soils. Canadian Journal of Soil Science, v.57, p.361$370,1977$. 
APÊNDICE 
Tabela 1. Quadro de análise de variância para teor de cálcio no solo, no experimento que envolveu solos e métodos de determinação de NC.

\begin{tabular}{ccrrr}
\hline Causa de Variação & GL & \multicolumn{1}{c}{ SQ } & \multicolumn{1}{c}{ QM } & \multicolumn{1}{c}{ F } \\
\hline Método & 4 & 1507,73 & 376,93 & $25,55^{* *}$ \\
Solo & 2 & 9909,43 & 4954,72 & $335,79^{* *}$ \\
Mét. x Solo & 8 & 6599,57 & 74,95 & $5,08^{* *}$ \\
Resíduo & 45 & 664,00 & 14,76 & \\
\hline Total & 59 & 12680,73 & &
\end{tabular}

** siginificativo a $1 \%$

Tabela 2. Quadro de análise de variância para teor de magnésio no solo, no experimento que envolveu solos e métodos de determinação de NC.

\begin{tabular}{ccrrr}
\hline Causa de Variação & GL & \multicolumn{1}{c}{ SQ } & \multicolumn{1}{c}{ QM } & \multicolumn{1}{c}{ F } \\
\hline Método & 4 & 1195,57 & 298,89 & $99,26^{* *}$ \\
Solo & 2 & 4201,73 & 2100,87 & $697,70^{* *}$ \\
Mét. x Solo & 8 & 207,93 & 25,99 & $8,63^{* *}$ \\
Resíduo & 45 & 135,50 & 3,01 & \\
\hline Total & 59 & 5740,73 & & \\
\hline
\end{tabular}

** siginificativo a $1 \%$

Tabela 3. Quadro de análise de variância para $\mathrm{pH}$ em $\mathrm{H}_{2} \mathrm{O}$ no solo, no experimento que envolveu solos e métodos de determinação de NC.

\begin{tabular}{ccccc}
\hline Causa de Variação & GL & SQ & QM & F \\
\hline Método & 4 & 0,57 & 0,14 & $10,21^{* *}$ \\
Solo & 2 & 1,26 & 0,63 & $44,83^{* *}$ \\
Mét. x Solo & 8 & 0,60 & 0,08 & $5,36^{* *}$ \\
Resíduo & 45 & 0,63 & 0,01 & \\
\hline Total & 59 & 3,07 & & \\
\hline
\end{tabular}

** siginificativo a $1 \%$ 
Tabela 4. Quadro de análise de variância para $\mathrm{pH}$ em $\mathrm{CaCl}_{2}$ no solo, no experimento que envolveu solos e métodos de determinação de NC.

\begin{tabular}{ccccc}
\hline Causa de Variação & GL & SQ & QM & F \\
\hline Método & 4 & 1,13 & 0,28 & $19,47^{* *}$ \\
Solo & 2 & 0,70 & 0,35 & $24,05^{* *}$ \\
Mét. x Solo & 8 & 0,37 & 0,05 & $3,19^{* *}$ \\
Resíduo & 45 & 0,65 & 0,01 & \\
\hline Total & 59 & 2,86 & & \\
\hline
\end{tabular}

** siginificativo a $1 \%$

Tabela 5. Quadro de análise de variância para saturação por bases no solo, no experimento que envolveu solos e métodos de determinação de NC.

\begin{tabular}{ccrrr}
\hline Causa de Variação & GL & \multicolumn{1}{c}{ SQ } & QM & \multicolumn{1}{c}{ F } \\
\hline Método & 4 & 2110,29 & 527,57 & $9,02^{* *}$ \\
Solo & 2 & 111423,43 & 55711,72 & $952,66^{* *}$ \\
Mét. x Solo & 8 & 818,79 & 102,35 & $1,75^{\text {ns }}$ \\
Resíduo & 45 & 2631,62 & 58,48 & \\
\hline Total & 59 & 116984,13 & & \\
\hline
\end{tabular}

** siginificativo a $1 \%$, ns - não significativo.

Tabela 6. Quadro de análise de variância para material seco, no experimento que envolveu solos e métodos de determinação de NC.

\begin{tabular}{ccccc}
\hline Causa de Variação & GL & SQ & QM & \multicolumn{1}{c}{ F } \\
\hline Método & 4 & 11,71 & 2,93 & $2,79^{*}$ \\
Solo & 2 & 39,56 & 19,78 & $18,91^{* *}$ \\
Mét. x Solo & 8 & 6,39 & 0,79 & $0,76^{\text {ns }}$ \\
Residuo & 45 & 47,06 & 1,05 & \\
Total & 59 & 104,71 & &
\end{tabular}

* significativo a $5 \%$; ** siginificativo a $1 \%$; ns - não significativo. 